\title{
Article
}

\section{Assimilationist Bias in Equal Protection: \\ The Visibility Presumption and the Case of \\ "Don't Ask, Don't Tell"}

Kenji Yoshino ${ }^{\dagger}$

\section{CONTENTS}

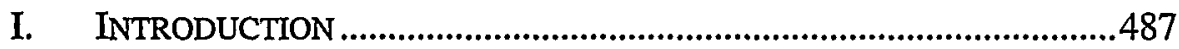

II. EQUAL PRoteCtION IMMUTABILITY AND VISIBILITY DEFINED ......493

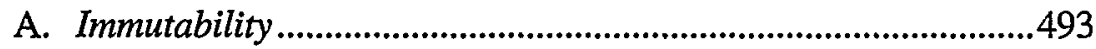

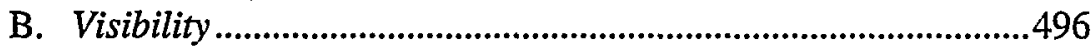

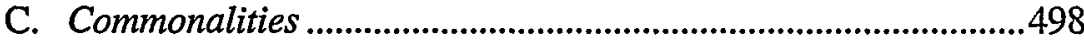

III. EQUAL PROTECTION'S ASSIMIIATIONIST BIAS.................................500

A. The Substantive Defense and Its Shortcomings ..........................504

B. The Political Process Defense ..................................................506

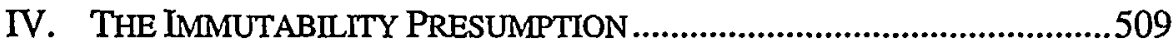

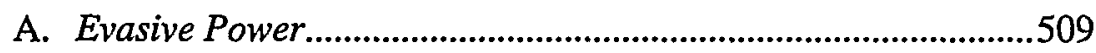

B. Transformative Power .................................................................510

C. Immutability as Harbinger........................................................518

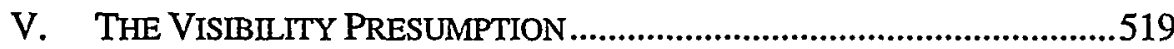

$\dagger$ Associate Professor, Yale Law School. I thank Bruce Ackerman, Akhil Amar, Steven Bromer, Bo Burt, Bob Ellickson, George Fisher, Owen Fiss, Paul Kahn, Martha Minow, Carol Rose, Bill Rubenstein, Reva Siegel, Wendy Weiser, and Tobias Wolff. Rick Baker, Romana Mancini, Rose Saxe, and Eric Sonnenschein supplied excellent research assistance. 


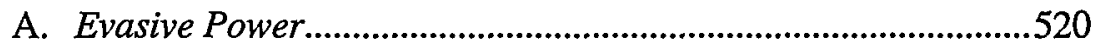

1. Visibility's Vulnerability......................................................520

2. The Costs of Evasion ...........................................................527

B. Transformative Power .............................................................530

1. The Infiltration Effect ......................................................530

2. The Auto-Identification Effect ...............................................534

3. The Exit/Voice Effect ...........................................................535

4. The Manipulation Effect .......................................................536

C. The Harm of the Visibility Presumption .......................................537

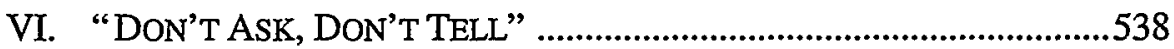

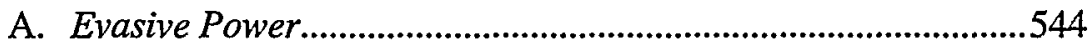

1. Evasive Advantages Dampened...........................................544

2. Evasive Disadvantages Amplified ........................................545

B. Transformative Power .............................................................551

1. The Infiltration Effect ............................................................551

2. The Auto-Identification Effect ...............................................554

3. The Exit/Voice Effect ............................................................555

4. The Manipulation Effect .........................................................556

C. The Invisible Irony of Don't Ask, Don't Tell ..............................557

VII. RECONSTRUCTING THE HEIGHTENED SCRUTINY JURISPRUDENCE ..557

A. The Origins of the Immutability and Visibility Factors .559

B. A Refined Political Powerlessness Analysis as a Limiting Principle. .563

C. Coalition Building......................................................................568

VIII. CONCLUSION .570 


\section{INTRODUCTION}

Equal protection heightened scrutiny jurisprudence currently privileges the talismanic classifications of race and, to a lesser extent, sex. In considering arguments that other classifications be accorded heightened scrutiny, the courts have required claimants to demonstrate the similarities these classifications share with race and sex. Commonalities between the two paradigm classifications thus play a powerful gatekeeping role.

Two commonalities emphasized by the courts are that race and sex ostensibly mark individuals with immutable and visible traits. A classification will therefore be less likely to receive heightened scrutiny if its defining traits can be altered or concealed. By withholding protection from these classifications, the judiciary is subtly encouraging groups comprised by such classifications to assimilate by changing or hiding their defining characteristic. This is an assimilationist bias in equal protection, ${ }^{1}$ which I will critique in this Article.

Under current equal protection doctrine, the question of whether a classification deserves heightened scrutiny precedes the question of whether the legislation is sufficiently related to its objective. Indeed, the answer to the first question determines the force with which the second is asked. Thus, if a classification is deemed to merit "strict" scrutiny, the state must meet the exceedingly high standard of showing that its classification is necessary to promote a "compelling governmental interest." ${ }^{2}$ If the classification garners "intermediate" scrutiny, the state must show that the classification "serves important governmental objectives and is ... substantially related to ... those objectives." 3 Finally, if the classification is merely accorded "rational review," the government need only show that the classification bears "a rational relationship [to] ... some

1. As the indefinite article suggests, this is not the only assimilationist bias in equal protection doctrine. I discuss three forms of assimilationist bias further at the beginning of Part III. See infra notes 60-73 and accompanying text.

2. See, e.g., Adarand Constructors v. Pena, 515 U.S. 200, 227 (1995) (plurality opinion); see also City of Cleburne v. Clebume Living Ctr., 473 U.S. 432, 440 (1985) (noting that statutes using classifications subjected to strict scrutiny such as race, national origin, and alienage will be upheld only if "suitably tailored to serve a compelling state interest"); Bernal v. Fainter, 467 U.S. 216, 219 (1984) (noting that statutes discriminating on the basis of alienage, a classification subject to strict scrutiny, will be upheld only if they "advance a compelling state interest by the least restrictive means available").

3. United States v. Virginia, 518 U.S. 515, 516 (1996) (citations and internal quotation marks omitted); see also Clark v. Jeter, 486 U.S. 456, 461 (1988) (noting that statutes using classifications subject to intermediate scrutiny, such as sex or illegitimacy, will be upheld only if "substantially related to an important governmental objective"); Mississippi Univ. for Women v. Hogan, 458 U.S. 718, 723 (1982) (noting that "statutes employing gender classifications will be upheld only if the classifications serves "important governmental objectives" and "the discriminatory means employed are substantially related to the achievement of those objectives" (citations and internal quotation marks omitted)). 
legitimate governmental purpose." ${ }^{4}$ As a practical matter, "strict scrutiny" almost invariably leads to the invalidation of legislation, while "rational review" almost invariably leads to the upholding of legislation. ${ }^{5}$ The determination of the level of scrutiny is therefore a crucial threshold step in the analysis of whether legislation will survive. ${ }^{6}$

4. Heller v. Doe, 509 U.S. 312, 319 (1993); see also Lyng v. International Union, 485 U.S. 360,370 (1988) (noting that when a statute does not impact a fundamental right or a protected class, a court's inquiry is confined to determining "whether the statutory classification is rationally related to a legitimate governmental interest" (citation and internal quotation marks omitted)).

5. Historically, the application of strict scrutiny led to such consistent invalidation of legislation that the standard was understood to be "strict' in theory but fatal in fact." Gerald Gunther, The Supreme Court, 1971 Term-Foreword: In Search of Evolving Doctrine on a Changing Court: A Model for a Newer Equal Protection, 86 HARV. L. REv. 1, 8 (1972) (coining the phrase); see also Fullilove v. Klutznick, 448 U.S. 448, 519 (1980) (Marshall, J., concurring) (noting that conventional strict scrutiny is "strict in theory, but fatal in fact" (citing Regents of the Univ. of Cal. v. Bakke, 438 U.S. 265, 362 (1978))). Similarly, the rational review standard resulted in such uniform upholding of statutes that it was understood to constitute a free pass for legislation. See CONSTITUTIONAL LAW 606 (John E. Nowak \& Ronald D. Rotunda eds., 5th ed. 1995) (noting that the correlation between the application of rational review and the upholding of legislation appeared to be perfect between 1937 and 1976).

More recently, both understandings have required revision. The Supreme Court has expressly disavowed that strict scrutiny is always fatal in practice. See Adarand, 515 U.S. at 237 ("[W]e wish to dispel the notion that strict scrutiny is 'strict in theory but fatal in fact."' (citing Fullilove, 448 U.S. at 519)). Legisiation has also been struck down on rational review, see Cleburne, 473 U.S. 432; Plyler v. Doe, 457 U.S. 202 (1982), leading some commentators to believe that a fourth tier of review-the so-called "rational basis with teeth" standard-has been created, see, e.g., Daniel Farber \& Suzanna Sherry, The Pariah Principle, 13 CONST. COMmentary 257, 260 (1996) (citing David O. Stewart, Supreme Court Report: A Growing Equal Protection Clause?, 71 A.B.A. J. 108, 112 (1985)).

These exceptions, however, have not seriously altered the status quo. The Supreme Court's observation in a post-Adarand case that "[s]trict scrutiny remains, nonetheless, strict," Bush v. Vera, 517 U.S. 952, 978 (1996), is bolstered by the fact that, even after Adarand, legislation has been systematically struck down when strict scrutiny is applied, see, e.g., id. at 952; Miller v. Johnson, 515 U.S. 900 (1995); Hopwood v. Texas, 78 F.3d 932 (5th Cir. 1996), cert. denied, 518 U.S. 1033 (1996). Similarly, the Court's statement in a post-Cleburne case that rational review remains highly deferential, see Heller, 509 U.S. at 319-21, is supported by the fact that, even after Plyler and Cleburne, legislation has been repeatedly upheld when rational basis review is applied, see, e.g., Heller, 509 U.S. at 312; Vacco v. Quill, 117 S. Ct. 2293 (1997); Washington v. Glucksberg, 117 S. Ct. 2258 (1997). But see Romer v. Evans, 517 U.S. 620 (1996). Indeed, the reality that the new nomenclature of "rational review with teeth" was necessary to describe rational review leading to the invalidation of legislation reflects the power of the intuition that rational review simpliciter never results in such invalidation.

6. Since the formal recognition of intermediate scrutiny in Craig v. Boren, 429 U.S. 190 (1976), the Supreme Court has divided scrutiny into three thetorical categories-strict, intermediate, and rational. See cases cited supra notes 2-4. In the aftermath of United States v. Virginia, however, it has become unclear whether there is any real difference between strict and intermediate scrutiny. The majority in Virginia stated that in order to survive the intermediate scrutiny test triggered by gender-based classifications, the state must proffer an "exceedingly persuasive justification" for its action. See 518 U.S. at 531 (citations omitted). As Chief Justice Rehnquist's concurrence noted, the majority's holding "introduce[d] an element of uncertainty respecting the appropriate test," because this standard seems quite close to strict scrutiny. Id. at 559 (Rehnquist, C.J., concurring).

It is unclear not only whether there is now any real difference between strict and intermediate scrutiny but also whether there ever has been. Cass Sunstein has pointed out that while the Virginia Court " did not merely restate the intermediate scrutiny test but pressed it closer 
To date, the Supreme Court has extended some form of heightened scrutiny to classifications based on race, ${ }^{7}$ sex, ${ }^{8}$ national origin, ${ }^{9}$ alienage, ${ }^{10}$ and illegitimacy. ${ }^{11}$ The Court has not, however, provided a clear overarching rationale for why these five classifications, and not others, are particularly deserving of judicial solicitude. ${ }^{12}$ It has instead deployed, again without much explanation, a set of factors to determine whether a group is worthy of heightened scrutiny. These factors, which are not requirements, include the history of discrimination suffered by the group, the group's political powerlessness, and the immutability and visibility of the characteristic defining the group. ${ }^{13}$

to strict scrutiny," this rapprochement was "not a dramatic innovation." Cass Sunstein, The Supreme Court 1995 Term -Foreword: Leaving Things Undecided, 110 HARV. L. REV. 4, 75 (1996). This is because " $t$ t]he revision of the standard of review is unlikely to produce different results from those that would have followed under the intermediate scrutiny standard, which has operated quite strictly 'in fact."' Id. (citation omitted).

It seems useful to recognize rhetorically the Court's practical conflation of these two terms. I therefore use the term "heightened scrutiny" in this Article to encompass both strict and intermediate scrutiny. This usage is not meant to express disagreement with the position that intermediate scrutiny could mean something different from strict scrutiny. See generally Jay Wexler, Defending the Middle Way: Intermediate Scrutiny as Judicial Minimalism, 66 GEO. WASH. L. REV. 298 (1998) (arguing for an intermediate scrutiny standard that is distinct from the current strict scrutiny standard). Rather, it is predicated on the pragmatic assumption that the Court is unlikely to differentiate between the two standards.

7. See, e.g., Vera, 517 U.S. at 952 (subjecting voting districts drawn with race as the predominant factor to strict scrutiny); Adarand, 515 U.S. at 200 (subjecting federal contracting program designed to help racial minorities to strict scrutiny); Korematsu v. United States, 323 U.S. 214 (1944) (subjecting legislation excluding individuals of Japanese ancestry from the U.S. West Coast to the "most rigid" scrutiny).

8. See, e.g., United States v. Virginia, 518 U.S. at 515 (subjecting a public college's genderbased admissions policy to intermediate scrutiny); J.E.B. v. Alabama ex rel. T.B., 511 U.S. 127 (1994) (subjecting gender-based peremptory strikes to intermediate scrutiny); Craig, 429 U.S. at 190 (subjecting gender-based discrimination in statutes regulating the sale of alcohol to intermediate scrutiny).

9. See, e.g., Wygant v. Jackson Bd. of Educ., 476 U.S. 267 (1986) (subjecting to heightened scrutiny a public school's preferential layoff protection scheme for employees based on, inter alia, their national origin); Oyama v. California, 332 U.S. 633 (1948) (subjecting a land-transfer statute that discriminated on the basis of national origin to heightened scrutiny).

10. See, e.g., Bernal v. Fainter, 467 U.S. 216 (1984) (subjecting a statute that required notaries public to be U.S. citizens to strict scrutiny); Nyquist v. Mauclet, 432 U.S. 1 (1977) (subjecting a statute barring certain resident aliens from state financial assistance for higher education to strict scrutiny); Graham v. Richardson, 403 U.S. 365 (1971) (subjecting legislation that conditioned welfare benefits on citizenship to heightened scrutiny).

11. See, e.g., Clark v. Jeter, 486 U.S. 456 (1988) (subjecting to heightened scrutiny a statute that imposed a six-year statute of limitations for establishing paternity); Lalli v. Lalli, 439 U.S. 259 (1978) (subjecting to intermediate scrutiny a statute that required illegitimate children to prove paternity before inheriting from their putative fathers); Trimble v. Gordon, 430 U.S. 762 (1977) (subjecting to heightened scrutiny a statute that permitted legitimate, but not illegitimate, children to inherit from their intestate fathers).

12. See Cass R. Sunstein, The Anticaste Principle, 92 MrCH. L. REv. 2410, 2441 (1994).

13. See, e.g., Bowen v. Gilliard, 483 U.S. 587, 602-03 (1987) (quoting Lyng v. Castillo, 477 U.S. 635, 638 (1986)) (denying application of the heightened scrutiny standard when reviewing statutory classifications in the federal Aid to Families with Dependent Children program); Lyng, 477 U.S. at 638 (reaching the same conclusion for statutory classifications created by the federal Food Stamps program). For other applications of these factors, see, for example, High Tech Gays 
An assimilationist bias in equal protection jurisprudence manifests itself in the immutability and visibility factors. These factors make courts more likely to withhold heightened scrutiny from groups that can change or conceal their defining trait. (I will call such groups indistinct, in contrast to distinct groups that cannot assimilate in either of these ways.) Through these factors, the jurisprudence creates an incentive for indistinct groups to assimilate into the political mainstream when faced with burdensome legislation. The primary normative argument of this Article is that the assimilationist bias embodied in the immutability and visibility factors is pernicious and that these factors should both be retired.

Although I want to consider both factors, I place most of my emphasis on visibility. This emphasis should be uncontroversial, as the immutability factor has already been subjected to extensive criticism. Academics have made eloquent substantive arguments against it. ${ }^{14}$ And the courts have variously cast doubt on immutability by citing academic critiques of it, ${ }^{15}$ by interpreting it expansively, ${ }^{16}$ by emphasizing that it is a factor rather than a requirement, ${ }^{17}$ and by simply omitting it from their formulations of the

v. Defense Industrial Security Clearance Office, 895 F.2d 563, 573 (9th Cir. 1990); Watkins v. United States Army, 837 F.2d 1428, 1444-48 (9th Cir.), amended by 847 F.2d 1329 (9th Cir. 1988), vacated and aff'd on other grounds, 875 F.2d 699 (9th Cir. 1989) (en banc); Ledesma v. Block, 825 F.2d 1046, 1052 (6th Cir. 1987); Cervantes v. Guerra, 651 F.2d 974, 979 (5th Cir. Unit A July 1981); and Spence v. Miles Laboratories, Inc., 810 F. Supp. 952, 962 (E.D. Tenn. 1992).

14. See, e.g., JOHN HART ELY, DEMOCRACY AND DISTRUST 150 (1980) (arguing that because a plurality of the Court in Frontiero v. Richardson, 411 U.S. 677 (1973) (plurality opinion), explicitly noted that intelligence and physical disability are not suspect despite their immutability, and because race and gender are mutable at some level, immutability is not actually a factor and that the real test is relevance to legislative purposes); J.M. Balkin, The Constitution of Status, 106 YALE L.J. 2313, 2323-24 (1997) (noting that immutability is neither necessary nor sufficient because the issue is really whether a trait can sustain a stable social meaning); Chai $\mathbf{R}$. Feldblum, Sexual Orientation, Morality, and the Law: Devlin Revisited, 57 U. PIrT. L. REV. 237, 278-79 (1996) (arguing that immutability can describe traits that are either beyond the bearer's control or passive rather than behavioral, and that the first meaning may be read broadly to include characteristics that are difficult to change); Janet E. Halley, The Politics of the Closet: Towards Equal Protection for Gay, Lesbian, and Bisexual Identity, 36 UCLA L. REV. 915, 92627 (1989) [hereinafter Halley, Politics of the Closet] (arguing that courts are retreating from the immutability factor and that under a process failure theory, mutable groups may have less political power); Janet E. Halley, Sexual Orientation and the Politics of Biology: A Critique of the Argument from Immutability, 46 STAN. L. REV. 503, 507-16 (1994) Thereinafter Halley, Politics of Biology] (arguing that the courts have replaced immutability with a concern for political process failure); Nan D. Hunter, Life After Hardwick, 27 HARV. C.R.-C.L. L. REv. 531, 550 (1992) (arguing that the question of immutability is less important than the question of coercion).

15. See, e.g., City of Cleburne v. Cleburne Living Ctr., 473 U.S. 432, 442-43 n.10 (1985) (quoting ELY, supra note 14, at 150); Watkins, 837 F.2d at 1446 (citing Laurence Tribe, The Puzzling Persistence of Process-Based Constitutional Theories, 89 YALE L.J. 1063, 1073-74 n.52 (1980)). For Tribe's critique of immutability, see infra note 83.

16. See, e.g., Watkins, 837 F.2d at 1446.

17. See, e.g., High Tech Gays v. Defense Indus. Sec. Clearance Office, 909 F.2d 375, 377 (9th Cir. 1990) (Canby, J., dissenting); Able v. United States, 968 F. Supp. 850, 863 (E.D.N.Y. 1997), rev'd on other grounds, 155 F.3d 628 (2d Cir. 1998); Jantz v. Muci, 759 F. Supp. 1543, 1548 (D. Kan. 1991), rev'd, 976 F.2d 623 (10th Cir. 1992). 
heightened scrutiny test. ${ }^{18}$ Indeed, the question more likely to arise is why I discuss the immutability factor at all, as such a discussion seems tantamount to cataloguing new ways to flog a dying horse. My purpose here, however, is not to hasten the factor's imminent demise but to enable a comparison between immutability and visibility. ${ }^{19}$ By making that comparison, I seek to show that the visibility factor also should be retired.

In Part II, I briefly describe how the courts define immutability and visibility. Although the courts appear to begin with the ordinary definitions of immutability as an inability to change ${ }^{20}$ and of visibility as an ability to be seen, ${ }^{21}$ they then add two definitional restrictions to each term. First, the courts do not interpret either immutability or visibility to mean that the characteristic must be strictly incapable of being changed or hidden. Second, the courts tend to think of immutability and visibility as corporeal traits, rather than as social ones. These restrictions are only two of the many ways in which the terms are conceptually intertwined. It is therefore unsurprising that while the courts distinguish between these two terms as a formal matter, they constantly conflate them as a practical matter.

In Part M, I turn to the ways in which the immutability and visibility factors might be justified, noting that the factors can be defended on either substantive or processual grounds. The substantive defense rests on the fact that the immutability and visibility factors isolate classifications defined by traits largely outside an individual's control. Treating individuals unequally based on qualities they cannot influence, it is argued, violates a norm of equality. This defense is easily defeated on the grounds that it is both overand underinclusive.

The processual defense, however, presents a more difficult case. It asserts that the courts must direct their solicitude solely towards those who are disadvantaged in the political process. It then maintains that distinct groups are relatively disadvantaged because they do not have the option of assimilation. When faced with state discrimination, indistinct groups may simply disappear-temporarily or permanently-into the mainstream. Judicial protection is thus withheld from these groups because they have the capacity to engage in self-help.

18. See, e.g., Cleburne, 473 U.S. at $440-41$; Massachusetts Bd. of Retirement v. Murgia, 427 U.S. 307, 312-14 (1976); San Antonio Indep. Sch. Dist. v. Rodriguez, 411 U.S. 1, 24-28 (1973).

19. That immutability has been soundly critiqued at the academic level, however, does not mean that it is not still a live issue at the litigation level. See William B. Rubenstein, Divided We Litigate: Addressing Disputes Among Group Members and Lawyers in Civil Rights Campaigns, 106 YALE L.J. 1623, 1642-43 (1997). Thus, if my points about immutability persuade anyone to jettison the immutability factor, that outcome will be welcomed as a positive externality of this argument.

20. See 7 THE OXFORD ENGLISH DICTIONARY 693 (2d ed. 1989).

21. See 19 id. at 687 . 
The next three Parts seek to respond to this processual defense, which is no less misguided for requiring a more elaborate rebuttal. That rebuttal does not maintain that indistinct groups are more powerless than distinct groups, but rather that no generalizations can be made either way. It thus seeks to dissolve, rather than to invert, the hierarchy between distinct and indistinct groups posited by current doctrine. In attempting to do so, the rebuttal disaggregates the assumption that distinct groups are more vulnerable than indistinct groups into its two components: (1) the tenet that immutable groups are more vulnerable than mutable groups; and (2) the tenet that visible groups are more vulnerable than invisible groups.

In Part IV, I consider the claim that immutable groups are more disabled than mutable groups in the political process. That claim rests on two rationales: (1) the rationale that immutable groups are less able to evade discrimination; and (2) the rationale that immutable groups are less able to alter discriminatory attitudes about them. Close examination reveals that both rationales are deeply flawed. It is thus unsurprising that equal protection jurisprudence has begun to retire the immutability factor. Though the visibility factor has not been subjected to serious criticism, it is similarly untenable.

In Part V, I turn to the claim that visible groups are uniquely vulnerable in the political process. The rationales for that claim parallel those adduced in the immutability context. Thus, visible groups are said to have less power to evade prejudices than invisible groups. They are also said to have less power to alter those prejudices. While these arguments are stronger for visibility than the analogous arguments are for immutability, they still are ultimately unpersuasive. Whether a group's visibility (or invisibility) empowers or disempowers it in the political process is a deeply contextual inquiry. It is therefore impossible to generalize about the effects of visibility (or invisibility) across those contexts.

Because the visibility factor has not yet been seriously criticized, I provide in Part VI a concrete example of how visibility distorts the heightened scrutiny inquiry. Although the courts do not recognize that the net effects of invisibility can be debilitating in some contexts, the state clearly does. When the state has animus against an invisible group, it can manipulate the context in which the group functions to ensure that the net effects of its invisibility are disempowering. The most egregious injustice of the visibility bias manifests itself in these scenarios, in which courts defer to such state action because they assume that invisibility is empowering, even as the state is banking on the opposite presumption.

This dynamic is illustrated by the case of gays in the military. By using the framework laid out in Part V, I make a detailed showing that the military's "don't ask, don't tell" policy manipulates the context in which gays operate, amplifying the disempowering aspects (and dampening the 
empowering aspects) of their invisibility. I then point out the untenable nature of the judicial assumption that invisibility is always empowering to gays by highlighting the military's investment in precisely the opposite dynamic.

By Part VII, the need for doctrinal reconstruction should be evident. I begin with the question of why the courts have relied on immutability and visibility. A look at the origins of the factors reveals that they were created to capture the similarities between race-based and sex-based classifications. They were then retained because of their gatekeeping function of privileging these classifications while excluding others. The courts will therefore be reluctant to jettison the factors without developing an alternative gatekeeping mechanism. I suggest that this alternative mechanism should be a refinement of the currently existing inquiry into the group's political powerlessness, which would operate in lieu of the immutability and visibility factors. I conclude on a pragmatic note by pointing out that this solution should be attractive even to the groupsindicatively blacks and women - that traditionally have been favored under the immutability and visibility frameworks.

\section{EQUAL PROTECTION IMMUTABILITY AND VISIBILITY DEFINED}

As employed by the courts in the equal protection context, immutability and visibility are terms of art that share many features. Indeed, when the terms are defined and compared, it becomes clear why the courts often tend to confuse them.

\section{A. Immutability}

Heightened scrutiny's immutability factor is easy to find. One prong of the standard test asks whether the classification relies on an immutable characteristic. ${ }^{22}$ Understanding what the factor means, however, is more difficult. To my knowledge, the Ninth Circuit's opinion in Watkins $v$. United States Army ${ }^{23}$ provides the most extensive judicial analysis of the

22. See, e.g., Bowen v. Gilliard, 483 U.S. 587, 602 (1987) (citing Lyng v. Castillo, 477 U.S. 635,638 (1986)). For other applications of this test, see cases cited supra note 13.

23. 837 F.2d 1428 (9th Cir.), amended by 847 F.2d 1329 (9th Cir. 1988), vacated and aff'd on other grounds, 875 F.2d 699 (9th Cir. 1989) (en banc). After 14 years of exemplary service, Perry Watkins was discharged by the Army because of statements he had made about his own homosexuality. See Watkins, 837 F.2d at 1429. Although he had informed the U.S. Army that he was gay when he enlisted, Watkins was permitted to serve until new regulations were promulgated in 1981, requiring the discharge of all homosexual servicemembers. See id. Watkins then brought suit challenging his discharge on, inter alia, equal protection grounds. See id. at 1433. In considering the equal protection claim, a panel of the Ninth Circuit found that homosexuals were a suspect class deserving of heightened scrutiny, in part because they were marked by an immutable trait. See id. at 1446. Subjecting the regulation to such scrutiny, the 
factor. While this definitional discussion does not provide a perfect description of the manner in which the courts deploy the term "immutability," it provides a useful starting point. The Watkins court distinguished among three different kinds of immutability-"strict" immutability, in which the bearer must be unable to change the trait, ${ }^{24}$ "effective" immutability, in which changing the trait is possible but difficult; ${ }^{25}$ and "personhood" immutability, in which the bearer's ability to change the trait is irrelevant, as long as it is central to her identity. ${ }^{26}$ The Ninth Circuit panel cogently reasoned that the Supreme Court could not be requiring strict immutability, because that requirement would disqualify many members of all categories-race, sex, national origin, alienage, and illegitimacy-currently given heightened scrutiny. ${ }^{27}$ It therefore concluded that one of the other two kinds of immutability was involved.

Although it was not necessary for the Watkins court to distinguish between effective and personhood immutability, ${ }^{28}$ it seems clear that the Supreme Court could not be referring to personhood immutability. The Ninth Circuit's conjecture (without citation) that the case law, read "in a more capacious manner," 29 supported personhood immutability seems overly generous to that jurisprudence. The personhood theory has nothing to do with whether a person can change a trait; it focuses instead on whether she should change the trait. ${ }^{30}$ The Supreme Court's jurisprudence, however, emphasizes the descriptive issue of whether a person can control a characteristic rather than the prescriptive one of whether she should do so. $^{31}$

A further refinement is necessary, because courts do not characterize all traits that are hard to change-such as race, sex, national origin, religion, alienage, and illegitimacy -as immutable. To the contrary, the courts in the equal protection context have only accorded race, sex, and national origin

panel struck down the regulations. See id. at 1448-51. The panel's decision was then appealed to the Ninth Circuit sitting en banc. The en banc court found that the case was better decided (again in Watkins' favor) on equitable estoppel grounds, and the panel's decision was withdrawn. See Watkins, 875 F.2d at 711. Because the en banc court did not address the equal protection issue, however, it should not be read as registering disapproval (or approval) of the panel decision's discussion of immutability.

24. Watkins, 837 F.2d at 1446.

25. Id.

26. $I d$.

27. See id.

28. See id. ("Under either formulation, we have no trouble concluding that sexual orientation is immutable for the purposes of equal protection doctrine.").

29. Id.

30. The Watkins panel's deployment of personhood immutability can be read as a valiant attempt to circumvent assimilationist bias, as personhood immutability diverts the courts' attention away from the group's ability to assimilate and redirects it toward the validity of the legislation.

31. See, e.g., Frontiero v. Richardson, 411 U.S. 677, 686 (1973) (plurality opinion) (describing race, sex, and national origin, but not alienage, as immutable characteristics). 
uncontroversial status as immutable traits. ${ }^{32}$ Religion and alienage, on the other hand, are generally not recognized as immutable ${ }^{33}$ while illegitimacy has been deemed quasi-immutable. ${ }^{34}$

In grouping the categories in this way, the courts appear to be making a distinction between "corporeal" and "social" traits. If a trait is perceived to be defined by nature rather than by culture, then the courts will be more likely to call it immutable. Race and sex, for example, are clearly viewed as biologically determined. If, on the other hand, the trait is perceived to be more defined by culture, the courts will withhold the immutability designation. Religion and alienage, for example, are viewed not to have a biological substrate and, thus, are not deemed immutable.

I emphasize that I am not endorsing this distinction between corporeal and social traits, or saying that it is stable. I believe that the courts are reasoning from a widely shared intuition that religion and alienage are socially constructed classifications, while race, sex, national origin, and perhaps illegitimacy are biologically determined ones. Yet as a number of

32. See, e.g., id.

33. The existence of the First Amendment has generally prevented courts from entertaining the claim that religious classifications deserve heightened scrutiny. See Benjamin Hoorn Barton, Note, Religion-Based Peremptory Challenges After Batson v. Kentucky and J.E.B. v. Alabama: An Equal Protection and First Amendment Analysis, 94 MiCH. L. REV. 191, 204 (1995) (noting that the failure of courts to grant religious classifications heightened scrutiny "is traceable to the fact that religious discrimination cases have traditionally been decided under the First Amendment"). Nonetheless, religion has sometimes been recognized as a mutable characteristic in the equal protection context. See, e.g., Holmes v. California Army Nat'l Guard, 124 F.3d 1126, 1137 (9th Cir. 1997) (Reinhardt, J., dissenting) (suggesting that members of religious groups may be less oppressed than members of racial groups because they at least have the option of conversion).

Similarly, alienage has not been generally recognized as an immutable characteristic. See, e.g., Able v. United States, 968 F. Supp. 850, 863 (E.D.N.Y. 1997) (stating that "alienage is not immutable"), rev'd on other grounds, 155 F.3d 628 (2d Cir. 1998). Compare Frontiero, 411 U.S. at 682 (plurality opinion) (noting that alienage, race, sex, and national origin are suspect classifications), with id. at 686 (noting that race, sex, and national origin are immutable but omitting alienage). Frontiero only listed four (rather than the current five) suspect classifications because the cases finding that legitimacy was a suspect classification had not then been decided. See Clark v. Jeter, 486 U.S. 456 (1988); Lalli v. Lalli, 439 U.S. 259 (1978); Trimble v. Gordon, 430 U.S. 762 (1977).

It is true that some courts have stated, without further explanation, that alienage is immutable. See, e.g., Parham v. Hughes, 441 U.S. 347, 351 (1979); Berman v. United States, 572 F. Supp. 1486, 1489 (N.D. Ga. 1983). The absence of analysis in these cases, however, leads me to suspect that these courts are erroneously inferring that a group is immutable if it has received heightened scrutiny. See, e.g., Parham, 441 U.S. at 351 (noting that race, like the four other classifications based on "immutable human attributes," is a suspect classification); Berman, 572 F. Supp. at 1489 (noting that wrongful death plaintiffs are not a suspect class because the classification is not based on "immutable human attributes" such as those defining the five suspect classifications).

34. Although illegitimacy has been characterized as an immutable characteristic, see, e.g., Regents of the Univ. of Cal. v. Bakke, 438 U.S. 265, 360 (1978); Bridges v. Phillips Petroleum Co., 733 F.2d 1153, 1155 (5th Cir. 1984), the Supreme Court has correctly noted that it may not always be immutable from the perspective of the parent of the illegitimate child because some states permit parents to legitimate children born out of wedlock through a court order, see Parham, 441 U.S. at 353. 
commentators have shown, these latter categories are not solely biologically determined. ${ }^{35}$ I agree with those commentators, but I do not seek to replicate their work. Rather than challenging the judicial definition of immutability, I accept it in order to contest most directly the manner in which it is deployed. These two observations-that the Court targets effective and corporeal immutability-will undergird the remainder of this Article.

\section{B. Visibility}

The standard heightened scrutiny test requires courts to consider: (1) whether the group has suffered a history of discrimination; (2) whether the group is politically powerless; and (3) whether the group is distinguished by an "obvious, immutable, or distinguishing characteristic[]." 36 The bias favoring visible groups is most explicitly stated in the third prong, where the words "obvious" and "distinguishing" stand as proxies for the concept of visibility. Yet the Supreme Court has expressed solicitude for visible groups under the other two prongs as well. In Mathews v. Lucas, ${ }^{37}$ for example, the Court hypothesized that the history of discrimination suffered by illegitimate children was less severe than that suffered by women or blacks "perhaps in part because illegitimacy does not carry an obvious badge." " Similarly, in Frontiero $v$. Richardson, ${ }^{39}$ a plurality of the Court noted that "it can hardly be doubted that, in part because of the high visibility of the sex characteristic, women still face pervasive, although at times more subtle, discrimination." 40 This conclusion served as a predicate for finding women to be politically powerless. ${ }^{41}$

35. On the socially constructed nature of race, see, for example, LAN F. HANEX LOPEZ, WHITE BY LAW: THE LEGAL CONSTRUCTION OF RACE (1996). On the socially constructed nature of sex, see, for example, JUDITH BUTLER, GENDER TROUBLE: FEMINISM AND THE SUBVERSION OF IDENTITY (1990). National origin and illegitimacy are very easily seen as socially constructed categories, as the borders that define nations and the relations that define legitimacy are obviously creations of culture rather than of nature. See Anne Reichman Schiff, Frustrated Intentions and Binding Biology: Seeking AID in the Law, 44 DUKE L.J. 524, 530-31 (1994) (noting that biological kinship is neither necessary nor sufficient for a legal determination of legitimacy); Frank H. Wu, The Future of the American Mosaic: A Moderate Proposal for Immigration Reform, 7 STAN. L. \& POL'Y REV. 35, 55 n.132 (1996) (noting that national origin is not a biological matter).

36. Bowen v. Gilliard, 483 U.S. 587, 602 (1987) (citing Lyng v. Castillo, 477 U.S. 635, 638 (1986)). For other applications of this test, see cases cited supra note 13.

37. 427 U.S. 495 (1976).

38. Id. at 506 .

39. 411 U.S. 677 (1973) (plurality opinion).

40. Id. at 686; see also Craig v. Boren, 429 U.S. 190, 218 (1976) (Rehnquist, J., dissenting) (noting that the Frontiero plurality recognized "that the pervasive and persistent nature of the discrimination experienced by women is in part the result of their ready identifiability").

41. This is not to say that invisible groups are barred from receiving heightened scrutiny, as indicated by the cases of illegitimacy and alienage. That these classifications have attained protected status, however, simply means that invisibility operates as a factor, as opposed to a 
An analogue of the set of definitional restrictions placed on immutability applies to visibility. For the reasons stated by the Watkins court, the courts cannot mean "strict" visibility or "personhood" visibility. If the courts meant strict visibility, the ability of some blacks and women to "pass" would undermine the claims of these groups to heightened scrutiny. Similarly, it is unlikely that the courts mean personhood visibility, as invisible traits that could be constitutive of an individual's selfconception-such as illegitimacy-have been deemed not to satisfy the visibility factor. ${ }^{42}$ I thus assume that by visibility, the courts mean effective visibility.

I also distinguish between "effective corporeal visibility" and "effective social visibility." By corporeal visibility, I mean the perceptibility of traits such as skin color that manifest themselves on the physical body in a relatively permanent and recognizable way. ${ }^{43}$ Social visibility, on the other hand, designates the perceptibility of nonphysical traits. ${ }^{44}$ By visibility, the courts mean corporeal visibility rather than social

requirement, in the analysis. And insofar as it operates as a factor, invisibility cuts against a finding that a classification deserves heightened scrutiny. Thus, illegitimacy was accorded heightened scrutiny as a classification in spite of its invisibility. See Mathews, 427 U.S. at 506. The case of alienage is slightly different, given that, as I later argue, alienage was accorded heightened scrutiny before the inauguration of the visibility factor. See infra note 330. Graham $v$. Richardson, 403 U.S. 365 (1971), which held that alienage was suspect, preceded Frontiero, which I argue introduced the visibility factor, by two years. It is significant, however, that academic commentary contending that the visibility factor dates back to United States v. Carolene Products Co., 304 U.S. 144 (1938), maintains that alienage should not have received heightened scrutiny precisely because of the social inability to identify aliens on sight. See, e.g., Louis Lusky, Footnote Redux: A Carolene Products Reminiscence, 82 COLUM. L. REV. 1093, 1105 n.72 (1982); cf. infra note 322 (considering the pedigree of the visibility factor).

42. See, e.g., Mathews, 427 U.S. at 506.

43. As this definition indicates, corporeal visibility is not exhausted by traits discernible through the sense of sight. I borrow Erving Goffman's disclaimer:

Since it is through our sense of sight that the stigma of others most frequently becomes evident, the term visibility is perhaps not too misleading. Actually, the more general term, "perceptibility" would be more accurate, and "evidentness" more accurate still. A stammer, after all, is a very "visible" defect, but in the first instance because of sound, not sight.

ERVING Goffman, Stigma: Notes on the Management of Spolled IdentiTy 48 (1963).

44. Social visibility includes "declarative visibility," which arises when a corporeally invisible trait is made visible through speech. For example, an immigrant who self-identifies as such is declaratively visible. Social visibility also includes what Kathryn Abrams has dubbed "political visibility" and "programmatic visibility." Kathryn Abrams, The Supreme Court, Visibility, and the "Politics of Presence," 50 VAND. L. REV. 411, 414-15 (1997). Political visibility "arises when a person claims group membership as a central and constitutive feature of her identity." Id. at 414. An immigrant who articulates her world view as shaped by her immigrant status would thus be politically visible, while an immigrant who feels that she just "happens to be" an immigrant could be described as declaratively visible but politically invisible. Programmatic visibility, in turn, "arises from group members' efforts to connect their groupbased identities with a particular political interest or program." Id. An immigrant who militated against the ban on HIV-positive immigrants might be seen as programmatically visible, while one who views her immigrant status as identity-constitutive only in her personal life might be declaratively and politically visible but programmatically invisible. For the purposes of this 
visibility. ${ }^{45}$ This can be inferred from the fact that the Court deems visibility to be disempowering. ${ }^{46}$ Far from being viewed as disempowering, social visibility has traditionally been understood by the courts to be a proxy for political power. For example, the courts consider such forms of social visibility as a group's presence in the "[n]ation's decisionmaking councils" ${ }^{47}$ or its ability "to attract the attention of ... lawmakers" ${ }^{48}$ as indicia of political power.

Once again, the distinction between social and corporeal visibility is retained not because it is accurate, but because it accurately describes the intuition of the courts. There is no such thing as a purely biologically visible trait, for visibility is always relational, requiring a performer and an observer. Whether a trait is visible will thus depend not only on the trait but also on the "decoding capacity of the audience," 49 which in turn will depend on the social context. Thus, to use Erving Goffman's example, one presumes that the syphilitic will be invisible to passers-by but not to a medical specialist. ${ }^{50}$ If both observers fail to notice the syphilis, the first failure will be ascribed to the invisibility of the trait, while the second will be ascribed to the blindness of the observer (as evidenced by the fact that the syphilitic can sue the doctor for failing to diagnose him correctly). Visibility, like immutability, is therefore always socially determined.

\section{Commonalities}

Having defined immutability and visibility, I now turn to the ways in which the courts often blur the distinctions between the two concepts. The Supreme Court's test for heightened scrutiny runs the two concepts together by asking whether a classification creates classes marked by " 'an obvious, immutable, or distinguishing characteristic." 51 Immutability and visibility thus not only occupy the same prong of the test, but also coexist as

Article, the subdivisions of social visibility will be less important than the distinction between corporeal and social visibility.

45. It bears note that the relationship between these two kinds of visibility is highly complex. There may well be a correlation between corporeal visibility and the various forms of social visibility: The corporeal invisibility of pedophiles may contribute to their social invisibility, and the corporeal visibility of blacks may contribute to their social visibility. But the correlation, if it exists, is imperfect, for corporeal visibility is neither necessary nor sufficient to ensure social visibility. A corporeally visible trait like eye color can have so little social significance that it is not socially visible. Conversely, a corporeally invisible trait like belonging to the Communist Party might be so fraught with significance as to be highly socially visible.

46. See Mathews, 427 U.S. at 506; Frontiero v. Richardson, 411 U.S. 677, 686 (1973) (plurality opinion); supra notes $37-40$ and accompanying text.

47. Frontiero, 411 U.S. at $686 \mathrm{n} .17$ (plurality opinion).

48. City of Cleburne v. Cleburne Living Ctr., 473 U.S. 432,445 (1985).

49. GoFFMAN, supra note 43 , at 51 .

50. See id. at 50-51.

51. Bowen v. Gilliard, 483 U.S. 587, 602 (1987) (quoting Lyng v. Castillo, 477 U.S. 635, 638 (1986)). 
disjunctive requirements, with the implication that they are sufficiently related such that only one requirement need be met.

The connection between immutability and visibility can be seen even more clearly in Watkins v. United States Army, ${ }^{52}$ where the Ninth Circuit panel relied on the language of visibility to define immutability. Thus, the opinion began by noting that "by 'immutability' the [Supreme] Court has never meant strict immutability in the sense that members of the class must be physically unable to change or mask the trait defining their class." ${ }^{53}$ The opinion then maintained that national origin is not strictly immutable, not because it can be changed, but because it can be concealed: "People can frequently hide their national origin ...." ${ }^{4}$ The court made a similar point in the race context: "Lighter skinned blacks can sometimes 'pass' for white, as can Latinos for Anglos, and some people can even change their racial appearance with pigment injections." ${ }^{55}$ Thus, the definition of immutability is laced with the rhetoric of visibility-masking, hiding, passing, and appearing.

It is easy to understand why the courts might conflate these two concepts. First, visibility as defined by the courts refers to corporeal visibility that is effectively permanent. To see this point, consider whether the courts would deem visible a Jewish person who was visible as such only when he wore a yarmulke, or a Christian who was visible as such only when she wore a crucifix. But if visibility must be effectively permanent, it becomes a subset of immutability. When the courts abandon immutability in favor of visibility, they thus are not shifting to another justification but merely narrowing the old one; it is now not immutable characteristics generally but rather visible immutable characteristics that are deemed worthy of judicial solicitude. ${ }^{56}$ Second, both visibility and immutability protect historically protected groups such as those based on race and $\operatorname{sex}^{57}$ while freezing out traditionally unprotected groups such as those based on sexual orientation or class. ${ }^{58}$ Third, both factors direct judicial attention to

52. 837 F.2d 1428 (9th Cir.), amended by 847 F.2d 1329 (9th Cir. 1988), vacated and aff d on other grounds, 875 F.2d 699 (9th Cir. 1989) (en banc).

53. Id. at 1446 (emphasis added).

54. Id. (emphasis added).

55. Id. (emphases added).

56. No court has noted that visibility is logically nested within immutability. To engage judicial analysis on its own terms, I therefore use the words as the courts do. Thus, when I state that the courts have jettisoned the immutability factor, see infra text accompanying notes 136-137, I do not mean that they have retired visibility as well, but that they have scuttled immutability as they define it.

57. See, e.g., Frontiero v. Richardson, 411 U.S. 677, 685-86 (1973) (plurality opinion).

58. Gays have been denied heightened scrutiny both on the basis of their mutability and invisibility. See, e.g., Equality Found. of Greater Cincinnati v. City of Cincinnati, 128 F.3d 289, 293 (6th Cir. 1997) [Equality Foundation II] (denying gays heightened scrutiny, in part because of their invisibility), on remand from 518 U.S. 1001 (1996), vacating 54 F.3d 261, 167 (6th Cir. 1995) [Equality Foundation I], cert. denied, 66 U.S.L.W. 3749 (U.S. Oct. 13, 1998) (No. 97- 
the corporeal body rather than to the body politic. In other words, the immutability and visibility factors both focus on how traits are situated within group members. In contrast, the other aspects of the heightened scrutiny test-history of discrimination and political powerlessness-look to how group members are situated in society. Fourth, both factors justify themselves through the fact that the groups they define are unable to take advantage of the ostensibly empowering aspects of assimilation. ${ }^{59}$ It is to this final justification that I now turn.

\section{EQUAL PROTECTION'S ASSIMILATIONIST BIAS}

Before contesting the assimilationist bias inherent in the immutability and visibility factors, I wish to note two limitations I have placed on my critique of assimilation. First, although there are (at least) three different kinds of assimilationist bias in equal protection doctrine, I focus on only two. The three biases are converting, passing, and covering. Converting bias means that a group is asked to change the trait that defines it. Converting bias is at issue, for example, when gays are forced into psychotherapy to alter their sexual orientation. ${ }^{60}$ Passing means that a group is forced to hide its identity. Passing is at issue, for example, when gays are permitted to serve in the military as long as they do not disclose their orientation. ${ }^{61}$ Covering means that a group is permitted both to retain and articulate its identity as long as it mutes the difference between itself and the mainstream. ${ }^{62}$ Covering is at issue, for example, when an employer retains "out" gays, but not a lesbian who "flaunts" her homosexuality by entering into a public commitment ceremony with her same-sex lover. ${ }^{63}$

1795); High Tech Gays v. Defense Indus. Sec. Clearance Office, 895 F.2d 563 (9th Cir. 1990) (denying gays heightened scrutiny, in part because "[h]omosexuality is not an immutable characteristic").

The homeless have also been denied heightened scrutiny on the basis of mutability. See Johnson v. City of Dallas, 860 F. Supp. 344, 357 (N.D. Tex. 1994), rev'd on other grounds, 61 F.3d 442 (5th Cir. 1995). Homelessness is obviously only a rough proxy for class, but I rely on it here because the Supreme Court case denying the poor suspect status did not clearly articulate the basis for its holding. See San Antonio Indep. Sch. Dist. v. Rodriguez, 411 U.S. 1 (1973).

59. See infra notes $91-120,143-221$ and accompanying text.

60. See JONATHAN KATZ, GAY AMERICAN HISTORY 129-207 (1976) (documenting case studies).

61. See infra Part VI.

62. The coinage of the term "covering” appears to be Erving Goffman's. See GOFFMAN, supra note 43 , at $102-04$.

63. See Shahar v. Bowers, 114 F.3d 1097, 1111 n.27 (11th Cir. 1997) (upholding the dismissal of a lesbian attorney and noting that she was dismissed not because of her sexual orientation but because of her participation in a public same-sex commitment ceremony), cert. denied, 118 S. Ct. 693 (1998). Another example of forced covering for gays occurs in the family law context, where gays are permitted to retain visitation rights with their biological children only as long as they do not "flaunt" their homosexuality while in the presence of their children. See, e.g., Pennington v. Pennington, 596 N.E.2d 305 (Ind. Ct. App. 1992) (requiring absence of father's male and allegedly gay friend during periods of visitation); S.E.G. v. R.A.G., 735 S.W.2d 
Covering is perhaps a less familiar concept than either converting or passing, and it is also easily confused with passing. For these reasons, it may be helpful to describe it further. As Goffman notes, even when a trait is visible (and therefore passing is not at issue), there is the further question of its obtrusiveness-that is, the issue of how much the visible trait impedes the flow of "normal" interaction. ${ }^{64}$ Thus, "at a business meeting a participant in a wheelchair is certainly seen to be in a wheelchair, but around the conference table his failing can become relatively easy to disattend." ${ }^{65}$ This distinction between keeping a trait invisible and keeping a trait unobtrusive is the distinction between passing and covering. The businessman is not attempting to pass as a person who is not disabled, but he is covering the obtrusiveness of his disability.

As indicated by the examples given above, all three assimilationist demands may be made on indistinct groups. Gays, for example, can be asked to convert, to pass, or to cover. In contrast, converting and passing are generally not assimilationist demands made on distinct groups. Blacks and women, for example, are not commonly required to change or to hide their race or sex. Covering, however, is an assimilationist strategy that can be used against distinct groups as well as indistinct groups. When a black woman is told that she is "too black" or "too feminine," a demand to cover is being made.

To see how members of distinct groups can be asked to cover even when they are not asked to convert or to pass, consider the following statement by Patricia Williams:
A man with whom I used to work once told me that I made too much of my race. "After all," he said, "I don't even think of you as black." Yet sometime later, when another black woman became engaged in an ultimately unsuccessful tenure battle, he confided to me that he wished the school could find more blacks like me. I felt myself slip in and out of shadow, as I became nonblack for purposes of inclusion and black for purposes of exclusion; I felt the boundaries of my very body manipulated, casually inscribed by definitional demarcations that did not refer to me. ${ }^{66}$

Covering, rather than conversion or passing, is at issue here. Williams's colleague was not asking her to convert to being white or to pass as white. Rather, he was suggesting that she might cover her blackness by not

164 (Mo. Ct. App. 1987) (limiting child visitation rights of an openly gay mother); In re Jane B., 380 N.Y.S.2d 848 (Sup. Ct. 1976) (requiring the absence of any homosexual other than the lesbian mother herself during visitation period).

64. See GOFFMAN, supra note 43 , at 49.

65. Id.

66. PATRICIA J. WILLIAMS, THE ALCHEMY OF RACE AND RIGHTS 9-10 (1991). 
making "too much of [her] race." ${ }^{67}$ That expression is telling-Williams is entitled to her race, but not to "too much" of it; there is a set of unspecified race-related traits that extends beyond the acceptable bounds of black identity. Covering also inheres more subtly in the colleague's wish that the school be able to find "more blacks like" ${ }^{68}$ Williams, which, by his own admission, is defined at least in part as a category of persons whom he does not even think of as black. The colleague's statements, while contradictory in the way Williams notes, nonetheless arise from a consistent assumption that there is such a thing as "excessive blackness." That excess both disrupts the relationship he and Williams could otherwise have and disqualifies the other black woman from that relationship. It is this excess, which extends beyond skin color alone, that needs to be covered. ${ }^{69}$

All three assimilationist demands inhere in current equal protection doctrine. The demands to convert and to pass are explicitly made in the immutability and visibility factors, respectively. The immutability factor withholds protection from groups that can convert, leaving them susceptible to legislation that pressures them to do so. ${ }^{70}$ The visibility factor similarly withholds protection from groups that can hide their defining trait, making them vulnerable to legislation that induces them to pass. ${ }^{71}$

In contrast, the demand to cover has a more subtle and pervasive presence in equal protection doctrine. It is not captured in any discrete factor, but rather in a classification-based-as opposed to classbased-view of equal protection. A classification-based view of equal protection seeks to treat all classes created by a classification the same, while a class-based view privileges the disadvantaged class(es) created by a

67. Id. at 9.

68. Id. at 10 .

69. One reason why converting, passing, and covering are often confused is that they are not only all strategies of assimilation, but strategies that are theoretically understood by analogy to each other. Thus, when examining Williams's rhetoric, one sees that while she is formally speaking of covering, she invokes the language both of conversion and of passing to describe the demand to cover. In the confines of one sentence, the colleague's words are understood through the rhetoric of mutability (conversion) - "I became nonblack for the purpose of inclusion and black for the purpose of exclusion," and that of visibility (passing)_- "I felt myself slip in and out of shadow." Id. For an analogous example of a court deploying the language of visibility (passing) while speaking of immutability (conversion), see supra notes 52-55 and accompanying text.

70. See Garcia v. Gloor, 618 F.2d 264, 269-70 (5th Cir. 1980) (holding that English-only employment rules do not violate Title VII's prohibition of national origin discrimination because speakers choose the language they use); see also Christopher David Ruiz Cameron, How the Garcia Cousins Lost Their Accents: Understanding the Language of Title VII Decisions Approving English-Only Rules as the Product of Racial Dualism, Latino Invisibility, and Legal Indeterminacy, 10 LA RAZA L.J. 261, 281-85 (1998) (discussing the use of the immutability factor to disadvantage groups with mutable traits); Halley, Politics of Biology, supra note 14, at 517-18 (describing anti-gay attempts to justify discrimination on the grounds that sexual orientation is chosen and that "waverers" therefore can be legitimately deterred by the state).

71. See Equality Foundation II, 128 F.3d at 293 (noting that gays should not get heightened scrutiny, in part because they are not corporeally visible). 
classification. Because it tends to ignore differences between the classes created by a classification, the classification-based view often results in the demand to cover. The ideal of "colorblindness" is perhaps the best example of such a classification-based view. In attempting to be colorblind, the judiciary often garners results that not only ignore the real disparities between whites and blacks but evaluate blacks by implicitly white standards. ${ }^{72}$ In order to succeed, blacks are forced to meet those standards, and thereby must mute any cultural and historical differences between whites and blacks. In such a scenario, blacks are not being asked to convert or to pass, but they are being asked to cover. ${ }^{73}$

Although I am critical of all three assimilationist demands, I restrict my critique primarily to the first two. This is because the biases to convert and to pass inhere in the immutability and visibility factors, which offer themselves as a unified doctrinal target. As will become evident below, ${ }^{74}$ however, an argument for retiring these factors is an argument against a classification-based view of equal protection. In assailing the doctrinal bias toward converting and passing, I thus build the foundation for a challenge to covering. The job of comprehensively critiquing covering, however, is left for another day.

The second substantive limitation of the Article is my focus on the judiciary. This focus does not presume that the assimilationist bias is one to which the judiciary is particularly prone. To the contrary, I assume that the assimilationist bias is pervasive, and that its doctrinal traces merely reflect the judiciary's complicity in contemporary American culture. Providing a programmatic critique of assimilation in society at large, however, is beyond the scope of the Article. My critique is therefore ultimately doctrinal, rather than political. Its narrow prescription is that the judiciary limit, rather than further, the effects of social bias.

Having entered these caveats, I can now begin my critique. Constitutional theories of judicial review provide two means of justifying the immutability and visibility factors. ${ }^{75}$ The first is a substantive theory, pursuant to which the courts strike down legislation that violates a constraining constitutional value, ${ }^{76}$ here the equality principle embedded in the equal protection guarantee. The second is a processual theory, pursuant to which courts protect groups that are disadvantaged in the political

72. See Jerome M. Culp, Jr., Black People in White Face: Assimilation, Culture and the Brown Case, 36 WM. \& MARY L. REV. 665, 669 (1995).

73. See id. at 676-81; Enid Trucios-Gaynes, The Legacy of Racially Restrictive Immigration Laws and Policies and the Construction of American National Identity, 76 OR. L. REV. 369, 38687 (1997).

74. See infra notes $356-360$ and accompanying text.

75. See Bruce A. Ackerman, Beyond Carolene Products, 98 HARV. L. REv. 713, 740-46 (1985).

76. See id. at 741. 
process. ${ }^{77}$ This Part shows that the immutability and visibility factors cannot be justified on substantive grounds and then prepares the way for the more complex challenges presented by the processual argument.

\section{A. The Substantive Defense and Its Shortcomings}

The substantive defense of the immutability and visibility factors and much of the critique of that defense are set forth in Janet Halley's important work, Sexual Orientation and the Politics of Biology. ${ }^{78}$ The defense begins by pointing out that classifications based on immutable traits (which, as noted above, include classifications based on visible traits) ${ }^{79}$ divide people into groups based on traits that are effectively beyond their control. It then notes that these classifications violate "the basic concept of our system that legal burdens should bear some relationship to individual responsibility." ${ }^{80}$ In other words, treating people differently because of traits they cannot change violates fundamental norms of fairness and equality.

This defense is both over- and underinclusive. It is overinclusive because it is impossible for society to operate without discriminating on the basis of some immutable characteristics. The Frontiero Court admitted as much when it stated that many immutable characteristics, such as intelligence and physical disability, may provide the basis of legitimate discriminatory decisions. ${ }^{81}$ Immutability thus extends protection to more groups than we wish to protect.

The defense is also underinclusive. The immutability and visibility factors presume that legislation is less problematic if it burdens groups that can assimilate into mainstream society by either converting or passing. That presumption seems misguided, as the ability of a group to respond to legislation-through assimilation or through other means-seems irrelevant

77. See id. at 740-41.

78. See Halley, Politics of Biology, supra note 14, at 507-09.

79. Halley's discussion of this defense and critique restricts itself formally to immutability. It is also applicable to visibility, however, if visibility is correctly understood to be a kind of immutability. See supra note 56 and accompanying text.

80. Frontiero v. Richardson, 411 U.S. 677, 686 (1973) (plurality opinion) (quoting Weber v. Aetna Cas. \& Sur. Co., 406 U.S. 164, 175 (1972)).

81. See Halley, Politics of Biology, supra note 14, at 507-08 (citing Frontiero, 411 U.S. at 688 (plurality opinion)). Halley rightly notes that the Court's examples are "a little dubious," given that intelligence and physical disability are not definitively immutable traits. Id. at 508. Yet the infelicity of the examples does not detract from the correctness of the Court's statement that society must retain the ability to discriminate on the basis of some immutable traits, such as adult height. See, e.g., City of Cleburne v. Cleburne Living Ctr., 473 U.S. 432, 472 n.24 (1985) (Marshall, J., concurring in the judgment in part and dissenting in part) (noting that immutable traits such as height can be valid bases for government classification). 
to the question of whether legislation is legitimate. ${ }^{82}$ Jews generally can change or conceal their religion, while blacks generally cannot change or conceal their race. This surely does not make anti-Semitic legislation more legitimate than racist legislation. ${ }^{83}$

To the contrary, if legislation is illegitimate, it should be invalidated regardless of whether its object is an indistinct or a distinct group. In that circumstance, it is the state, not the burdened group, that is engaged in wrongdoing, and thus it is the state, not the group, that should alter its behavior. To ask the indistinct group to adapt to the state's wrongdoing is to blame the victim.

In making this criticism of the immutability and visibility factors, I emphasize that the problem does not inhere in state-sponsored assimilation per se. Such a wholesale objection would be overbroad. Assimilation has positive, as well as negative, aspects. ${ }^{84}$ For example, one does not commonly hear complaints about the state's forcing would-be criminals to become law-abiding through the criminal law system, or about the state's requiring the illiterate to become literate through the public education system. A categorical objection to state-sponsored assimilation would also be utopian. ${ }^{85}$ To protect plural notions of the good, the state must enforce certain ground rules of mutual respect. Those rules, however, have a substantive content that will burden some conceptions of the good more than others. Thus, although they attempt to preserve heterogeneity, these rules will be seen by some as enforcing homogeneity. For example, rules that protect all racial identities as equally entitled to respect will be

82. See Halley, Politics of Biology, supra note 14, at 509 (making this point in the context of immutability)

83. Another way of approaching the same insight is to ask, as Laurence Tribe has done, whether racism would be constitutionally unproblematic if blacks could easily alter their race. See Tribe, supra note 15 , at $1074 \mathrm{n} .52$ (noting that "even if race or gender became readily mutable by biomedical means, I would suppose that laws burdening those who chose to remain black or female would properly remain constitutionally suspect" ); see also Watkins v. United States Army, 837 F.2d 1428, 1446 (9th Cir.) (citing Tribe for the proposition that "[r]acial discrimination, for example, would not suddenly become constitutional if medical science developed an easy, cheap, and painless method of changing one's skin pigment"), amended by 847 F.2d 1329 (9th Cir. 1988), vacated and aff'd on other grounds, 875 F.2d 699 (9th Cir. 1989) (en banc).

84. Assimilation, which is defined as the act of becoming similar, is understood to have two connotations. The positive connotation views assimilation as "a process which liberates individuals from the binding force of particularistic traditions," thereby inducting them into a community with shared values. Nomi M. Stolzenberg, Un-Covering the Tradition of Jewish "Dissimilation": Frankfurter, Bickel, and Cover on Judicial Review, 3 S. CAL. INTERDISC. L.J. 809,814 (1994). The negative connotation casts assimilation as "substituting the dominant culture's values for those of the subordinated subgroup, rather than transcending the values and beliefs of any particular culture." Id. at 814-15.

85. Both classical and modern proponents of liberalism share this view. Compare, e.g., ThOMAS HOBBES, LEVIATHAN 227-28, 376 (C.B. MacPherson ed., 1985) (1651) (giving an account of how the state requires individuals to give up certain rights in order to protect their abilities to pursue their various notions of the good), with, e.g., JOHN RAWLS, POLITICAL LIBERALISM 133-40 (1996) (noting that the coercive power of the state is the predicate for political liberalism, which holds that multiple notions of the good should be respected). 
experienced by racists as a substantive imposition on their beliefs. The paradox of liberal heterodoxy is that it must be built on a foundation of assimilationist orthodoxy. ${ }^{86}$

The objection to the assimilationist bias, then, is not to state-sponsored assimilation but to state-sponsored assimilation that fails adequately to question whether the assimilation in question is appropriate. Because of the assimilationist bias implicit in the immutability and visibility factors, the courts are not asking this question with sufficient force. Once a group is found to be indistinct, the likelihood is high that it will only receive rational review. Once it receives rational review, the likelihood is overwhelming that the legislation allegedly burdening it will be upheld. The descriptive claim that a group can assimilate thus transmutes into the prescriptive claim that it should assimilate without much intervening investigation by the courts into the legitimacy of the legislation. This analysis marginalizes an inquiry that should be central-whether the assimilation at issue is appropriate.

It is tempting to end the argument here, for it seems irrefutable as a matter of substantive equality that groups cannot be denied protection simply because they can evade discrimination by assimilating into the political mainstream. But there is another means of justifying the assimilationist bias, to which I now turn.

\section{B. The Political Process Defense}

The alternative defense is grounded in political process theory, which limits judicial review to cases where the normal political process has proven inadequate. ${ }^{87}$ The theory begins with the premise that minorities can be expected to lose in a liberal democracy. A given minority group, however, should not be expected to lose all the time, because majorities are coalitions of minority blocs. These coalitions will shift as blocs realign on

86. This paradox replicates itself in the Constitution. The most obvious hallmark of the Constitution is its heterodoxy, leading one commentator to maintain that the antitotalitarian principle is a "transcendental doctrine" of the Constitution. Jed Rubenfeld, The Right to Privacy, 102 HARV. L. REV. 737, 805 (1989). And it is true that the explicitly antiassimilationist principles embodied in, for example, the Free Speech, Freedom of Exercise, and Establishment Clauses, are far more prominent than the explicitly assimilationist principles articulated in, for example, the Bill of Attainder and the Titles of Nobility Clauses. But even the most obviously heterodox principles of the Constitution, when closely examined, reveal themselves to be based on a conception of orthodoxy. For instance, in the First Amendment context, the Court has acknowledged that the question is not whether, but how much, assimilation is appropriate. Compare Minersville Sch. Dist. v. Gobitis, 310 U.S. 586 (1940) (upholding a flag salute provision against a First Amendment challenge because it deemed the flag salute to be integral to inculcating a crucial sense of citizenship), with West Va. State Bd. of Educ. v. Barnette, 319 U.S. 624 (1943) (reiterating that certain measures inculcating citizenship are appropriate but overnuling Gobitis because flag salutes are not among them).

87. This theory is elegantly set forth in Ackerman, supra note 75, at 719-20. 
different issues. If a minority consistently loses, this may indicate that other minority groups are not forming coalitions with it out of prejudice-in other words, that the democratic process has failed that group.

Unless the process has failed, the judiciary should not intervene to protect a minority group. Such an intervention would disrupt the democratic process of wheeling and dealing through which different minority groups pursue their agendas. Burdened as it is with the countermajoritarian difficulty, the judiciary suffers a legitimacy deficit whenever it causes such a disruption. The only time the judiciary may intervene is when the process has broken down. In cases where a minority bloc is consistently unable to form coalitions with other blocs because of the prejudice those blocs harbor towards it, the legislative process itself suffers from a legitimacy deficit. In correcting that deficit, the judiciary is keeping, rather than breaking, faith with the democratic process.

Process theory is not casually invoked by name these days. Subsequent critiques of it have cast doubt on whether courts are indeed capable of discerning when there has been a failure of the ordinary political process. ${ }^{88}$ These critiques raise the concern that courts may simply be effectuating their own substantive judgments under the guise of curing process failure. Yet some version of this form of legitimating judicial review clearly endures. ${ }^{89}$

In considering the validity of assimilationist bias, process theory does not ask whether the legislation burdening the indistinct group is just or unjust. Indeed, it eschews that question as calling for precisely the kind of normative judgment that courts ought to avoid. Rather, process theory seeks to discover and protect groups that are systematically disempowered in the political process. Only such groups deserve the court's solicitude; other groups must use their political power to fend for themselves.

Under this standard, the assimilationist bias seems more plausible. It can be justified by arguing that distinct groups are politically powerless because, inter alia, they cannot evade discrimination. When confronted with discrimination, an indistinct group may temporarily or permanently escape

88. See, e.g., Paul Brest, The Fundamental Rights Controversy: The Essential Contradictions of Normative Constitutional Scholarship, 90 YALE L.J. 1063, 1064-65 (1981) (noting that "process-oriented strategies [are] covertly value-laden"); Tribe, supra note 15, at 1063-64 (noting that a process-based theory of constitutional law actually masks substantive decisionmaking).

89. See Ackerman, supra note 75, at 740-41 (arguing that judicial protection is necessary to protect the participation and bargaining abilities of some minority groups in the modern political process); Daniel A. Farber \& Philip P. Frickey, Is Carolene Products Dead? Reflections on Affirmative Action and the Dynamics of Civil Rights Legislation, 79 CAL. L. REv. 686 (1991) (arguing that the political process framework provided by Carolene Products should be retained for use in cases of racial discrimination); Michael J. Klarman, The Puzzling Resistance to Political Process Theory, 77 VA. L. REV. 747 (1991) (arguing that, although certain forms of process theory have been criticized justly for reliance on substantive judgment, "pure" process theory is sufficiently powerful to achieve the goals of the equal protection guarantee). 
it by changing or hiding its defining trait. Distinct groups do not have this chameleon-like ability and are thus subject to the full force of discrimination.

To defeat the claim that distinct groups are uniquely disempowered, I lay out the best arguments for the opposite case, which posits that indistinct groups are less politically powerful than distinct groups. It bears emphasis, however, that the success of my argument does not turn on proving the opposite case. My aim here is to call into question the assimilationist bias of the equal protection jurisprudence. To accomplish that goal, all that I need to show is that indistinct groups cannot be assumed a priori to be more powerful than distinct groups. My objective is not to invert the jurisprudence's current hierarchy between distinct and indistinct groups but rather to dismantle it.

I thus proceed by breaking the assimilationist bias into its two components: (1) the "immutability presumption" (underlying the eponymous factor) that immutable groups are more politically vulnerable than mutable groups; and (2) the "visibility presumption" (also underlying the eponymous factor) that visible groups are more politically vulnerable than invisible groups. In both analyses, two different forms of power will be in play. "Evasive power" describes a group's ability to elude discrimination directed against it, while "transformative power" describes a group's ability to convince others to cease discriminating against it. The distinction is between a group's capacity for flight and its capacity to fight.

Of these two types of power, transformative power seems to relate more directly to the political power at issue in the processual framework. Indeed, a critic might fairly ask why this analysis considers evasive power at all. My response is that when a group has low evasive power, it is subjected to discrimination that impinges on its self-esteem and aspirations. The inroads that such assaults on identity make on a group's political power will be assumed to be no less potent for being difficult to measure. ${ }^{90}$

Analyzing the presumptions in terms of evasive and transformative power will reveal that both presumptions implicate the same issues. Both presumptions are bolstered by the intuitively powerful claims that immutability and visibility deprive their groups of evasive power. These claims, however, need to be qualified by noting the costs that evasion imposes on mutable and invisible groups.

Both presumptions also support themselves with the claims that immutability and visibility deprive their groups of transformative power in two ways. First, both qualities allegedly preclude their groups from

90. It also bears note that the analysis below will show that evasive power, standing alone, provides the strongest justification for both the immutability and visibility presumptions. Thus, even if the critic persists in believing that evasive power is irrelevant to this analysis, his disbelief only strengthens my ultimate argument that the presumptions should be retired. 
capitalizing on the "infiltration effect," through which groups penetrate institutions of power to create social and political change. Second, both qualities putatively impair their groups from forming cross-group coalitions because of the "auto-identification effect," in which nongroup members experience more empathy for conditions that they themselves could acquire.

Finally, both the immutability and visibility presumptions are undercut by two other effects relating to transformative power that favor distinct groups. These two effects show that evasive power and transformative power are negatively correlated, such that a distinct group's lack of the former results in compensatory gains in the latter. One such correlation is the "exit/voice effect," in which a lack of evasive power contributes to a group's transformative power by securing accountable members for it. The other is the "manipulation effect" in which the ability of indistinct groups to assimilate tempts third parties to interfere with their social identities.

While the immutability and visibility presumptions converge in these ways, they also diverge in others. The divergence between them is sufficient to warrant independent discussion of each. Part IV thus addresses the immutability presumption; Part V considers the visibility presumption.

\section{THE IMMUTABILITY PRESUMPTION}

The immutability factor presumes that immutable groups are more vulnerable than mutable groups in the political process. In testing that claim, I consider the two varieties of power described above-evasive power and transformative power.

\section{A. Evasive Power}

The linkage between immutability and evasive power has a surface plausibility. After all, immutable groups are by definition locked into their statuses in a way that mutable groups are not. When faced with a legislative burden, a mutable group has the option to assimilate, while the immutable group does not. This intuition underlies language in a recent opinion by a federal appellate judge. Considering the constitutional claims of homosexuals, he maintained that "there is no more justification for discrimination against individuals because of their sexual orientation, which is most frequently a happenstance of birth, than there is for discrimination against blacks, Hispanics or Asians-or against Catholics, Jews, or Muslims, who at least have the option to convert." ${ }^{91}$ Although the judge was certainly not condoning discrimination against religious groups, he

91. Holmes v. California Army Nat'l Guard, 124 F.3d 1126, 1137 (9th Cir. 1997) (Reinhardt, J., dissenting). 
nonetheless implied that their ability to convert might blunt the effects of discrimination against them.

The problem with this argument is that it fails to consider the toll that such assimilation exacts from mutable groups. When those costs are considered, it becomes clear that mutable groups have a similar claim on our sympathies. Quite simply, conversion results in the dissolution of a group's identity. This basic fact problematizes the statement that mutable groups have more evasive power in two ways. First, many technically mutable groups will not consider evasion to be a real option, as they will find the cure of conversion worse than the disease of discrimination. Indeed, some groups may fear conversion so much that they will engage in defensive separatism to protect the integrity of the group, even if this strategy results in heightened discrimination. The biggest impetus behind the early growth of the Catholic school system, for example, was the fact that public schools were being used to inculcate Protestant tenets. ${ }^{92}$ Second, even if a group feels that it can and should exercise the option to convert, the conversion may be experienced less as an evasion from discrimination than as an effect of that discrimination. ${ }^{93}$ If a Communist recants on her political ideology because of anti-Communist sentiment, is her conversion an escape from that prejudice or the ultimate capitulation to it? The advantage of evasion that mutable groups possess is thus highly questionable.

\section{B. Transformative Power •}

The argument that immutability increases transformative power rests on two grounds: (1) the infiltration effect; and (2) the auto-identification effect. The infiltration effect recognizes a positive correlation between a group's evasive power and its transformative power. The effect presumes that if group members can evade discrimination, they can bypass discriminatory gatekeeping and penetrate the institutions that affect a group's transformative power.

This infiltration effect, however, is much more powerful in the context of invisibility than in the context of mutability. In the context of invisibility, a group member can presumably infiltrate such an institution simply by masking an unchanged essence. ${ }^{94}$ In the context of mutability, however,

92. See Kenneth L. Karst, Paths to Belonging: The Constitution and Cultural Identity, 64 N.C. L. REV. 303, 327 (1986).

93. This may be especially true if the discrimination intends to effectuate that transformation. See infra notes 124-126 and accompanying text.

94. I will later qualify the statement that masking a trait leaves its essence intact, see infra notes 193-197 and accompanying text, but not in a way that damages the relative claim pertinent here-that an individual generally surrenders less of the essence of a trait when she passes than when she converts. 
infiltration requires that this underlying essence be changed. This will make it less likely that individuals will help their original class through conversion, given that the conversion itself is a significant breach of solidarity with that class. Indeed, it seems intuitively plausible that when a group assimilates into an institution by changing its defining characteristic, it is just as likely to be coopted by the institution as to subvert it, whatever its original intentions. For practical purposes, the advantage of the infiltration effect may be unavailable to either mutable or immutable groups.

The second effect that supposedly impinges on the transformative power of immutable groups is the auto-identification effect. ${ }^{95}$ The effect begins with the axiom that we are most likely to identify with individuals like ourselves. Various courts engaged in antidiscrimination analysis have expressed this axiom. In the equal protection context, some courts have assumed that racial and ethnic groups tend to favor group members. ${ }^{96}$ Similarly, in the Title VII context, some courts have assumed that individuals cannot subordinate members of their own sex on the basis of sex. ${ }^{97}$

A corollary to this axiom is that, after the traits we possess ourselves, the traits we might possess (or have possessed) are most likely to inspire empathy in us. ${ }^{98}$ And among the traits we do not possess, we are more likely to possess (or to have possessed) mutable traits than immutable ones. Therefore, the argument goes, we are more likely to have empathy for the

95. The argument about the auto-identification effect tracks John Hart Ely's argument. See ELY, supra note 14, at 160.

96. See, e.g., Batson v. Kentucky, 476 U.S. 79, 138 (1986) (Rehnquist, J., dissenting); United States v. Leslie, 783 F.2d 541, 554 (5th Cir. 1986) (noting that the assumption "that each race ... may tend to favor its own" does not violate equal protection); Partida v. Castaneda, 384 F. Supp. 79, 91 (S.D. Tex. 1974) ("Here, the Mexican-Americans are a governing majority, and it cannot be presumed they would purposefully and intentionally discriminate against themselves."), rev'd, 524 F.2d 481 (5th Cir. 1975), aff'd, 430 U.S. 482 (1977). In Batson, Justice Rehnquist noted in dissent that:

The use of group affiliations, such as ... race... as a 'proxy' for potential juror partiality, based on the assumption or belief that members of one group are more likely to favor defendants who belong to the same group, has long been accepted as a legitimate basis for the State's exercise of peremptory challenges.

Batsan, 476 U.S. at 138 (Rehnquist, J., dissenting).

97. See, e.g., Martin v. Norfolk S. Ry., 926 F. Supp. 1044, 1049 (N.D. Ala. 1996) (noting that if the theory of harassment is subordination of one sex, "same-sex hostile working environment sexual harassment is not actionable under Title VII"); Quick v. Donaldson Co., 895 F. Supp. 1288, 1296 (S.D. Iowa 1995) ("As a male in a male-dominated environment, Quick cannot successfully complain that he was discriminated against based upon his gender."), rev'd, $90 \mathrm{~F} .3 \mathrm{~d}$ 1372 (8th Cir. 1996); Hopkins v. Baltimore Gas \& Elec. Co., 871 F. Supp. 822, 833 (D. Md.) (noting that the male defendant "certainly does not despise the entire group, nor does he wish to harm its members, since he is a member himself" (citations and internal quotation marks omitted)), aff'd, 77 F.3d 745 (4th Cir. 1994).

98. See GOFFMAN, supra note 43 , at 19-20. 
mutable traits we do not possess than the immutable traits we do not possess.

Based on this logic, the auto-identification effect posits that mutable groups are less likely than immutable groups to encounter empathy failure from nongroup members. Age is perhaps the classic example of a mutable trait that inspires empathy. ${ }^{99}$ Age divides people into groups, but the members of these groups are constantly changing. Individuals look up at the elder generation and see their potential future selves, or look back on the younger generation and see their past selves. In contrast, immutable traits will not create such bonds. Thus, a fifty-year-old white might be expected to have more empathy for a sixty-year-old white than for a fifty-year-old black, because the likelihood that he will someday be sixty exceeds the likelihood that he will someday be black.

Yet the syllogism underlying the auto-identification effect is open to two challenges. We might begin by contesting the axiom that we have the most empathy for those traits we have ourselves. This principle of selfrespect may not extend to socially stigmatized aspects of the self. Selfhatred is a common response to such stigmatization, ${ }^{100}$ as exemplified by the instances of the self-hating black, ${ }^{101} \mathrm{Jew},{ }^{102}$ or homosexual. ${ }^{103}$ This point

99. See ELY, supra note 14 , at 160 . Although age seems to be the classic example, it is also a problematic one. As Ely recognizes, it may be something more than mutability alone that makes us empathize with persons of different ages. Specifically, it is not just age's mutability but also its inevitability that engenders empathy-so long as we live long enough, we will at some point in our lives have been the same age as everyone around us. The Supreme Court recognized this point in Massachusetts Board of Retirement v. Murgia, 427 U.S. 307 (1976) (per curiam), where it found that age was not a suspect classification because old age "marks a stage that each of us will reach if we live out our normal span." Id. at 313-14. In so saying, the Court was not adducing age's mutability but rather aging's universality as the reason why age-based classifications were relatively unproblematic.

100. See Richard Delgado, Words That Wound: A Tort Action for Racial Insults, Epithets, and Name-Calling, 17 HARV. C.R.-C.L. L. REV. 133, 136 (1982) (quoting PHILIP MASON, RACE RELATIONS 2 (1970)).

101. See Adelbert H. Jenkins, The Psychology of the AFro-American: A HUMANISTIC APPROACH 24 (1982) ("Many observers have concluded that there is a considerable amount of 'self-hatred' in the Black community, even among Black children."); Paul Butler, Racially Based Jury Nullification: Black Power in the Criminal Justice System, 105 YALE L.J. 677, 694 (1995) (“'Black-on-black' violent crime ... can be attributed to internalized racism, which causes some African-Americans to devalue black lives-either those of others or their own."). As Patricia Falk notes:

[A] major mechanism through which racism may affect mental health ... is to compromise the self-esteem of individuals in the persecuted group. If racism is premised upon the notion of racial superiority, it is not surprising that one sequela is self-contempt on the part of minority-group members.... This self-hatred may lead to feelings of despair, depression, hopelessness, and helplessness.

Patricia J. Falk, Novel Theories of Criminal Defense Based upon the Toxicity of the Social Environment: Urban Psychosis, Television Intoxication, and Black Rage, 74 N.C. L. REV. 731, 778 (1996).

102. See SANDER L. GIlman, Jewish Self-Hatred (1986).

103. See EVE KosofSKY SEDGWICK, EPISTEMOLOGY OF THE Closet 81, 242-46 (1990) (describing the phenomenon of homophobic homosexuals); Aklilu Dunlap, The Bellows of Dying Elephants: Gay-, Lesbian-, and Bisexual-Protective Hate Crime Statutes After R.A.V. v. City of 
appears to have trickled into judicial consciousness, for while some courts have presumed that groups will not discriminate against their own, ${ }^{104}$ the Supreme Court has cautioned against this presumption. Thus, in the equal protection context, the Court has noted that " $[\mathrm{b}]$ ecause of the many facets of human motivation, it would be unwise to presume as a matter of law that human beings of one definable group will not discriminate against other members of their group." 105 And in the Title VII context, the Court has asserted that "nothing in Title VII necessarily bars a claim of discrimination 'because of ... sex' merely because the plaintiff and the defendant ... are of the same sex." 106

This in turn underscores the limitations of the axiom's corollary, which is that we are more likely to have empathy for those traits that we do not have but might possess. In the case of a possessed stigma, respect for the self and disrespect for the stigma are in conflict. The possibility thus exists that the individual's affinity for himself will force him to reconsider his aversion to the stigma. ${ }^{107}$ In the case of the threatened stigma, however, there is no need for such reconciliation, as self-respect and contempt for the stigma are aligned. Self-preservation will dictate the disavowal of the stigma into which the self is in danger of falling.

Thus we should not be surprised to find that in a variety of contextssuch as class, sexual orientation, and disease-it is not immutability, but its opposite, that creates empathy failure. In the context of class, Jack Balkin notes that American colonial aristocrats treated their social inferiors with an affection and noblesse oblige that gave way to fear and distrust only when class became a more fluid concept in the years after the Revolution. ${ }^{108}$ The shift in attitudes may be explained by the fact that in the original order, the class system was rigid enough to make class an effectively immutable characteristic. In such a regime, the upper classes could interact with the lower ones while remaining "confident that their social status was unaffected by such encounters." 109 As class boundaries became more contested, this was no longer the case. Balkin maintains that the paradox of status hierarchy is that the empathy failure between classes increases not in

St. Paul, 12 LAW \& INEQ. J. 205, 220 (1993) (noting that gay individuals suffer feelings of "humiliation, isolation, and self hatred" as a result of hate crimes).

104. See cases cited supra notes 96-97.

105. Castaneda v. Partida, 430 U.S. 482,499 (1977).

106. Oncale v. Sundowner Offshore Servs., 118 S. Ct. 998, 1001-02 (1998) (quoting 42 U.S.C. $\$ 2000 \mathrm{e}(2)(\mathrm{a})(1)(1994))$.

107. See Ann E. Freedman, Feminist Legal Method in Action: Challenging Racism, Sexism and Homophobia in Law School, 24 GA. L. REV. 849, 856-57 (1990) (explaining that intemalized sexism has influenced her professional relationships with other women, and also noting that people are born with a sense of their own self-worth that needs to be given positive reinforcement in order to develop).

108. See Balkin, supra note 14, at 2333 (citing GoRdON S. WOOD, THE RADICALISM OF THE AMERICAN REVOLUTION 41-42, 271-86 (1991)).

109. Id. 
spite of, but because of, the fact that the actual differences between them have decreased. ${ }^{110}$ Thus, it is exactly when class identity is most unstable that the privileged classes must defend themselves from the depredations of the less privileged ones.

Speaking of sexual orientation, Leo Bersani notes that homophobia is energized precisely by the perceived mutability of sexual orientation. ${ }^{111}$ Without denying the harmfulness of racism, he notes that racism and homophobia are different in this regard. The perceived immutability of race means that "not even racists could ever fear that blacks will seduce them into becoming black." ${ }^{112}$ In contrast, "to let gays be open about their gayness, to give them equal rights, to allow them to say who they are and what they want, is to risk being recruited." 113 Here again, the empathy failure that is homophobia seems to be excited, not quieted, by the perceived mutability of the underlying trait.

Disease is perhaps the paradigm case, because the infection model of disease-in which a stigmatized group endlessly wins converts from a "normal" one-has proven so metaphorically seductive in other contexts. ${ }^{114}$ The possibility of transmission - the mutability of the diseasecreates empathy failure, and the more contagious the disease, the more empathy failure can be expected. Ironically, it is fear of the perfect empathy that would be involuntarily achieved if one were infected that precludes the imperfect empathy one might otherwise feel. This need for ontic security in one's uninfected status is accepted as a rational precondition to imperfect empathy. The justificatory force of this need is underscored when prejudices toward diseases that are not particularly contagious manifest themselves through exaggerations of that contagiousness. ${ }^{115}$ AIDSphobia, for example, justifies itself precisely through such hyperbole. ${ }^{16}$ And AIDSphobia, like homophobia, is aptly named, insofar as it is the fear of becoming the other, and thus of the trait's mutability. ${ }^{117}$

110. See id. at 2333-34.

111. See LEO BERSANI, HoMOS 27 (1995).

112. Id.

113. Id.

114. See generally SUSAN SONTAG, ILLNESS AS METAPHOR (1978) (noting the multiple ways in which illness is used as a figure for nonmedical conditions).

115. See EdWARd E. Jones et al., Social Stigma: The Psychology of Marked RELATIONSHIPS 70 (1984) (noting that the terror of being contaminated by a stigma may lead one to perceive the threat of contamination as being greater than it actually is).

116. See Paula A. Treichler, AIDS, Homophobia, and Biomedical Discourse: An Epidemic of Signification, in AIDS: CULTURAL ANALYSIS/CulTuRAL ACTIVISM 31, 35-36 (Douglas Crimp ed., 1988). By "AIDSphobia," I mean any irrational fear of the disease, even if that fear is not diagnosed as the psychiatric syndrome of the same name. See Mandana Shahvari, Comment, Afraids: Fear of AIDS as a Cause of Action, 67 TEMP. L. REV. 769, 778 (1994) (describing "AIDS phobia").

117. Indeed, psychologists have noted that the disease paradigm may control even when the stigma is manifestly neither contagious nor a disease. In one study, one-third or more of college student subjects stated that they would not go swimming in a pool used by mental patients and 
This is not to say that auto-identification never obtains. But it is to say that we cannot determine ex ante whether mutability will engender empathy or empathy failure. This is not only because the empathy effects of mutability vary across traits, but also because they vary within them, as exemplified by the case of AIDS. On the one hand, the overreporting of the disease's mutability generates empathy failure. ${ }^{118}$ On the other hand, the simultaneous underreporting of the disease's mutability-as in the concept that the disease is confined to "risk groups"-also produces empathy failure, insofar as AIDS is seen by "normals" as a disease that only strikes others. ${ }^{119}$ Both the auto-identification effect and its opposite are thus at work within the confines of a single trait. In any context, the responses of nongroup members will be shaped by any number of complex factors, not least of all their own faculties of imagination and compassion. ${ }^{120}$ This very unpredictability makes auto-identification incapable of supporting a blanket immutability presumption.

The infiltration and auto-identification effects would seem to exhaust the support for the proposition that immutable groups have less transformative power. Before concluding the discussion, however, we must also consider two other effects that actually undermine the immutability presumption: (1) the exit/voice effect; and (2) the manipulation effect. These effects show that a lack of evasive ability translates into compensatory gains in transformative ability.

The exit/voice effect denotes an inverse correlation between evasive power and transformative power first recognized by Albert Hirschman ${ }^{121}$ and subsequently applied to political process theory by Bruce Ackerman. ${ }^{122}$ The effect arises from the fact that individuals faced with oppression will often confront the choice of exiting the group (evasive power) or of voicing opposition to that discrimination (transformative power). The more available the exit option is, the less likely they are to stay and fight. By making the exit option of conversion impossible, ${ }^{123}$ immutable characteristics make it more likely that group members will organize against the oppression.

that they would wash their hands after touching a mental patient. See JONES ET AL., supra note 115 , at 71 .

118. See Leo Bersani, Is the Rectum a Grave?, in AIDS: CUltuRAL ANALysis/Cultural ACTrVISM, supra note 116 , at 197, 199-201.

119. Treichler, supra note 116 , at 65-67.

120. See, e.g., TIMOTHY F. MURPHY, ETHCS IN AN EPIDEMIC: AIDS, MORALITY, AND CULTURE 173-81 (1994) (describing how biomedical research and treatment priorities are decided).

121. See Albert O. Hirschman, Exit, VoICE, AND LoYAity 44-54 (1970).

122. See Ackerman, supra note 75 , at 730-31.

123. As I will discuss later, conversion is not the only exit option. Group members may also conceal their defining characteristics in lieu of challenging discrimination against the group. See infra notes 143-158, 222-223 and accompanying text. 
The other effect positing a negative correlation between evasive power and transformative power is the manipulation effect. This occurs because social actors see that mutable groups are open to social engineering in a way that immutable groups are not. ${ }^{124}$ Thus, dominant groups may be tempted to manipulate the identities of mutable groups through strategies that would be futile if directed toward immutable groups. For example, they might force mutable groups to change their identities, as in coerced conversions of religion, ${ }^{125}$ or to retain unwanted identities, as in bars on naturalization for aliens. ${ }^{126}$

The manipulation effect will not obtain for immutable groups. The perception that immutable groups cannot change gives an air of futility to social attempts to make them do so. ${ }^{127}$ That perception also generates the related normative claim that it is morally abhorrent to penalize persons for what they cannot control. ${ }^{128}$ Immutability thus garners immunity even for conditions that would be condemned if mutable. ${ }^{129}$ For instance, even though regular use of illegal drugs is widely viewed as immoral,,${ }^{130}$ the

124. This distinction has been drawn in the psychology literature:

In the case of stigmas for which people cannot be held responsible, the restriction or termination of social relations is likely to be an end itself. Racial discrimination, for example, tends to remove blacks from competition for high-prestige jobs, and institutionalization of the mentally retarded can remove them from the social mainstream altogether. With stigmas over which persons have some control, however, the restriction or termination of social relations may not be the only end. Suppose that religious heretics are banished from a country. Such a reaction has the immediate consequence of ridding the country of persons with deviant religious beliefs. At the same time, it can be a means of discouraging other persons from adopting similar beliefs.

Mark C. Stafford \& Richard R. Scott, Stigma, Deviance, and Social Control, in THE DLEMMA OF DIFFERENCE: A MULTIDISCIPLINARY VIEW OF STIGMA 77, 88 (Stephen C. Ainlay et al. eds., 1986).

125. See, e.g., Alan E. Brownstein, Harmonizing the Heavenly and Earthly Spheres: The Fragmentation and Synthesis of Religion, Equality, and Speech in the Constitution, 51 OHIO ST. L.J. 89, 110-11 (1990) (noting that religious beliefs require protection from coerced conversion because they are mutable).

126. See, e.g., Charles J. McClain, Tortuous Path, Elusive Goal: The Asian Quest for American Citizenship, 2 ASIAN L.J. 33, 34-36 (1995) (describing the history of bars on Asian naturalization).

127. Because we are not speaking of "strict" immutability, I frame the futility of forcing immutable groups to change as a perception rather than as a reality.

128. See, e.g., Frontiero v. Richardson, 411 U.S. 677, 686 (1973) (plurality opinion) (quoting Weber v. Aetna Cas. \& Sur. Co., 406 U.S. 164, 175 (1972)).

129. The reverse is also true-the morality of a group identity, once established, moots the question of whether the group identity is immutable. "[T]he very question of "how we got that way' would in many quarters not be asked if it were not assumed that we ended up the wrong way ...." BERSANI, supra note 111 , at 57 .

130. See, e.g., EDWIN J. DelatTRE, Character and COPS: ETHICS IN POLICING 128 (2d ed. 1994) ("Because drug use adversely affects families and the broader society, opponents say, government has a rightful interest in prohibition."); James Q. Wilson, Drugs and Crime, in DRUGS AND CRIME 521, 523 (Michael Tonry \& James Q. Wilson eds., 1990) ("The moral reason for attempting to discourage drug use is that the heavy consumption of certain drugs is destructive of human character... The dignity, autonomy, and productivity of many users, already impaired by other problems, is destroyed."). 
often-related status of being a drug addict is protected by the (at least shortterm) immutability of the status. ${ }^{131}$

Under this formulation, the argument that immutable groups are vulnerable because they lack evasive power is revealed to be weak not because it is false, but because it would appear to be widely accepted. Its broad currency leads one to expect that social actors, including legislatures, will consider it in making their determinations. This in turn calls into question the need for the judiciary to intervene in that decisionmaking process. As Ely has noted: "Surely one has to feel sorry for a person disabled by something that he or 'she can't do anything about, but I'm not aware of any reason to suppose that elected officials are unusually unlikely to share that feeling." 132

Ely's position is supported by the fact that groups sometimes defend themselves by proving immutability rather than disavowing it. The rising fascination with genetic identity may be partially explained by an interest in this strategy. ${ }^{133}$ Stigmatized traits that have been attributed to genetics include "mental illness, homosexuality, aggressive personality, dangerousness, ... exhibitionism, the tendency to commit arson, ... [and] shyness." 134

These two inverse correlations between evasive and transformative ability mean that when a group gains a quantum of evasive power, it tends to lose a quantum of transformative power. This is damaging, if not fatal, to any generalization about the relative power of immutable and mutable groups. To see this, suppose I attempted to argue, contrary to the conventional wisdom among judges, that immutable groups are more powerful than mutable groups. I would base this claim in part on the limited evasive power of mutable groups-changing their social identity is at best a debilitating option for them. A critic could then point out that if this were so, mutable groups would accrue compensatory gains in transformative power through the exit/voice effect and the manipulation effect. ${ }^{135}$ This

131. See Robinson v. California, 370 U.S. 660, 666-67 (1962).

132. ELY, supra note 14 , at 150 .

133. See Rochelle Cooper Dreyfuss \& Dorothy Nelkin, The Jurisprudence of Genetics, 45 VAND. L. REV. 313, 329-32 (1992).

134. Id. at 320 .

135. The inverse correlation between evasive power and transformative power that obtains in the context of the manipulation effect is complicated by the fact that the manipulation effect gives transformative gains to groups that are perceived to have no evasive power. One could thus imagine a scenario in which a group was vulnerable to attempted manipulation because it was perceived to have evasive power, even if it effectively did not.

The fact that religion is perceived by many to be a mutable characteristic, for example, has left religious groups vulnerable to the manipulation effect. See Brownstein, supra note 125, at 110-11. Many individuals, however, may not experience religion to be a mutable attribute. See Lori Kraft-Jacobs, What Is "Religion" in Religion-Based Peremptory Challenges?, 65 U. CIN. L. REV. 1291, 1322 n.226 (1997) (noting that while religious affiliation "is certainly not immutable 
critic would then deny that the vectors of evasive and transformative power would net out in a predictable way. The core of her objection would thus be that such a net effect was unlikely to obtain across all contexts. And she would be right, which is why I am arguing not that immutable groups are more powerful than mutable groups, but rather that no generalizations can be made either way.

\section{Immutability as Harbinger}

A review of the processual defense of the immutability presumption reveals its tenuousness. The argument that immutable groups lack evasive power initially appears plausible. But when more closely examined, the evasive power of mutable groups proves only to be the power of selfannihilation.

The two arguments ostensibly supporting the proposition that immutable groups consistently have less transformative power also evanesce on closer examination. The hypothesis that immutable groups are less likely to be able to take advantage of the infiltration effect proves weak as mutable groups, who must convert to infiltrate, are also unlikely to capitalize on the effect. The auto-identification effect similarly fails to provide unambiguous support for the immutability presumption because the effect simply does not obtain in a variety of contexts.

In contrast, the two contentions that immutable groups have more transformative power than mutable groups have some analytical force. The exit/voice effect ensures that immutable groups will draw on a more secure base of accountable members, although this relative advantage will be qualified by the aforementioned exit burdens on mutable groups. And the manipulation effect shows that certain state strategies of eradication and suppression are deployable only against mutable groups.

It is thus unsurprising that courts have begun to withdraw the immutability factor ${ }^{136}$ and that recent academic commentary seems univocal in calling for its retirement even as a factor. ${ }^{137}$ What is surprising is that the incipient demise of the immutability factor has not affected the visibility factor, especially since, as noted above, ${ }^{138}$ visibility is logically nested within immutability. Even as the Court has retreated from immutability, it has not questioned, much less repudiated, its historical reliance on "high visibility," 139 and "obvious badge[s]." ${ }^{140}$ And progressive constitutional

\footnotetext{
in the literal way in which race is immutable, [it] is, for most people, a matter of birth and not a matter of choice").

136. See cases cited supra notes $15-18$.

137. See sources cited supra note 14.

138. See supra note 56 and accompanying text.

139. Frontiero v. Richardson, 411 U.S. 677, 686 (1973) (plurality opinion).
} 
scholarship that approves or accepts the demise of the immutability factor has ignored or even validated the visibility factor. Cass Sunstein, for example, simultaneously notes that immutability is neither necessary nor sufficient for heightened scrutiny ${ }^{141}$ and argues for an equality principle that would direct its concern toward groups that are defined by "highly visible and morally irrelevant" characteristics. ${ }^{142}$

One explanation for why courts and commentators have not retired visibility is that the rejection of both factors would open the floodgates to a new set of groups claiming heightened scrutiny. The demise of the immutability factor is a blow to the equal protection paradigm that privileges race and sex. When immutability is withdrawn, it becomes harder to see why race and sex are protected as the two talismanic classifications, and why others-such as sexual orientation or class-are not. Fortunately for defenders of the status quo, the visibility factor performs the same gatekeeping function as immutability. Like immutability, visibility retains race and sex as privileged categories while excluding other classifications. The failure of the courts to extend their criticism of immutability to visibility thus might arise because the visibility factor provides a means of retaining the status quo.

While politically expedient, that position is logically untenable. The next Part argues that the rejection of immutability should be a harbinger for the repudiation of visibility. The application of the analytical framework deployed above will reveal important differences between the two factors that make the visibility presumption more tenable than the immutability presumption. More significant than these differences, however, are the similarities. Visibility, like immutability, has an equivocal relationship to political powerlessness. I now describe that relationship.

\section{THE VISIBILITY PRESUMPTION}

The Supreme Court has not proffered an explicit rationale for why corporeally visible groups are more vulnerable than corporeally invisible groups. That theoretical vacuum has been filled by lower courts and academic commentators, as well as the Court's own intimations. When

140. Mathews v. Lucas, 427 U.S. 495, 506 (1976).

141. See Sunstein, supra note 12 , at 2443.

142. Id. at 2411 . Given that I will ultimately disagree with Sunstein's argument, it is only fair to repeat his caveats to the "anticaste principle." First, Sunstein proffers this principle as one of many possible equality principles, and not the only one required by the Constitution. See id. at 2411-12. Second, Sunstein is not explicitly attempting to justify the bias toward visibility in the equal protection context. See id. at 2432-33. These caveats demonstrate that Sunstein did not formulate his principle with my context in mind. Sunstein's analysis, however, emphasizes visibility's disempowering aspects without considering the debilitating effects of invisibility. As such, his analysis provides a rationale for the visibility factor. 
pieced together, these rationales cohere into an argument that closely tracks the earlier one about immutability. Once again, the basic claim is that visible groups always have less evasive and transformative power than invisible groups. Once again, this argument cannot be sustained.

\section{A. Evasive Power}

The analysis of the evasive power held by visible groups is more complex than the analysis of the evasive power held by immutable groups. It begins with the same point-namely, that visible groups lack the discretion to fade into the political mainstream. But it also notes that visible groups suffer from debilities that do not affect immutable groups, such as their vulnerability to superficial judgment and the asymmetry of information between them and invisible groups. It then observes that invisible groups are more likely than mutable groups to take advantage of their evasive ability. It qualifies these points, however, by noting that invisible groups encounter significant epistemic and ontic harms when they engage in this evasion.

\section{Visibility's Vulnerability}

In considering the evasive power of visible groups, it will be useful to begin with an extravagant claim made in the Federal Reports. In Equality Foundation of Greater Cincinnati v. City of Cincinnati, ${ }^{143}$ the Sixth Circuit claimed that invisible groups are invulnerable to state discrimination. In denying homosexuals heightened scrutiny, the Sixth Circuit quoted the Supreme Court's language that a group seeking such protection needed to be marked by an "obvious, immutable, or distinguishing characteristic[]." 144 It noted that "the reality remains that no law can successfully be drafted that is calculated to burden or penalize, or to benefit or protect, an unidentifiable group or class of individuals whose identity is

143. 54 F.3d 261 (6th Cir. 1995) [Equality Foundation I], vacated 518 U.S. 1001 (1996), on remand 128 F.3d 289 (6th Cir. 1997) [Equality Foundation II], cert. denied, 66 U.S.L.W. 3749 (U.S. Oct. 13, 1998) (No. 97-1795). In discussing the Sixth Circuit's view of invisibility in this case, I quote from its first opinion, Equality Foundation $I$. This may seem problematic given that this opinion has been vacated. The vacatur, however, had nothing to do with the court's argument that gays should be denied heightened scrutiny in part because of their invisibility. Moreover, on remand, the Sixth Circuit resurrected that argument in Equality Foundation II, 128 F.3d at 293 (quoting Equality Foundation I, 54 F.3d at 267) (noting that a suspect class cannot be defined "by subjective and unapparent characteristics such as innate desires, drives and thoughts"). The argument that gays should not receive heightened scrutiny in part because of their invisibility is thus still good law in the Sixth Circuit. The reason that I quote from Equality Foundation I as opposed to Equality Foundation II is that the analysis of the former was abbreviated in the latter. (1987)).

144. Equality Foundation I, 54 F.3d at 267 (quoting Bowen v. Gilliard, 483 U.S. 587, 602 
defined by subjective and unapparent characteristics such as innate desires, drives, and thoughts." ${ }^{145}$ Based on this analysis, it concluded that "[b]ecause homosexuals generally are not identifiable 'on sight' ... they cannot constitute a suspect class or a quasi-suspect class." ${ }^{146}$ The point appears to be that invisible groups exist outside the law, such that they are impervious to its harms (as well as to its benefits); ${ }^{147}$ the logic behind it appears to be that if the state cannot discriminate between two groups, it cannot discriminate against one of them.

The Sixth Circuit's idea that corporeally invisible groups are beyond the law is hard to sustain. Under this definition, political and religious groups, which are also defined by "subjective and unapparent characteristics," ${ }^{148}$ would also be impervious to state harm or help. For this to be true, the invisible would have to be unable to communicate their invisible trait in any way to others; they would have to be locked into the category of invisibility in the same way that the visible are locked into the category of visibility. No such symmetry exists-it is much harder to convert visibility to invisibility than to convert invisibility to visibility. As a practical matter, "there is nothing a black woman plausibly may do to hide the fact that she is black or female." ${ }^{149}$ All a Catholic lesbian need do to transform her corporeal invisibility into declarative visibility, however, is to

145. Id.

146. Id. As the Seventh Circuit recently noted, the Equality Foundation I court's "analysis appears to conflate the requirement that discrimination be based on membership in a definable class to trigger equal protection analysis with the requirement that the class have 'obvious, immutable, or distinguishing characteristics' to trigger heightened or strict scrutiny." Nabozny v. Podlesny, 92 F.3d 446, 457 n.10 (7th Cir. 1996) (citations omitted). I ignore that doctrinal confusion here, as it does not bear on the merits of the court's argument about visibility.

147. As bizarre as it may seem, this conception of invisibility as a grant of unfettered power to its possessor has an ancient pedigree. In Book II of The Republic, Plato recounts the story of Gyges the Lydian, a shepherd who finds a ring that can make him invisible at will. See 1 PLATO, THE REPUBLIC 117-19 (T.E. Page ed. \& Paul Shorey trans., G.P. Putnam's Sons 1937). Gyges uses the ring to seduce the wife of the king, kill the king, and ultimately to possess the kingdom. See id. According to Plato, the invisible man ultimately stands outside the law, because he can "with impunity take what he wishes even from the marketplace, and enter into houses and lie with whom he pleases, and slay and loose from bonds whomsoever he would, and in all other things conduct himself among mankind as the equal of a god." Id.

It would fall to later commentators to interrogate the assumption that invisibility imbues its bearer with absolute power. Thus, H.G. Wells's invisible man begins with this assumption, only to be disabused of it over the course of the novel. Compare H.G. WELLS, THE INVISIBLE MAN 84 (Macdonald Daly ed., 1995) (1897) ("I beheld, unclouded by doubt, a magnificent vision of all that invisibility might mean to a man-the mystery, the power, the freedom. Drawbacks saw I none."), with id. at 111 ("The more I thought it over ... the more I realised what a helpless absurdity an Invisible Man was ...."). Critical commentary has argued that Wells's novel was a conscious revision of the Gyges parable. See Macdonald Daly, Introduction to WELLS, supra, at xxix, xxxvii.

148. Equality Foundation I, 54 F.3d at 267.

149. Ackerman, supra note 75 , at 729 . Obviously, there are "passing exceptions" to this rule-some blacks and some women are capable of passing as whites or men, respectively. See, e.g., Watkins v. United States Army, 837 F.2d 1428, 1446 (9th Cir.), amended by 847 F.2d 1329 (9th Cir. 1988), vacated and aff'd on other grounds, 875 F.2d 699 (9th Cir. 1989) (en banc). 
avow membership in either group. ${ }^{150}$ This asymmetry means that the Equality Foundation court's premise that invisible groups are invulnerable ${ }^{151}$ to legislation is illogical. Legislation can burden invisible groups by impeding them from exercising the option to become visible (or to remain invisible). To the extent that corporeally invisible groups value this option, they will be deeply affected by legislation that burdens their declarative visibility (or invisibility). By penalizing these conversions, such legislation can hurt those who engage in them and chill the desire of those who would otherwise do so.

A refinement of the Equality Foundation court's point recognizes that it is precisely the asymmetry between their abilities to manipulate their social visibility that may make invisible groups more powerful than visible groups. Discrimination often targets visible markers that are stable over time. Those who are so marked "will probably trigger reactions from others in a wide variety of spheres, even in the interstices of everyday life." 152 Conversely, those who are not marked by a stable and visible characteristic cannot be as easily policed, as "visibility is a precondition of surveillance." ${ }^{153}$ Members of invisible groups are therefore more likely than their visible counterparts to be able to control public perceptions of their identity. This discretion contributes to greater power in some circumstances because an individual can modulate the expression of her identity in an adaptive way. ${ }^{154}$ The refined version of the Equality Foundation principle thus discards the absolute claim that invisible groups are invulnerable in

150. There are exceptions to this rule as well. It is hard for groups marked by invisible characteristics to be totally "out" about their identities. This is because social norms make it difficult to communicate invisible traits to people in a continuous and unambiguous way. For example, even a lesbian who seeks to be "out" in every context will have a hard time making her homosexuality as apparent as it would be if it were corporeally visible. Verbal speech is simply not capable of disseminating information in the same way as a visible trait-social norms make it difficult to state one's homosexuality in every encounter with "a new boss, social worker, loan officer, landlord, doctor." SEDGWICK, supra note 103, at 68. Thus, gays may instead rely upon physically visible-albeit noncorporeal-traits, such as an earring in the right ear or a pink triangle button. Although continuously performative in a way that speech is not, these accessories suffer from ambiguity. This is in part because audiences may not have the interpretive capacity to decode them. Moreover, even if the audience possesses that interpretive faculty, the fact that anyone may don these signifiers overdetermines them. A pink triangle button, for example, may mean that the wearer is pro-gay rather than gay.

151. Equality Foundation I, 54 F.3d at 267.

152. Sunstein, supra note 12, at 2432.

153. BERSANI, supra note 111 , at 11 .

154. The most obvious instance of this is that a black person will have a harder time making it past a racist lynch mob than a homosexual will making it past a homophobic lynch mob. But discretion will also be important to combat the subtle and daily forms of discrimination that take their toll over the long term. For example, one study comparing the adjustment of children with scars from facial burns with the adjustment of those with congenital heart disease found that the latter were better adjusted, despite the fact that their condition was much more life-threatening. See JONES ET AL., supra note 115, at 35 (citing Richard T. Goldberg, Adjustment of Children with Invisible and Visible Handicaps: Congenital Heart Disease and Facial Burns, 21 J. COUNSELING PSYCHOL. 428 (1974)). 
favor of the relative claim that visible groups are more vulnerable than invisible groups because they have relatively less discretion over the expression of their identities.

The hypothesis that invisible groups are relatively empowered by their discretion finds support in the fact that efforts to disempower those who have invisible characteristics often attempt to remove this discretion. The original Greek meaning of the word "stigma" was a physical sign "cut or burnt into the body," and "designed to expose something unusual and bad about the moral status of the signifier." ${ }^{155}$ Similarly, one of the purposes of torture was to leave a permanent brand of the crime on the criminal's body, so that his invisible inner state was manifested in a visible outer one. ${ }^{156}$ Even after the rejection of physical branding, the idea endures that invisible traits are shorn of some of their power when made visible. We have simply substituted the forced declarative visibility of the scarlet letter for the forced corporeal visibility of the bodily sign. ${ }^{157}$ Modern courts deploying such "scarlet letter" shame sanctions have adopted such measures as compelling a drunk driver to place a bumper sticker on his vehicle that read "CONVICTED DUI-RESTRICTED LICENSE" and compelling a convicted sex offender to place stickers on the doors of his home and vehicle reading "DANGEROUS SEX OFFENDER-NO CHILDREN ALLOWED." 158

The argument that heightened discretion leads to heightened evasive power sounds in the earlier discussion of immutability. Visibility, however, impinges on the evasive ability of its bearers in two ways that do not have ready analogues in the immutability context. The first is that visible characteristics can call forth the most superficial kinds of judgments. The second is that visible traits create power inequities between visible performers and invisible observers.

155. GoFFMAN, supra note 43 , at 1 .

156. See MICHEL FOUCAULT, DISCIPLINE AND PUNISH 34 (Alan Sheridan trans., 1977).

157. See Neal Kumar Katyal, Deterrence's Difficulty, 95 MiCH. L. Rev. 2385,2456 n.237 (1997) ("Physical torture of course is not the only means of marking people out [to reveal their stigmatized identity] .... The 'Scarlet Letter' is a less physically invasive version of the impulse, which, unlike torture, has broad literal and figurative appeal today (for example, Megan's Law).").

158. See Goldschmitt v. State, 490 So. 2d 123, 124 (Fla. Dist. Ct. App. 1986) (per curiam) (DUI case); State v. Bateman, 771 P.2d 314, 315 (Or. Ct. App. 1989) (en banc) (sex offender case). For discussions of these cases, see, for example, Rosalind Kelley, Sentenced To Wear the Scarlet Letter: Judicial Innovations in Sentencing-Are They Constitutional?, 93 DICK. L. REV. 759,759 (1989). For normative discussions of modern shame sanctions, compare David M. Boyers, Emotion over Reason: California's New Community Notification and Chemical Castration Laws Feel Good, but Fail "Sensible" Scrutiny, 28 PAC. L.J. 740, 750 (1997), and Toni Massaro, Shame, Culture and American Criminal Law, 89 MICH. L. REv. 1880, 1881-83 (1991), which argue against shame sanctions, with Kelley, supra, which argues for shame sanctions. 
To see why visible traits call forth superficial judgments, we must understand vision's virtues and vices. In his essay The Nobility of Sight, ${ }^{159}$ Hans Jonas provides such an understanding. He points out that vision has been recognized as "the most excellent of the senses" ${ }^{160}$ for three related reasons. First, sight is incredibly efficient because of its synoptic quality. While the other senses only work over time, sight permits the observer to take a snapshot of her surroundings. ${ }^{161}$ Second, sight gives one a bigger picture because it can operate at a remove. Indeed, it is the only sense that gains with distance: Touch and taste require direct engagement; hearing and smell require a more attenuated but nonetheless close interaction. Vision, unlike all of these, requires nothing but the most glancing contact between the observer and the observed. ${ }^{162}$ Third, because of this temporal and spatial disengagement, sight is deemed to be more objective. It seems to permit knowledge "of the thing as it is in itself as distinct from the thing as it affects [the viewer]." ${ }^{163}$ With its promise of fast, expansive, and objective perception, it is no wonder that we think that "we know it when we see it," ${ }^{164}$ that we think that vision is the sense most conducive to, and productive of, knowledge.

But Jonas predictably goes on to note that vision has the vices of its virtues. As it can operate at a distance, it is not forced into a closer relationship with the things it senses. ${ }^{165}$ Because it does not seem to implicate the viewer, it diminishes and/or falsifies the interactive component of perception. ${ }^{166}$ (He might have completed his critique by noting that vision, being quick, misperceives things that unfold over time. $)^{167}$ By noting these intrinsic limitations of vision, Jonas uncovers what another commentator has called the "false promise of the visible as an epistemological guarantee." 168

When vision's linked virtues and vices are understood, so are its dangers. ${ }^{169}$ Vision is dangerously seductive; it promises knowledge but

159. Hans Jonas, The Nobility of Sight: A Study in the Phenomenology of the Senses, 14 PHIL. \& PHENOMENOLOGICAL RES. 507 (1954).

160. Id. at 507 .

161. See id. at 507-08.

162. See id. at 517-18.

163. Id. at 515 .

164. Cf. Jacobellis v. Ohio, 378 U.S. 184, 197 (1964) (Stewart, J., concurring) (responding famously to the problem of defining pornography by stating, "I know it when I see it.").

165. See Jonas, supra note 159 , at 516.

166. See id. at 515-16.

167. See Carol M. Rose, Seeing Property, in PROPERTY AND PERSUASION: ESSAYS ON THE HISTORY, THEORY, AND RHETORIC OF OWNERSHIP 267, 270-71 (1994).

168. Elaine $\mathrm{K}$. Ginsberg, The Politics of Passing, PASSING AND THE FICTIONS OF IDENTITY 1 , 4 (Elaine K. Ginsberg ed., 1996) (quoting Amy Robinson, It Takes One To Know One: Passing and Conmunities of Common Interest, 20 CRITICAL INQUIRY 715, 716 (1994)).

169. Carol Rose has considered the role that vision's virtues and vices play in the context of property theory. Rose notes that "property's visibility ... is especially attuned to letting people speak to each other, over time, about their relation to place" because "one can read the messages 
never quite delivers on it. That visible characteristics are "cheaply used as a proxy for other things" ${ }^{170}$ provides an often irresistible urge to use them, with or without the knowledge that they are a reductive proxy. This makes visible characteristics "especially likely to be a basis for statistical discrimination and to fuel prejudice from third parties." ${ }^{171}$ In this sense, "we know it when we see it" may be more accurate as a description of how we operate as human beings than as a prescription for how we ought to behave. One might thus see vision as incompatible with justice, and evidence that our culture does so can be found in the longevity of the icon of blind Justice. ${ }^{172}$

The second way in which visibility distinctively trenches on the evasive capacities of its bearers is by exposing them to invisible viewers. In arguing that visible groups are more vulnerable than invisible ones, $I$ have thus far focused on the visibility of the group, noting the visible group's vulnerability to inescapable and superficial judgment. Yet an account of the oppression suffered by visible groups would be incomplete without an examination of the relative invisibility of those who observe them. Discrimination is a dynamic in which a trait held by a victim and an attitude held by a discriminator interact; just as the victim group is defined by its trait, the discriminating group is defined by its attitude. Yet, unlike the victims' traits, which are sometimes corporeally visible, the discriminators' attitudes are always corporeally invisible. The discrimination suffered by those with visible characteristics such as race and sex is surely enhanced by the fact that those who discriminate against them are invisible-that is, by the fact that although race and sex are corporeally visible, racism and sexism are corporeally invisible.

To recognize that race and sex implicate themselves in a dynamic in which visible victims are watched by invisible discriminators is to recognize that the scopic regimes of racism and sexism are panoptic. As most famously described by Michel Foucault, such a regime replicates the

of successive generations through the way that property looks." Rose, supra note 167, at 268. Rose goes on, however, to acknowledge the power of the scholarly "attack on vision as an objectifying, static model for knowledge-an attack that has disturbing implications for the notion of property as a persuasive enterprise, since persuasion is necessarily intersubjective and dynamic." Id.

170. Sunstein, supra note 12 , at 2416.

171. Id. at 2432 .

172. Positive interpretations of the blindness of Justice are that she is blindfolded: (1) to shut out " "the misleading evidence of the senses," Dennis E. Curtis \& Judith Resnik, Images of Justice, 96 YALE L.J. 1727, 1755 (1987) (quoting CESARE RIPA, BAROQUE AND ROCOCO PICTORIAL IMAGERY 120 (Edward A. Maser ed., 1971)); (2) to show that Justice stands apart "from the cares, pleasures, and complexities of humanity," id. at 1756; (3) to shield Justice from "fear or favor," by precluding her from seeing the "signals a sovereign might send on how to decide a case" and "the power of the litigants or witnesses who might seek to intimidate her," $i d$. at 1757-58; or (4) to underscore that "insight and visdom were not dependent upon what was perceived," id. at 1758 . 
relationship created by Jeremy Bentham's Panopticon-a ring-shaped building surrounding a tower. ${ }^{173}$ The inside of the ring was divided into cells, and each cell had a window through which the individual in the cell could be observed at all times from the tower. ${ }^{174}$ The cells were constructed, however, such that an inmate could never see his observer. Thus, the inmate knew he was always visible without ever knowing whether he was watched. Foucault describes the major effect of the Panopticon as "induc[ing] in the inmate a state of conscious and permanent visibility that assure[d] the automatic functioning of power." ${ }^{175}$ In other words, the Panopticon was a structure that inspired paranoia in those incarcerated within it and that deployed this paranoia as a means of control. That paranoia sprang directly from the interaction between the acute visibility of the inmates and the invisibility of the putative watchguard in the tower. Because the paranoid imagination projected an ever-present guard onto the scrim left studiously blank by the Panopticon's architects, "the surveillance [was] permanent in its effects, even if it [was] discontinuous in its action." 176

The physical structure of the Panopticon is merely the instantiation of a more pervasive social relationship, ${ }^{177}$ as reflected in the cases of race and sex. To be black, or to be a woman, in present-day America is to inhabit a virtual Panopticon. This is because the visibility of race and sex and the invisibility of racism and sexism create "naturally" the dynamic that the architects of the Panopticon sought to replicate artificially. This dynamic is one in which an actor perceives her visibility to be heightened precisely because the invisibility of her putative observers causes her own imagination to act as a perpetual watchguard. Thus, when a black woman enters a room of people she does not know, everyone immediately knows she is both black and female without her knowing-immediately or perhaps ever-whether none, some, or all of them are racist or sexist. This asymmetry of information is likely to have disquieting effects for her. Barbara Flagg posits that even if a committee subjected individual interviewees to the identical intense questions about their competence, a black interviewee might take particular "exception to that line of questioning because of the common white stereotype of blacks as not very intelligent." ${ }^{178}$ If the candidate has no prior knowledge of her interlocutors, "she might reasonably at least wonder whether the questions arise from that

173. See FoUCAULT, supra note 156, at 200.

174. See id.

175. Id. at 201.

176. $I d$.

177. As Foucault notes, the Panopticon "must be understood as a generalizable model of functioning; a way of defining power relations in terms of the everyday life of men." Id. at 205.

178. Barbara J. Flagg, "Was Blind, But Now I See": White Race Consciousness and the Requirement of Discriminatory Intent, 91 MiCH. L. REV. 953, 975 (1993). 
stereotype, even if they in fact do not." ${ }^{179}$ In other words, the invisibility of racism may cause a rational black woman to entertain constantly at least the possibility that she is dealing with a racist. Entertaining that possibility may itself become a liability in her interactions. It is thus not only the visibility of the observed but also the invisibility of the observer that contributes negatively to the experience of visibility.

\section{The Costs of Evasion}

The argument that visibility seriously impinges on a group's evasive ability is stronger than the analogous argument made in the immutability context. And the counterargument in the visibility context-which again looks to the costs of evasion-appears weaker. For unlike evasion in the immutability context, evasion in the visibility context seems not to concern a change in essence but merely one in appearance. Because the costs of evasion are less drastic, we can expect that invisible groups will be more likely to take advantage of their option to evade discrimination by "passing" than mutable groups will by "converting."

This does not mean, however, that those costs are not substantial. I will divide them into two varieties-epistemic and ontic. Epistemic harms relate to one's expression, or to how one is known, while ontic harms relate to one's being, or to how one is constituted. ${ }^{180}$

There are at least three epistemic harms to passing, all of which have been ably canvassed by Erving Goffman. The first is the alienation that the passer feels from both the nonstigmatized group into which he has passed and the stigmatized group from which he has passed. Passers are uniquely isolated. The support they get from the nonstigmatized group is not support they receive for their real stigmatized selves; indeed, they may be particularly privy to insults against the stigmatized group that circulate only among "normals." They are also unlikely to get support from the stigmatized group, which may not recognize the passer as one of its own and may not accept him if it does. Goffman gives the example of a spinster masquerading as a married woman, who endures both the negative attitudes that her married friends direct towards the unmarried, as well as the envy of other spinsters who do not recognize her for what she is. ${ }^{181}$

Outside the equal protection context, the Supreme Court has recognized the isolating effect of passing. In Powell v. Texas, ${ }^{182}$ the Court noted that the problem of alcoholism in the United States is exacerbated "by the fact that

179. Id.

180. The lines between these two harms will not always be clear. See infra notes 193-197 and accompanying text.

181. See GOFFMAN, supra note 43 , at 87-88.

182. 392 U.S. 514 (1968). 
a very large percentage of the alcoholics in this country are 'invisible'they possess the means to keep their drinking problems secret, and the traditionally uncharitable attitude of our society toward alcoholics causes many of them to refrain from seeking treatment from any source." 183 The Court thus acknowledged that discriminatory attitudes toward invisible groups cause group members to pass, and that this passing alienates them from potential sources of support. Yet it has not applied this insight, generated in the Eighth Amendment context, to its analysis of invisibility in the equal protection context. ${ }^{184}$

The second cost of passing is the sheer work it entails. Goffman gives the firsthand testimony of the stutterer who must constantly rearrange his speech and thought to avoid certain words; ${ }^{185}$ of the visually impaired person who must greet anyone who looks like his significant other with familiarity to keep his condition secret from her; ${ }^{186}$ and of the wife of the mental patient who cannot allow anyone into her apartment without first removing material identifying her husband's hospital. ${ }^{187}$ Studies of lesbians, gay men, and bisexuals describe the sheer work of passing as including the work of (1) "constantly decid[ing] whether or not to tell, whom to tell, and when to tell"; (2) "constantly monitor[ing] ... emotional responses in order not to reveal ... true feelings"; and (3) "maintaining an image of being stern, businesslike, efficient, and task oriented" in order to maintain a safe distance from others. ${ }^{188}$

The third epistemic harm of passing is a moral harm. Passing is not merely a movement from an oppressed position to a privileged one. Rather, it is a movement that would not be possible without deception. To pass is always to trespass; ${ }^{189}$ the individual who passes always simultaneously takes on the identity of a liar. When he comes out, he assumes two stigmatized identities; he is "exposed first in his differentness and secondly in his dishonesty and untrustworthiness." ${ }^{190}$ Thus, "[s]omeone who seems outwardly quite normal but is later found to have leprosy may not only

183. Id. at 527.

184. See, e.g., Bowen v. Gilliard, 483 U.S. 587, 602 (1987) (implying in the equal protection context that invisibility is empowering without mentioning this disempowering aspect of it); Mathews v. Lucas, 427 U.S. 495, 506 (1976) (same); Frontiero v. Richardson, 411 U.S. 677, 686 (1973) (plurality opinion) (same).

185. See GoFmMAN, supra note 43 , at 89.

186. See id. at 88 .

187. See id. at 89.

188. Joanne DiPlacido, Minority Stress Among Lesbians, Gay Men, and Bisexuals, in Stigma AND SEXUAL ORIEnTATION 138, $148-49$ (Gregory M. Harek ed., 1998) (collecting studies).

189. See Ginsberg, supra note 168, at 3 (noting that passing always has the metaphorical implication of trespassing a boundary).

190. GOFFMAN, supra note 43 , at 95 . 
appear blighted by a heinous condition, but may also appear deceitful and dangerous." 191

A defender of the visibility presumption might argue that these three harms are inconsequential relative to the harms incurred by mutable groups. She might maintain that when mutable groups convert, they are changing the underlying essence of their being, but that in contrast, when invisible groups pass, they are merely changing the expression of an essence that remains unaltered. In short, she might contend that the harms of passing are only epistemic, rather than ontic.

This distinction, however, proves untenable, for passing generates ontic harms as well. This is true even if we adopt an essentialist view of core identity, ${ }^{192}$ as Janet Halley demonstrates in the case of homosexuals:

$[\mathrm{H}]$ omosexuals who experience their sexual desire as immutably oriented towards persons of their own sex nevertheless may be coerced to pretend that they conform to the norm of heterosexuality. Such a result is no mere fib: it is a change. To be sure, what has changed is not the supposed essence of sexual orientation, but the representation of it available for social interpretation. But essences, conceding for a moment their existence, are not visible to legislatures, judges, employers, or police. Social agents work with social meaning; the fairness and indeed the constitutionality of their acts must be measured in the context of the practical, not the ideal, epistemology of their decisionmaking..$^{193}$

Although passing may not require a change in essence, its practical effects may be tantamount to such a change. It is in this sense that the

191. JONES ET AL., supra note 115 , at 35.

192. Edward Stein elucidates the difference between essentialism and constructionism, again in the context of sexual orientation, as follows:

Essentialists hold that a person's sexual orientation is a culture-independent, objective and intrinsic property while social constructionists think it is culture-dependent, relational and, perhaps, not objective.... Essentialists think that being a heterosexual or homosexual is like having a certain blood type or being a person taller than six feet. The essentialist would have no problem saying that there were heterosexuals and homosexuals in Ancient Greece; it is just a matter of whether or not a person has the relevant properties (such as a certain gene, hormone, psychological condition, etc. or some combination of these). Even though people in past cultures may have had no idea what constitutes a gene, a hormone, an Oedipal complex or whatever the relevant properties are, they either did or did not have such properties, and thus the essentialist would claim that they were thereby either heterosexual or homosexual (or whatever the appropriate categories of sexual orientation are). In contrast, while social constructionists agree that people in all cultures engaged in sexual acts, they think that only in some cultures (e.g., our culture) are there people who have sexual orientations.

Edward Stein, Conclusion: The Essentials of Constructionism and the Construction of Essentialism, in FORMS OF DESIRE: SEXUAL ORIENTATION AND THE SOCIAL CONSTRUCTIONIST CONTROVERSY 325-26 (Edward Stein ed., 1990) (citations omitted).

193. Halley, Politics of the Closet, supra note 14, at 934 (citations omitted). 
aforementioned conflation of immutability and visibility in the Watkins court's discussion of immutability ${ }^{194}$ becomes intelligible. ${ }^{195}$ In that discussion, the Ninth Circuit cited the ability of light-skinned blacks to pass to show that heightened scrutiny did not require strict immutability. ${ }^{196}$ The light-skinned black who passes, of course, is masking rather than changing his race. But that distinction proves unimportant insofar as "[s]ocial agents work with social meaning." ${ }^{197}$ For practical purposes, everyone will treat the light-skinned black as if he were white.

The passing dynamic becomes even more ontologically fraught if one suspends the assumption that essences exist. In such a model, expression is not just an effect of an underlying identity but potentially a cause of it as well. Thus, when that expression is burdened, the burden is not only an epistemic harm but also an ontic one.

\section{B. Transformative Power}

The discussion of the transformative power of visible groups is also more complex than the analogous one for immutable groups. Both discussions, however, implicate the same effects-the infiltration effect, the auto-identification effect, the exit/voice effect, and the manipulation effect.

\section{The Infiltration Effect}

The infiltration effect posits that invisible groups have an advantage over visible groups because they can evade discriminatory gatekeeping and penetrate organizations. As noted above, visible groups are prone to superficial visual judgments. ${ }^{198}$ The infiltration effect points out that in addition to this vulnerability, visible groups are harmed when such judgments are used for gatekeeping purposes because their superficiality is preserved by the distancing effect of physical or psychic segregation. In other words, visual judgments can preclude the social interaction necessary to reveal their superficiality. Justice Stevens made this point in the affirmative action context in distinguishing between decisions to exclude people from educational institutions solely on the basis of their race and decisions to include them on the same basis:

194. See Watkins v. United States Army, 837 F.2d 1428 (9th Cir.), amended by 847 F.2d 1329 (9th Cir. 1988), vacated and aff'd on other grounds, 875 F.2d 699 (9th Cir. 1989) (en banc).

195. See supra notes $52-55$ and accompanying text.

196. See Watkins, 837 F.2d at 1446.

197. Halley, Politics of the Closet, supra note 14, at 934.

198. See supra notes 159-172 and accompanying text. 
The exclusionary decision rests on the false premise that differences in race, or in the color of a person's skin, reflect real differences that are relevant to a person's right to share in the blessings of a free society. As noted, that premise is "utterly irrational," and repugnant to the principles of free and democratic society. Nevertheless, the fact that persons of different races do, indeed, have differently colored skin, may give rise to a belief that there is some significant difference between such persons. The inclusion of minority teachers in the educational process inevitably tends to dispel that illusion whereas their exclusion could only tend to foster it. ${ }^{199}$

Under this view, persons of different races need to be integrated not because they are different (as the traditional diversity rationale would assume), ${ }^{200}$ but rather because they are not. The problem with excluding individuals based on race is that it leaves unchallenged a shallow judgment made on the basis of vision-the judgment that "differently colored skin" reflects "some significant difference." ${ }^{201}$ If racial minorities are included, the superficiality of that decision will be revealed. If racial minorities are excluded, however, the information needed to reveal the superficiality of the discrimination will never be gathered. Thus, the harm in discriminatory gatekeeping based on visible traits is that it not only reflects but reinforces superficial judgment.

Although the infiltration effect favors invisible groups in this way, the metes and bounds of that advantage deserve close examination. Most obviously, that advantage will be conscribed by the invisible agent's fear of exposure. Any invisible person's advocacy for a stigmatized group may raise the suspicion that she belongs to that group. ${ }^{202}$ To the extent that an individual's standing in an institution is predicated on the preservation of her closet, she will have to choose her battles carefully.

A critic might argue that the constraint of feared exposure will not exert much force in two situations. First, there will be situations in which power may be exerted with minimal risk of exposure. Our culture has a "respected

199. Wygant v. Jackson Bd. of Educ., 476 U.S. 267, 316 (1986) (Stevens, J., dissenting) (internal citations omitted).

200. See, e.g., id. at 286 (" $[\mathrm{A}]$ lthough its precise contours are uncertain, a state interest in the promotion of racial diversity has been found sufficiently 'compelling,' at least in the context of higher education, to support the use of racial considerations in furthering that interest.") ( $O^{\prime}$ Connor, J., concurring in part and concurring in judgment); Regents of Univ. of Cal. v. Bakke, 438 U.S. $265,311-12,320$ (1978) (recognizing diversity in education as a compelling state interest, but holding that the racial classification policy at issue was not narrowly tailored to serve that interest).

201. Wygant, 476 U.S. at 316 (Stevens, J., dissenting).

202. See infra notes 220-221 and accompanying text. 
tradition of anonymity in the advocacy of political causes" ${ }^{203}$ precisely in order to protect the proponent of the message. Anonymous voting is perhaps the paradigm case, in which an agent may temporarily come out of her closet because it is nested in the larger closet of the voting booth. ${ }^{207}$ The social presumption against forcing political organizations to disclose their membership lists is another example. ${ }^{205}$ It should be noted, however, that these ostensible safe havens are never entirely secure. The privacy of the secret ballot has been qualified, ${ }^{206}$ as has the privacy of membership lists. ${ }^{207}$

In the alternative, the critic might argue that there are situations in which an invisible agent achieves power not in spite of exposure but because of it. When a person exposes herself as belonging to a stigmatized category, she forces those around her to reconcile their understanding of her with their understanding of the stigma. The advantage that an invisible agent has over a visible one is that she can allow others to get to know her independently of her stigma. This means that when the invisible individual ultimately reveals her stigma, she will be more likely to have the resource of intimacy at her disposal. Her revelation may thus have a potent disruptive effect on the prejudicial attitudes of her audience. ${ }^{208}$

The intuition that exposure has salvific potential for the stigmatized individual and her class runs deep. It was manifest in the buzz of speculation concerning Justice Powell's gay $\operatorname{clerk}^{209}$ after the Supreme

203. McIntyre v. Ohio Elections Comm'n, 514 U.S. 334, 343 (1995); see also American Constitutional Law Found. v. Meyer, 120 F.3d 1092, 1102 (10th Cir. 1997) (addressing the Supreme Court's protection of anonymous political expression); FEC v. Hall-Tyner Election Campaign Comm., 678 F.2d 416, 417 (2d Cir. 1982) (noting that "[a]nonymity has long been essential to uninhibited political activity in a democratic society").

204. See McIntyre, 514 U.S. at 343; Meyer, 120 F.3d at 1102; Hall-Tyner, 678 F.2d at 417; see also Universal Declaration of Human Rights, Dec. 10, 1948, art. 21.3 (declaring the guarantee of secret ballot or its equivalent to be a basic human right).

205. See, e.g., Bates v. City of Little Rock, 361 U.S. 516 (1960) (holding that the tax interests alleged by the city were insufficiently compelling to require the disclosure of membership); NAACP v. Alabama, 357 U.S. 449 (1958) (reversing a civil contempt order compelling the NAACP to disclose its membership); Adolph Coors Co. v. Wallace, 570 F. Supp. 202 (N.D. Cal. 1983) (denying a discovery order that would have required a gay rights organization to reveal its members); Pollard v. Roberts, 283 F. Supp. 248 (E.D. Ark. 1968) (enjoining a prosecuting attorney from using the subpoena power to force the disclosure of names of contributors to the Republican Party).

206. See, e.g., NLRB v. Groendyke Transp., 372 F.2d 137, 142 (10th Cir. 1967) (upholding the use of voting by mail as satisfying the requirement of secret ballot, despite the fact that voting by mail does not assure the same degree of ballot secrecy as that provided by use of voting booths).

207. See, e.g., Communist Party of the United States v. Subversive Activities Control Bd., 367 U.S. 1 (1961) (requiring the Communist Party to disclose, inter alia, its membership lists to the Subversive Activities Control Board); New York ex rel. Bryant v. Zimmerman, 278 U.S. 63 (1928) (upholding a statute requiring organizations with oath-bound membership criteria, such as the Ku Klux Klan, to provide membership lists to the state); see also Barenblatt v. United States, 360 U.S. 109 (1959) (upholding defendant's conviction for refusing to answer congressional inquiries into whether he was or had ever been a member of the Communist Party).

208. See SEDGWICK, supra note 103, at 74-78.

209. See id. at 74-75. 
Court upheld a sodomy statute against a due process challenge in Bowers $v$. Hardwick. ${ }^{210}$ The gay clerk, who had not revealed his homosexuality to Justice Powell prior to oral argument in the case, considered doing so shortly thereafter to persuade the undecided Justice to take a pro-gay position. ${ }^{211}$ After the clerk opted not to make this revelation, Justice Powell cast the fifth, and determinative, vote for the anti-gay position. ${ }^{212}$ Commentators have speculated that if Justice Powell had been confronted with his clerk's homosexuality, he might have reconsidered his beliefs, and thereby his vote, about homosexual sodomy. ${ }^{213}$ That intuition also finds some support in the fact that poll after poll demonstrates that those who know an "out" homosexual are much more likely to be pro-gay. ${ }^{214}$

But that intuition will not always hold. It seems quite likely that the revelation of stigma within the confines of an intimate relationship will generate cognitive dissonance in a listener who is now torn between respect for the person and disrespect for the class in which the person has just confessed membership. ${ }^{215}$ Yet the resolution of that dissonance in favor of the individual is far from a foregone conclusion. As Eve Sedgwick points out: "[W]e have too much cause to know how limited a leverage any individual revelation can exercise over collectively scaled and institutionally embodied oppressions." ${ }^{216}$ Moreover, even if the cognitive dissonance is resolved in favor of the individual, that may not save the class. The individual may be interpreted as the unstereotypical exception that proves the stereotypical rule. ${ }^{217}$ And finally, even if the cognitive dissonance is resolved in favor of the class, the outcome has to turn on one's impression of the class. ${ }^{218}$

210. 478 U.S. 186 (1986).

211. See JoHN C. JEFFRIES, JR., JUSTICE LEWIS F. POWELl, JR. 521-22 (1994).

212. See id. at 524 .

213. See SEDGWICK, supra note 103 , at 77.

214. See Jane S. Schacter, The Gay Civil Rights Debate in the States: Decoding the Discourse of Equivalents, 29 HARV. C.R.-C.L. L. REV. 283, 313 (1994).

215. See SEDGWICK, supra note 103, at 78-79.

216. Id. at 78; see also id. at 78-82 (noting seven factors that could prevent the clerk's disclosure from leading to a judicial change of heart).

217. See Jennifer Crocker \& Neil Lutsky, Stigma and the Dynamics of Social Cognition, in THE DILEMMIA OF DIFFERENCE: A MULTIDISCIPLINARY VIEW OF STIGMA, supra note 124, at 95, 117.

218. Thus, at least three barriers stood between the clerk's coming out and Justice Powell's taking a pro-gay position in Bowers. First, Justice Powell would have had to interpret in the clerk's favor the cognitive dissonance triggered by the revelation, using his positive impression of the clerk to discredit his negative impressions of homosexuals rather than vice versa. Second, even if he had done this, he would then have had to interpret the clerk as representing the class rather than as deviating from it. And finally, even if the clerk had persuaded him to reconsider his view of homosexuality, Justice Powell would have had to be persuaded that this changed view made a difference to the outcome of the case. What the clerk actually did say to Powell was that "the right to love the person of my choice ... would be far more important to me than the right to vote in elections." JEFrRIES, supra note 211, at 522. Powell's response was "[T]hat may be ... but that doesn't mean it's in the Constitution." Id. 
Thus, while the infiltration effect posits the relative privilege of invisible groups, a fuller analysis reveals that invisible groups may simply suffer from the obverse of the problem encountered by visible groups. Visible groups encounter the problem that their identities (as members of the stigmatized class) are immediately known, but their personalities (by which I mean their abilities, their temperaments, etc.) are not. Invisible groups, on the other hand, have the problem that their personalities are known, but their identities are not. Both groups thus face difficulties, for different reasons, in forming coalitions with others. People form coalitions with others by rubbing elbows with them. ${ }^{219}$ Members of visible groups have difficulty building such coalitions because the visibility of their stigma results in physical or psychic segregation-others will not "rub elbows" with them. Members of invisible groups have this difficulty despite their integration into mainstream society because their integration is predicated on their nondisclosure—others will not rub elbows with "them."

\section{The Auto-Identification Effect}

The analysis of the auto-identification effect given in the immutability context is applicable with a few modifications to this context. One could hypothesize that, as with immutability, visibility would lead to empathy failure because of the auto-identification effect. If people are visibly different from us, we are less likely to see ourselves (or our past or future selves) in them.

This effect, however, must again be qualified by noting that the epistemic uncertainty of invisibility can spawn not empathy but its opposite. To see this effect, consider how nongroup members are differently situated when they attempt to support a visible group as opposed to an invisible one. A white politician who supports blacks may be called a "nigger-lover," but she is unlikely to be called a "nigger." A nonCommunist politician who supports Communists, in contrast, is vulnerable not only to the charge that she is "Commie-lover" but also to the charge that she is herself a "Commie." Although both politicians must pay the price of association with a stigmatized group, ${ }^{220}$ the politician who supports an invisible group may also pay the price of having membership in that group ascribed to him. ${ }^{221}$

219. See ELY, supra note 14 , at 161.

220. See JONES ET AL., supra note 115 , at 71 .

221. See Kenji Yoshino, Suspect Symbols: The Literary Argument for Heightened Scrutiny for Gays, 96 COLUM. L. REV. 1753, 1807-08 (1996). 


\section{The Exit/Voice Effect}

The exit/voice effect confronted by invisible groups is an exacerbated version of that faced by mutable groups. Invisible groups incur lower costs than mutable groups when they engage in evasion. ${ }^{222}$ Thus, it is likely that the exit/voice effect will take a larger toll on invisible groups than it will on mutable groups.

The effect differs for invisible and mutable groups in another way. If a member of an invisible group chooses to exert her voice by converting her corporeal invisibility to declarative visibility, she has for practical purposes made an irreversible decision. What distinguishes the declaratively invisible from the declaratively visible is, quite simply, a declaration that disseminates knowledge of the underlying trait. The informational character of declarations makes them hard to retract. The exit/voice effect in this context thus contains a one-way ratchet-if individuals choose voice (or at least the kind of voice that requires disclosure of their identity), they are permanently forgoing exit. This means that, as I have noted elsewhere, ${ }^{223}$ the exit/voice dynamic in the visibility context may be represented as a prisoner's dilemma.

Under the prisoner's dilemma, the communally optimal situation for the two individuals marked by an invisible characteristic is for both of them to reveal themselves. Yet the parties will have difficulty reaching this communally optimal point because they lack information about each other. A prisoner cannot ask the question, "If I reveal myself, would you come out too?" because that question performs a partial act of revelation even as it is posed, and the one-way ratchet of the revelation makes retraction meaningless.

Individuals in the prisoner's dilemma must thus decide on their own whether to reveal themselves. If an individual decides to do so, there is always the risk that the other individual will not reciprocate. In that circumstance, the individual who reveals herself pays the price of disclosure without the support of the other individual. Conversely, the other individual evades the harms of visibility but can free ride on the benefits that accrue to the group through the visibility of the individual who reveals herself. ${ }^{224}$ Given this scenario, rational, risk-averse individuals will determine that the option more likely to empower them as individuals will be to remain hidden. But if both individuals remain closeted, they will be collectively disempowered.

222. See supra note 180 and accompanying text.

223. See Yoshino, supra note 221, at 1801-02.

224. It is true that the closeted individual must ultimately come out to claim the benefits that accrue to the group. In the meantime, however, such an individual can free ride on the political advances made by his out peers. 


\begin{tabular}{||l||l|l||}
\hline & \multicolumn{1}{|c|}{$A$ Comes Out } & \multicolumn{1}{|c|}{$A$ Remains Closeted } \\
\hline \hline $\begin{array}{l}B \text { Comes } \\
\text { Out }\end{array}$ & $\begin{array}{l}A \text { benefits } \\
B \text { benefits } \\
\text { (Cooperative Liberation) }\end{array}$ & $\begin{array}{l}A \text { benefits greatly } \\
(A \text { free rides on } B)\end{array}$ \\
\hline $\begin{array}{l}\text { B Remains } \\
\text { Closeted }\end{array}$ & $\begin{array}{l}\text { A benefits minimally } \\
B \text { benefits greatly } \\
(B \text { free rides on } A)\end{array}$ & $\begin{array}{l}A \text { benefits minimally } \\
B \text { benefits minimally } \\
\text { (Mutual Disempowerment) }\end{array}$ \\
\hline
\end{tabular}

The harshness of the prisoner's dilemma should not be exaggerated, for it may be tempered in two ways. First, there will be occasions in which Prisoner $A$ may come out only to Prisoner $B$, rather than to the public at large. The one-way epistemic ratchet will operate, but only with respect to $B$. If $A$ knows that $B$ will keep her secret, $A$ will thus be protected from harm even if $B$ does not reciprocate by coming out of the closet. Second, in cases where the prisoner's dilemma is iterated, some individuals can be expected to be out at the time $A$ and $B$ play the game. If $A$ knows any of them, she will not be relying on $B$ alone for potential support after she comes out of the closet.

\section{The Manipulation Effect}

Invisible groups are deeply vulnerable to the manipulation effect in ways that visible groups are not. This vulnerability arises not in spite of, but because of, the discretion invisible groups have over the expression of their identities. The fact that the expression of a trait is discretionary does not mean that its possessor holds that discretion; to the contrary, social actors can often wrest that discretion away from the possessor of the trait. By doing so, such actors can control the possessor's identity in a way that could not be applied to those who bear traits whose expression is not discretionary.

The distinctive forms of social control that third parties have over invisible traits concern both their forced disclosure and their forced repression. The state's forced disclosure of invisible traits may be seen in the use of Megan's Law to out sex offenders. ${ }^{225}$ Conversely, the state's

225. See, e.g., Ronald K. Chen, Constitutional Challenges to Megan's Law: A Year's Retrospective, 6 B.U. PUB. INT. L.J. 57 (1996) (discussing the background of Megan's Law, court 
forced repression of invisible traits may be seen in the context of its "don't ask, don't tell" policy. ${ }^{226}$ These means of controlling and shaping the identities of invisible groups could not logically be deployed against visible groups. To force a bearer of a visible trait to expose it would be moot; to force her to suppress it would be futile.

\section{The Harm of the Visibility Presumption}

When the analytical framework developed in the context of immutability is applied to the context of visibility, the results are complex. The claim that visible groups lack evasive power was buttressed by their lack of discretion, their vulnerability to superficial judgment, and their placement in a panoptic dynamic. Yet the costs that evasion imposed on invisible groups were also dramatic. These costs included the epistemic harms of alienation, the onerous labor of passing, and the moral burden of doing so. They also included the ontic harm of identity erasure.

The analysis of transformative power also failed to give clear support to the visibility presumption. The advantage the infiltration effect gave to invisible groups was shown to be qualified. The auto-identification effect again proved too unpredictable to support the visibility presumption (or its opposite). And the exit/voice effect and the manipulation effect supported the claim that visible groups were likely to have more transformative power than invisible groups.

This analysis should demonstrate that the visibility presumption, like the immutability presumption, is deeply flawed. There is no innate connection between visibility and political powerlessness, nor is there an innate connection between invisibility and political power. Rather, the net effects of visibility will depend on context, sometimes disempowering a group ${ }^{227}$ and sometimes empowering it. ${ }^{228}$

At this point, the argument for retiring both the immutability and the visibility presumptions is technically complete; the presumptions cannot be justified on either a substantive or a processual theory of judicial review. But to end the argument here fails to capture the injustice of the immutability and visibility presumptions. This is because I have thus far largely ignored the role of the state in participating in the social context in which the net effects of immutability (or mutability) and visibility (or invisibility) are determined. When the state participates in the animus

challenges to it, and similar legislation); Robert J. Martin, Pursuing Public Protection Through Mandatory Community Notification of Convicted Sex Offenders: The Trials and Tribulations of Megan's Laws, 6 B.U. PUB. INT. L.J. 29 (1996) (same).

226. See infra Part VI.

227. See JONES ET AL., supra note 115 , at 27-35.

228. See id. at 35-36. 
against a group, it is uniquely capable of structuring regimes that maximize the downsides and minimize the upsides of any of these traits. ${ }^{229}$ If the state's animus is directed against immutable or visible groups, the operation of the immutability and visibility presumptions makes it more likely that the courts will correct such state animus. If the state uses the mutability or the invisibility of a group against it, however, the courts will still presume that such mutability or invisibility empowers the group and therefore will be less likely to strike down the legislation. Given that the equal protection guarantee is supposed to protect groups against prejudicial state action, it is ironic that the courts assume that mutability and invisibility consistently lead to political power even in contexts where the state itself is providing a powerful counterexample.

Thus, although I have already demonstrated the illogic of the immutability and the visibility presumptions, I have yet to demonstrate the real urgency underlying the illogic. The severe harm that the presumptions can inflict cannot be understood without recognizing the power of the state to make a group's mutability or invisibility an immense liability to that group. To facilitate that recognition, the next Part considers a case in which the state has structured an invisible group's context so that that the net effects of its invisibility are deeply debilitating: the "don't ask, don't tell" policy of the United States military. ${ }^{230}$

\section{VI. “DON'T ASK, DON’T TELL”}

The policy of restricting homosexuals from serving in the United States Armed Forces dates back to World War I. ${ }^{231}$ Prior to the current statute, the governing standard was that of the 1981 Department of Defense Regulations, which stated that " $[\mathrm{h}]$ omosexuality [was] incompatible with military service." 232 In late 1992, President-elect Clinton indicated to the press that he intended to lift the ban on gays in the military, permitting homosexuals to serve openly with regulations only on their conduct. ${ }^{233}$

229. See Peter Nixen, The Gay Blade Unearthed: Unmasking the Morality of Military Manhood in the 1990s, An Examination of the U.S. Military Ban on Gays, 62 UMKC L. REV. 714, 748-50 (1994) (noting the "catch-22" situation created by prohibiting homosexuals from making their sexual orientation visible and then refusing to grant heightened scrutiny to review the military ban because sexual orientation does not appear to be immutable, precisely because it can be hidden).

230. My example concerns an invisible group rather than a mutable one because the visibility factor has not been as aggressively challenged as the immutability factor, See supra notes 136-142 and accompanying text.

231. See NATtONAl DEFense ResEarch INST., RAND CORP., SEXUAL ORIENTATION AND U.S. MIITARY PERSONNEL POLICY: OPTIONS AND ASSESSMENT 3 (1993) [hereinafter RAND]. (1997).

232. Enlisted Administrative Separations: Standards and Procedures, 32 C.F.R. pt. 41 app. A

233. See Janet E. Halley, The Status/Conduct Distinction in the 1993 Revisions to Military Anti-Gay Policy: A Legal Archaeology, 3 GAY L.Q. 159, 165 (1996). 
Opposition to such unilateral executive action, however, proved fierce-a number of Senators threatened to enact legislation that would override Clinton's proposed changes. ${ }^{234}$ Later that year, President Clinton had Secretary of Defense Les Aspin draft an executive order responsive to congressional concerns, but Congress ultimately rejected that order and enacted the first statute governing sexual orientation in the military. ${ }^{235}$ That statute and the Department of Defense regulations implementing it constitute the "don't ask, don't tell" policy.

The crux of the statute generally requires a member of the armed forces to be discharged if one of three findings is made. First, if "the member has engaged in, attempted to engage in, or solicited another to engage in a homosexual act or acts," the member will be discharged in the absence of mitigating circumstances. ${ }^{236}$ Second, if "the member has stated that he or she is a homosexual or bisexual," the member will be discharged unless there is a further finding "that the member has demonstrated that he or she is not a person who engages in, attempts to engage in, has a propensity to engage in, or intends to engage in homosexual acts." 237 Third, if "the member has married or attempted to marry a person known to be of the same biological sex," the member will be discharged. ${ }^{238}$ The language pertaining to the second finding constitutes the "don't tell" portion of the policy-gays and bisexuals are discharged for coming out unless they can rebut the presumption thereby created that they have engaged in or are likely to engage in homosexual conduct. In contrast to the "don't tell" provision, the "don't ask" provision is strictly a regulatory creation. The relevant regulation notes that "[a]pplicants for enlistment, appointment, or induction shall not be asked or required to reveal whether they are heterosexual, homosexual, or bisexual." 239

Litigants challenging the "don't ask, don't tell" policy have argued, inter alia, that the policy violates the equal protection component of the Fifth Amendment. ${ }^{240}$ Although this issue has not made it to the Supreme Court, all four circuit courts that have considered it have upheld the constitutionality of the policy. ${ }^{241}$

By running the "don't ask, don't tell" policy through the analytical framework developed in Part V, I seek to show in this Part that the policy

234. See id. at 166 .

235. See id. at 165 .

236. 10 U.S.C. $\$ 654$ (b)(1) (1994).

237. $I d$. $\$ 654(\mathrm{~b})(2)$.

238. Id. $\$ 654(\mathrm{~b})(3)$.

239. Dep't of Defense Directive No. 1304.26, encl. 1, § B(8)(a).

240. See Able v. United States, 155 F.3d 628, 631 (2d Cir. 1998); Phillips v. Perry, 106 F.3d 1420, 1424 (9th Cir. 1997); Richenberg v. Perry, 97 F.3d 256, 260 (8th Cir. 1996); Thomasson v. Perry, 80 F.3d 915, 927 (4th Cir. 1996).

241. See Able, 155 F.3d at 636; Phillips, 106 F.3d at 1429; Richenberg, 97 F.3d at 264; Thomasson, 80 F.3d at 934. 
ensures that the net effects of gay invisibility are negative. That framework showed that whether invisibility contributes to or detracts from the evasive and transformative power of a group depends on context. When the manner in which the military policy manipulates that context is examined, it becomes clear that the policy simultaneously dampens the empowering aspects and amplifies the disempowering aspects of gay invisibility.

Before embarking on that analysis, however, I address two objections to the use of "don't ask, don't tell" as a case study: the "military deference" objection and the "sui generis" objection. The military deference objection is that the deference the courts pay to the military makes it unlikely that my analysis, even if accepted, would lead the courts to hold the policy unconstitutional. This objection is supported by the fact that the circuit courts upholding the policy have all relied in part on military deference to reach their results, quoting the Supreme Court's statement that where Congress's authority over military affairs is concerned, "judicial deference ... is at its apogee." ${ }^{242}$

The quick response to the "military deference" objection is that the objection misconstrues the purpose of my case study. That purpose is not to argue the unconstitutionality of the policy; rather, it is to show how the state can manipulate the context in which an invisible group operates to ensure that the net effects of its invisibility are disempowering.

But is the quick response too quick? Even if one acknowledged that military deference is not damaging to the case study, one could nonetheless argue that it is damaging to the arguments that the study attempts to support. If the study shows that the state can make the net effects of invisibility disempowering, this becomes: (1) an argument for jettisoning the visibility factor, which then becomes (2) an argument for according gays heightened scrutiny, which in turn becomes (3) an argument for finding the policy unconstitutional. Thus, although military deference does not affect the validity of the case study, it is perhaps natural to ask whether it affects a plausible end to which the study could be put.

One answer to that question is that the study should not be used to support further arguments without deep consideration of military deference. The fact that "don't ask, don't tell" is such an overt example of the state's deploying the invisibility of gays against them makes the military a good place for gays to make the first argument noted in the previous paragraph. As a practical matter, however, litigators should not be enticed into challenging the policy without considering military deference, which raises difficulties in moving from the first argument to the second and third

242. Able, 155 F.3d at 632 (quoting Goldman v. Weinberg, 475 U.S. 503, 508 (1986) (quoting Rostker v. Goldberg, 453 U.S. 57, 70 (1981))); Phillips, 106 F.3d at 1425 (same); Richenberg, 97 F.3d at 261 (same); Thomasson, 80 F.3d at 925 (same). 
arguments. For even in the absence of the visibility presumption, deference could pose two difficulties: (1) it could preclude courts from granting gays heightened scrutiny (without which the policy is presumptively constitutional); ${ }^{243}$ and (2) even if heightened scrutiny were granted, it could still preclude courts from finding the policy unconstitutional. ${ }^{244}$ In other words, the context in which gays might most easily defeat the visibility presumption is also the context in which they will have the hardest time parlaying that victory into a finding of unconstitutionality.

I believe that these difficulties are ultimately surmountable, although I do no more here than sketch the contours of the ways in which they may be overcome. ${ }^{245}$ As to the first, it is hard to argue that military deference precludes a finding of heightened scrutiny, given that both paradigmatic heightened scrutiny classifications, race $^{246}$ and $\operatorname{sex}^{247}$ were granted heightened scrutiny in the military context. As to the second, it is at least an open question whether military deference could save a policy subjected to heightened scrutiny, given the stringent nature of that review. ${ }^{248}$ Moreover, even if courts found that gays deserved heightened scrutiny but deemed the military policy to survive it, gays could take that finding of heightened scrutiny to other contexts in which military deference does not apply. This

243. See Heller v. Doe, 509 U.S. 312, 319 (1993) (noting that a classification subjected to rational basis review "is accorded a strong presumption of validity").

244. See Korematsu v. United States, 323 U.S. 214, 216, $223-24$ (1944) (according race "the most rigid scrutiny" but upholding Japanese-American internment legislation in a military context).

245. Again, my treatment of the military deference objection is abridged because it does not directly affect the validity of my case study, but only the validity of one end to which my case study might be put. The curtailed nature of this treatment is manifest not only in the synoptic way my points are made, but also in my bracketing of the issue of whether military deference is legitimate in the first place. I do no more than mention that the literature against military deference in its current form is robust. See, e.g., Kirstin S. Dodge, Countenancing Corruption: A Civic Republican Case Against Judicial Deference to the Military, 5 YALE J.L. \& FEMINISM 1, $17-38,44$ (1992) (noting that "judicial deference to the military ignores the wisdom and cautions of the nation's founders and the civic-republican ideals that influenced them, and undermines the nation's ability to maintain and strengthen democratic self-government in our modern, heterogeneous social and political culture"); Kenneth L. Karst, The Pursuit of Manhood and the Desegregation of the Armed Forces, 38 UCLA L. REV. 499, 563-81 (1991) (critiquing the three rationales for judicial deference in military affairs: "deference in an emergency, deference based on the special needs of a 'separate community,' and deference based on the judiciary's relative incompetence to understand military matters"); Military Ban on Yarmulkes, 100 HARV. L. REv. 163, 170-71 (1986) (arguing, in the context of infringements on religious rights, against the status quo in which the military deference is a "mechanical sanction of military authority" and suggesting that deference should still require the military to adduce a robust rationale for its actions); John Nelson Ohlweiler, The Principle of Deference: Facial Constitutional Challenges to Military Regulations, 10 J.L. \& POL'Y 147, 175-\$1 (1993) (arguing that strict military deference need not apply when facial constitutional challenges are concerned, because these are less likely to threaten military effectiveness than individual personnel decisions).

246. See Korematsu, 323 U.S. 213 (according race-based classifications heightened scrutiny for the first time in a military context).

247. See Frontiero v. Richardson, 411 U.S. 677 (1973) (plurality opinion) (according sexbased classifications heightened scrutiny for the first time in a military context).

248. See supra note 5 . 
is because heightened scrutiny is not limited to the context in which it is granted, but follows the classification into all contexts. ${ }^{249}$

The last observation, however, raises a related objection, which I call the sui generis objection. Because heightened scrutiny follows the classification into all contexts, it makes sense to require that the group's claim to heightened scrutiny also hold across these contexts. ${ }^{250}$ This explains why the heightened scrutiny inquiry asks whether a group is (for example) politically powerless in all contexts rather than looking only at its powerlessness in one context. That requirement raises the concern that even if one finds that "don't ask, don't tell" disempowers gays, that disempowerment is limited to the military and therefore cannot serve as the sole predicate for heightened scrutiny.

The sui generis objection can be met by noting that although "don't ask, don't tell" is a particularly overt manifestation of the way in which the state uses the invisibility of gays against them, it is not unrepresentative. The state forges a link between gay invisibility and gay powerlessness whenever it participates in closeting homosexuals, making the invisibility of gays mandatory rather than discretionary. ${ }^{251}$ But this closeting occurs whenever the state engages in homophobic lawmaking that makes invisibility a prerequisite for gays who wish to enjoy the basic entitlements of a free society. It occurs whenever legal norms are created against the equal treatment of homosexuals in employment or other spheres, ${ }^{252}$ against

249. This is implicit in the very concept of a "heightened scrutiny classification," which anoints the classification, rather than the context, as being of judicial concern. Cf. City of Cleburne v. Cleburne Living Ctr., 473 U.S. 432, 451-55 (1985) (Stevens, J. concurring) (criticizing rigidity of existing heightened scrutiny analysis and arguing for more contextdependent analysis).

250. The prevailing tests of political powerlessness all look to the group's powerlessness in American society as a whole rather than allowing groups to make the case only on the basis of local powerlessness. See Cleburne, 473 U.S. at 445 (asking whether a group is unable "to attract the attention of lawmakers"); Frontiero, 411 U.S. at 686 n.17 (plurality opinion) (asking whether a group is underrepresented in the "Nation's decisionmaking councils"); United States v. Carolene Products, 304 U.S. 144, 153 n.4 (1938) (asking whether the group is a "discrete and insular minorit[y]").

251. See supra notes $155-158$ and accompanying text.

252. These legal norms include acts of omission. For example, there is no federal legislation currently prohibiting discrimination against homosexuals, despite the fact that bills proposing such legislation have been introduced in Congress for more than 20 years. See Carlos A. Ball, Moral Foundations for a Discourse on Same-Sex Marriage: Looking Beyond Political Liberalism, 85 GEO. L.J. 1871, 1873 n.9 (1997) (noting that Congress considered proposals for federal legislation protecting gays as early as 1974 and that the most recent attempt to pass such legislation was defeated in 1996); see also CASES AND MATERIALS ON SEXUAL ORIENTATION AND THE LAW 466 (William B. Rubenstein ed., 1997) (noting the longevity of attempts to enact federal legislation protecting gays) [hereinafter SEXUAL ORIENTATION AND THE LAW]. Existing federal legislation either ignores or explicitly excludes the sexual orientation category. Thus, Title VII of the Civil Rights Act of 1964, 42 U.S.C. $\$ \$ 2000$ e to $2000 \mathrm{e}-17$ (1996), prohibits employment discrimination on the basis of "race, color, religion, sex, or national origin," id. at $\$ 2000$ e-2(a), but omits any mention of sexual orientation. The Americans with Disabilities Act of 1990,42 U.S.C. $\$ \$ 12101-12213$ (1996), specifically notes that homosexuality and bisexuality do not fall within its ambit, id. at $\$ 12211$ (a). 
same-sex marriage $e^{253}$ or sodomy, ${ }^{254}$ or against gay adoption or custody. ${ }^{255}$ If "don't ask, don't tell" is sui generis, it is not in making the demand that gays be closeted, but in making that demand explicit.

Perhaps more strikingly, legal norms against the equal treatment of gays, lesbians, and bisexuals also include acts of commission. In 1993, for example, Colorado passed an amendment to its constitution whose caption asserted that there would be "No Protected Status Based on Homosexual, Lesbian, or Bisexual Orientation." CoLO. CoNST. art. II § 30(b). While the U.S. Supreme Court struck down this amendment on equal protection grounds, see Romer v. Evans, 517 U.S. 620 (1996), analogous provisions in an amendment to a city charter have been upheld by the Sixth Circuit even in the wake of Romer. See Equality Foundation II, 128 F.3d at 289 (upholding an amendment stating that the city of Cincinnati "may not enact, adopt, enforce, or administer any ordinance, regulation, rule or policy which provides that homosexual, lesbian, or bisexual orientation, status, conduct, or relationship constitutes, entitles, or otherwise provides a person with the basis to have any claim of minority or protected status, quota preference, or other preferential treatment").

253. Marriage between two individuals of the same sex has never been permitted and is not currently permitted in any jurisdiction in the United States. See Thomas B. Stoddard, Bleeding Heart: Reflections on Using Law to Make Social Change, 72 N.Y.U. L. REV. 967, 989 (1997).

254. Eighteen states still have sodomy statutes pertaining to sexual relations between human beings on their books. Seven states have sodomy laws that apply to homosexual relations only. See ARK. CODE ANN. \$ 5-14-122 (WESTLAW through 1997 Reg. Sess.); KAN. STAT. ANN. § 213505 (WESTLAW through 1997 Reg. Sess.); MD. CODE ANN. 1957, art. 27 \$ 553-54 (Michie, WESTLAW through 1997 Reg. Sess.); MICH. COMP. LAWS ANN. \$\$ 750.158, 750.338 (West, WESTLAW through P.A. 1998, No. 20); Mo. ANN. STATS. § 566.090 (Vernon, WESTLAW through 1997 2d Ex. Sess.); OKLA. STAT. ANN. 21 \$ 886 (West, WESTLAW through 1997 1st Reg. Sess.); TEX. PENAL CODE, \$ 21.06 (West, WESTLAW through 1997 Reg. Sess.).

Eleven states have sodomy laws that apply to both heterosexual and homosexual relations. See ALA. CODE § 13A-6-65(a)(3) (WESTLAW through 1997 Reg. Ses.); ARIZ. REV. STAT. ANN. \$§ 13-411 to 13-412 (West, WESTLAW through 1997 1st Reg. Sess. and 2d Sp. Sess.); FLA. STAT. ANN. \$ 800.02 (West, WESTLAW through 1997 1st Reg. Sess.); IDAHO CODE \$ 18-6605 (Michie, WESTLAW through 1997 Reg. Sess.); LA. REV. STAT. 14:89 (West, WESTLAW through 1997 Reg. Sess. Acts); MNN. STAT. ANN. \$ 609.293 (West, WESTLAW through 1997 3d Sp. Sess.); Miss. CODE § 97-29-59 (WESTLAW through 1998 Reg. Sess.); N.C. GEN. STAT. \$ 14-177 (Michie, WESTLAW through 1997 Reg. Sess.); S.C. CODE ANN. § 16-15-120 (WESTLAW through 1997 Reg. Sess.); UTAH CODE ANN. § 76-5-403 (WESTLAW through 1998 Gen. Sess.); VA. CODE § 18-2-361 (Michie, WESTLAW through 1998 Reg. Sess.). It bears mention that "[e]ven in the majority of states that retain gender neutral language, the ancillary effects of the sodomy prohibition are directed against lesbian and gay citizens." Hunter, supra note 14 , at 539.

As William Rubenstein notes, sodomy laws not only directly affect lesbians, gay men, and bisexuals by threatening them with "arrest simply [for] expressing their love for one another," but also indirectly affect them by providing a "basis for constraining - or denying-[other] legal rights." SEXUAL ORIENTATION AND THE LAW, supra note 252, at 282. For example, a number of courts have relied on the presence of sodomy laws to argue that sexual orientation cannot be a heightened scrutiny classification. See, e.g., High Tech Gays v. Defense Indus. Sec. Clearance Office, 895 F.2d 563, 571 (9th Cir. 1990) (noting that if homosexual conduct can be constitutionally criminalized, an identity constituted by that conduct cannot merit heightened scrutiny); Ben-Shalom v. Marsh, 881 F.2d 454, 464 (7th Cir. 1989) (same); Woodward v. United States, 871 F.2d 1068, 1076 (Fed. Cir. 1989) (same); Padula v. Webster, 822 F.2d 97, 103 (D.C. Cir. 1987) (same).

255. Courts have denied gays, lesbians, and bisexuals custody or visitation rights both by noting that homosexuality is per se incompatible with such rights and, more commonly, by noting that a parent's sexuality may be taken into account when it has some connection to his or her parenting abilities. See SEXUAL ORIENTATION AND THE LAW, supra note 252, at 810-11 (collecting cases). 
Having addressed these two objections, ${ }^{256}$ I now apply the analytic framewrork developed above to the military context.

\section{A. Evasive Power}

The analysis of the evasive power of invisible groups noted that invisible groups were advantaged over visible groups because: (1) they possessed more discretion over their identities; (2) they were less prone to superficial judgments based on their visible characteristics; and (3) they were less likely to be victimized by panoptic effects. It then noted that invisible groups were disadvantaged relative to visible groups because their evasive action generated a series of harms, including: (1) alienation; (2) the sheer work of passing; (3) moral stigma; and (4) identity erasure. "Don't ask, don't tell" mutes the evasive advantages and heightens the evasive disadvantages of invisibility.

\section{Evasive Advantages Dampened}

While visible groups are generally locked into their visibility, invisible groups can choose either to remain invisible or to convert their corporeal invisibility into declarative visibility. This ability to control the management of their social identity generally gives invisible groups an edge over visible groups. Social actors, however, may diminish that evasive advantage by diminishing the discretion of invisible groups. Thus, a common strategy employed to control invisible groups forces them to convert their invisibility into visibility - through brandings, scarlet letters, public notifications, and the like. ${ }^{257}$ Conversely, the discretion of invisible groups may be cabined by precluding them from voluntarily converting their invisibility into visibility.

"Don't ask, don't tell" exemplifies the latter strategy. It is true that the statute is carefully drafted not to penalize the act of converting corporeal invisibility to social visibility per se-homosexual servicemembers will not be discharged solely for making the statement of self-identification- "I am gay." ${ }^{258}$ Yet this safe harbor-designed to circumvent prohibitions on speech and status regulation-has proved insecure. A self-identifying statement raises a rebuttable presumption that the servicemember has

256. It bears note that even if either of these objections were sustained, that would not be fatal to the argument that the visibility factor should be retired. The state's manipulation of invisibility to disempower invisible groups underscores the irony that it assumes that invisibility is always empowering. But even in the absence of state manipulation, invisibility still would not be a good proxy for political power, as demonstrated supra Part V.

257. See supra notes $155-158$ and accompanying text.

258. See 10 U.S.C. $\$ 654(b)(2)$. 
engaged in homosexual conduct; if left unrebutted, the presumption is grounds for exclusion. ${ }^{259}$ And as a practical matter, the presumption has proved difficult to overcome-in a recent case, the government acknowledged that of forty-three servicemembers investigated for raising this presumption, only seven were able to rebut it and remain in the military. ${ }^{260}$ Through these means, the policy eliminates the "natural" advantage of discretion that invisible groups have over visible ones-under it, invisible groups are locked into their invisibility in a way similar to that in which visible groups are locked into their visibility.

A proponent of the visibility presumption could argue that permanently invisible groups are still more empowered than permanently visible groups because the former may evade superficial judgments while the latter may not. Yet while the invisibility of gays may free them from certain kinds of superficial judgment, it entraps them in others. As will be discussed further below, ${ }^{261}$ the superficial judgments about gays that justify the policy-that they destroy unit cohesion, that they trench on the privacy of heterosexual servicemembers, and that they create debilitating sexual tension-survive precisely because the coerced invisibility of gays prevents them from being challenged.

Finally, the proponent of the visibility presumption might point out that invisible groups generally do not occupy a disempowering position in a panoptic dynamic. But as demonstrated below, ${ }^{262}$ the policy has found a way around that axiom by depriving all military servicemembers of privacy. By placing all military servicemembers in a virtual Panopticon, the military eliminates any advantage invisible groups might have. The threat of constant surveillance as applied to all servicemembers thus captures even invisible homosexuals within its panoptic ambit.

\section{Evasive Disadvantages Amplified}

Just as the policy diminishes invisibility's evasive advantages, it also exacerbates its evasive disadvantages. We have seen that the evasive harms of invisibility may be divided into epistemic and ontic harms. ${ }^{263}$ The epistemic harms may in turn be subdivided into the passer's alienation from support communities, the work of passing, and moral harm.

The gay passer is isolated from both communities from which she could draw support-the straight community to which she pretends to belong, and the gay community that she has disavowed. "Don't ask, don't tell"

259. See id.

260. See Able v. United States, 88 F.3d 1280, 1298 (2d Cir. 1996).

261. See infra notes 301-305 and accompanying text.

262. See infra notes 273-276 and accompanying text.

263. See supra notes $180-197$ and accompanying text. 
exacerbates her isolation from both communities. First, the policy heightens the alienation a gay passer may feel toward the straight community by making it less likely that the straights with whom she associates will be progay or openly pro-gay. The policy makes it less likely that servicemembers will be pro-gay by enunciating homophobic norms-as Kenneth Karst has noted, "the policy is an authoritative statement stigmatizing homosexuality," in which "[e]very discharge of a gay soldier is an official degradation ceremony." 264 The policy also makes it less likely that even staunchly pro-gay servicemembers will express their sympathies. This is because-as will be discussed further below ${ }^{265}$ - the policy cultivates anxiety among straights that their pro-gay activities will lead them to be labeled as gay themselves. Given that the cost of that ascription is exclusion, the in terrorem effects of such anxiety are likely to be significant. Thus, even though a closeted lesbian could conceivably draw strength from pro-gay straights, such support is unlikely to be available to her in the military. ${ }^{266}$

The policy also diminishes the support gays might otherwise receive from other gays. In any context, the gay passer will only be able to draw direct support from other gays if she engages in selective passing-coming out only to members of her own group while remaining closeted to others. The ability of a homosexual to cultivate two such contradictory identities will depend on the distinctness of her audiences. The military makes it difficult to preserve this distinction in two ways. First, by forcing all gays into the closet, the military makes it harder for them to identify each other. Second, the military makes it difficult for gays to confide in even the gays they can identify by threatening all gays with witchhunts. Under the old policy, the military's strategy of witchhunting gays-particularly lesbians-was well known. ${ }^{267} \mathrm{~A}$ lesbian who had been caught would often be presented with the option of plea bargaining to receive a reduced punishment in return for turning in others. ${ }^{268}$ This had the effect of using the support network that gays had built for each other against them. The "don't ask" prong of the current policy is supposed to protect gays from direct

264. Karst, supra note 245 , at 546.

265. See infra notes $306-309$ and accompanying text.

266. The gay passer must therefore not only pass as a member of a straight community but as a member of a straight community marked by intolerance of gays. She may thus feel that to pass successfully she must engage in homophobic behavior. See Halley, Politics of the Closet, supra note 14, at $934 \mathrm{n} .67$ (recounting an interview with a homosexual Marine who stated that to evade detection, he would try to " "[b]e even more vociferous than everybody else"” when engaging in homophobic banter (quoting STUDS TERKEL, THE GOOD WAR: AN ORAL HISTORY OF WORLD WAR TWO 180 (1984))).

267. See Michelle M. Benecke \& Kirstin S. Dodge, Military Women in Nontraditional Fields: Casualties of the Armed Forces' War on Homosexuals, 13 HARV. WOMEN's L.J. 215, 222 (1990).

268. See id. at 224 ("One of the most common tactics used by investigators [wa]s to pressure women to name others who might be gay in order to save themselves."). 
questioning about their sexual orientation; there is serious question whether it does even this. ${ }^{269}$ What it does not do is protect gays from such plea bargaining. ${ }^{270}$ The Servicemembers Legal Defense Network has "documented 15 actual or attempted witch hunts under the new regulations where commanders and inquiry officials asked military members to identify other servicemembers who were or were suspected to be homosexual." 271 Indeed, it has been argued that one of the primary reasons that the military has reserved discretion to retain servicemembers who have engaged in homosexual conduct is to preserve the plea bargain option. ${ }^{272}$ The fact that the military can use the threat of such plea bargains against gay servicemembers is a powerful disincentive for gays to divulge their identity to other gays.

The second harm of evasion is the sheer work of passing. This burden is mitigated only when the passer enters a private sphere where she may doff her public persona to reveal a more authentic private self. Thus, that burden will be particularly heavy where the private sphere is conscribed. Current military regulations appear to recognize that some degree of privacy should be preserved for gays-the "don't ask" portion of the policy flows from the statement that "sexual orientation is considered a personal and private matter." 273 Yet even a cursory examination of this privacy reveals how narrowly circumscribed it is. Solicitude for sexual privacy, while expressed in the regulations, appears nowhere in the text of the statute. In fact, the congressional "findings" section of the statute takes great pains to indicate how little privacy actually exists in the military. Thus the section states that it is "necessary for members of the armed forces involuntarily to accept living conditions and working conditions that are often spartan, primitive, and characterized by forced intimacy with little or no privacy." 274 It also points out that the standards" of conduct for servicemembers apply "for 24 hours each day beginning at the moment the member enters military status and not ending until that person is discharged or otherwise separated from the armed forces." 275 And again, lest there be any mistake, "[t] hose standards of conduct ... apply to a member of the armed forces at all times that the member has a military status, whether the

269. See infra notes 291-294 and accompanying text.

270. See Kenneth Williams, Gays in the Military: The Legal Issues, 28 U.S.F. L. REv. 919, 926 (1994).

271. Samuel A. Marcosson, A Price Too High: Enforcing the Ban on Gays and Lesbians in the Military and the Inevitability of Intrusiveness, 64 UMKC L. REV. 59, 88 (1995) (quoting C. Dixon OsbuRn \& Michelle M. BeneCKe, SERVICEMEMBERs Legal DEFENSE NeTWork, CONDUCT UNBECOMING CONTINUES: ThE FIRST YeAR UnDER “DON'T ASK, DON'T TELL, DON'T PURSUE" 11 (1995)).

272. See Williams, supra note 270 , at 926.

273. Dep't of Defense Directive 1304.26, encl. 1, § B(8)(a) (Dec. 21, 1993).

274. 10 U.S.C. $\$ 654(a)(12)(1994)$.

275. Id. $\$ 654(\mathrm{a})(9)$. 
member is on base or off base, and whether the member is on duty or off duty." ${ }^{276}$ The picture painted in the statute is one in which soldiers can expect no privacy, at any time of the day, at any point in their military tenure. In this way, the policy gives with one hand and takes with the other-the regulations recognize sexuality as existing in a private space, while the statute points out that this space barely exists. The logical consequence of this is that the burdens of passing will be acute-gays are effectively required to engage in a twenty-four-hour performance of heterosexuality.

The final epistemic harm of evasion is the moral one, in which the passer must pretend to be something that she is not. The state exacerbates this harm both by coercing gays to pass and by forcing them to do so in a culture that otherwise inculcates honesty as a cardinal value. As one commentator has recently argued, the policy's bar on homosexual selfidentification requires gays to affirm a heterosexual identity. ${ }^{277}$ This is because the strength of the heterosexual presumption makes a homosexual's silence as pointed and as performative as speech affirming that she is straight. ${ }^{278}$ This compelled lie will take a particularly heavy toll in a context that holds honesty to be a fundamental tenet of honor. Explaining why he came out while at the Naval Academy, Joseph Steffan notes: "The Honor Concept at Annapolis is based on the tenet that personal honor is an absolute...." 279 Steffan states that if he had remained in the closet he "would have given up [his] honor, destroying everything it means to be a midshipman." ${ }^{280}$ By forcing only gays to lie about their identities in a culture in which lying is held to be deeply dishonorable, the military inculcates in them a conception of themselves as second-class citizens, not only because of their homosexuality, but also because of their duplicity. That it does so in the name of unit cohesion is particularly ironic given that, as the courts have noted, "[a] relationship built on deception is anything but a "bond of trust." 281

276. Id. $\$ 654(\mathrm{a})(10)$.

277. See Tobias B. Wolff, Compelled Affirmations, Free Speech, and the U.S. Military's Don't Ask, Don't Tell Policy, 63 BROOK. L. REV 1141, 1145 (1998).

278. See id.

279. JOSEPH STEFFAN, HONOR BOUND: A GAY NAVAL MIDSHIPMAN FIGHTS TO SERVE HIS COUNTRY 145 (1992).

280. Id.; see also Holmes v. California Army Nat'l Guard, 124 F.3d 1126, 1131 (9th Cir. 1997) (noting that Holmes came out to his commanding officer in a memorandum stating: " "[A]s a matter of conscience, honesty and pride, I am compelled to inform you that I am gay."').

281. Thomasson v. Perry, 80 F.3d 915, 953 (4th Cir.) (Hall, J., dissenting), cert. denied, 117 S. Ct. 358 (1996); see also Able v. United States, 880 F. Supp. 968, 979 (E.D.N.Y. 1995) (" [T] he court deems extraordinary ... the almost total lack of concern evidenced in the Congressional hearings and the Committee reports as to the impact on unit cohesion of the attempt to enforce secrecy on homosexuals and to enlist them in the perpetration of a hoax on heterosexuals. Common sense suggests that a policy of secrecy, indeed what might be called a policy of 
In addition to these three epistemic harms, I earlier noted that passing may lead to an ontic harm-the perception (or actuality) that the passer does not exist along the closeted axis of his identity. The military exacerbates this ontic harm by barring gays (and only gays) from engaging in any protected expression of their identities rather than simply precluding them from expressing their homosexuality in certain narrowly-specified ways. The distinction between the two kinds of harms may be seen by contrasting the "don't ask, don't tell" policy with the uniform regulation upheld in Goldman v. Weinberger, ${ }^{282}$ a case often adduced to quash First Amendment challenges to "don't ask, don't tell." ${ }^{283}$ In Goldman, the Supreme Court held that a military uniform regulation that prevented a Jewish Air Force member from wearing a yarmulke did not violate the First Amendment. ${ }^{24}$ But the regulation in Goldman can be distinguished from "don't ask, don't tell" in two fundamental ways. First, the Air Force regulation did not single out Jews to bear a particular burden-a Catholic who wished to wear a comparably obtrusive crucifix would have been similarly forbidden to do so. Second, the regulation did not bar the Jewish servicemember from articulating his religious belief or identity in other ways. ${ }^{285}$ The harm of not being able to express any identity in a particular way under the Air Force regulations must thus be distinguished from the harm of not being able to express a particular identity in any way under "don't ask, don't tell."

Blocking gays from expressing their identity in any way leads to their ontic erasure in the minds of straights and possibly in the minds of gays as well. That the military may be effectively eradicating the identity of gays when it forces them to pass helps explain a puzzling feature of "don't ask, don't tell." The puzzle is this-why has the military responded to the repeatedly articulated fear of straight servicemembers that gays are looking at them in the showers ${ }^{286}$ by adopting a policy that increases the invisibility

deception or dishonesty, will call unit cohesion into question."), vacated, $88 \mathrm{~F} .3 \mathrm{~d} 1280$ (2d Cir. 1996).

282. 475 U.S. 503 (1986).

283. See, e.g., Richenberg v. Perry, 73 F.3d 172, 173 (8th Cir. 1995) (citing Goldman, 475 U.S. 503); Watson v. Perry, 918 F. Supp. 1403, 1417 (W.D. Wash. 1996) (same), aff d sub nom. Holmes v. California Army Nat'1 Guard, 124 F.3d 1126 (9th Cir. 1997); Thomasson v. Perry, 895 F. Supp. 820, 825 (E.D. Va. 1995) (same), aff'd, 80 F.3d 915 (4th Cir. 1996).

284. Goldman, 475 U.S. at 509-10.

285. See Air Force Regulation 35-10 para. 1-6.h(3)(f) (1980).

286. See BERSANI, supra note 111 , at 16 ("I was not alone in being astonished by the prominence of shower rooms in the erotic imagination of heterosexual American males. Fear on the battlefield is apparently mild compared to the terror of being 'looked at' (and you know what that means for most males)."). As Kendall Thomas notes:

From the media stories on heterosexuals in the armed forces who oppose President Clinton's proposal to lift the ban on the inclusion of 'avowed' homosexuals in their ranks, it would seem that straight male soldiers and sailors are haunted by the specter of the 'gay look.' The scopic scene that appears to trigger the most concern among straight military men is the spectacle of the communal shower. In interview after 
of gays? As Judge Nickerson wrote in his first Able opinion, this response seems irrational, because "if indeed there are homosexuals who wish to peek at naked bodies, they might do so quite as readily when their orientation is a secret as when it is open." 287 The ontic theory that forced invisibility can have eradicating effects, however, explains that the military's position actually has a deep, if pernicious, logic to it. The military is relying on the premise that if gays are not permitted to identify themselves, they are effectively erased-a military in which gays are permanently invisible is a military in which the fantasy that no gays exist can be sustained. Lacking a known source from which to emanate, the gay gaze is dissolved.

The shower conundrum has led me to focus on one aspect of the ontic harm of invisibility-that straights can pretend that gays do not exist. A related but less intuitive aspect of that ontic harm is that gays themselves may cease to feel as if they exist. The nexus between expression and identity has been generally recognized in the gay rights movement, as indicated by the ACT UP slogan "I am out, therefore I am." ${ }^{288}$ The slogan makes the connection between speech and status, noting that if a homosexual is closeted, she may cease in some important way to be a homosexual. Under this interpretation, the statement "I am gay" is illocutionary ${ }^{289}$-like the statements "J'accuse," "I thee wed," or "I bet you," it not only describes, but performs, the action named..$^{290}$ In short, a lesbian who is denied any expression of her homosexuality may cease to be a lesbian.

Perhaps one reason why this harm is counterintuitive is that all of the challenges to the policy are brought by gays who appear to be confident about their own homosexual orientation. But we will never know how many more individuals who are not similarly confident have been chilled from "becoming" gay based on the policy. For such waverers, burdens on expression may ultimately also be burdens on identity. If so, these burdens on speech are not simple regulations of homosexual conduct, but also regulations of homosexual status.

interview, the shower has served as the chief conductor of the straight troop's deepest anxieties.

Kendall Thomas, Shower/Closet, 20 ASSEMBLAGE 80, 80 (1993) (citations omitted).

287. Able v. United States, 880 F. Supp. 968,978 (E.D.N.Y. 1995), vacated, 88 F.3d 1280

(2d Cir. 1996). Indeed, one might put the point more strongly-closeted gays are actually more likely than open gays to be able to engage in homoerotic voyeurism.

288. DOUGLAS CRIMP \& ADAM ROLSTON, AIDS DEMO GRAPHICS 102-03 (1990).

289. The term is J.L. Austin's. See J.L. AuSTIN, How To Do THINGS WITH WoRds 98 (J.O. Urmson \& Marina Sbisà eds., 2d ed. 1975).

290. See EVE KOSOFSKY SEDGWICK, Queer and Now, in TENDENCIES 1, 11 (1993). 


\section{B. Transformative Power}

The argument about the transformative power of invisible groups first noted that the two transformative advantages that invisible groups ostensibly possessed-the infiltration effect and the auto-identification effect-might not always work in their favor. It then pointed out that invisible groups would appear to suffer from two transformative disadvantages-the exit/voice effect and the manipulation effect. Again, the "don't ask, don't tell" policy highlights the disempowering dimensions of all of these effects.

\section{The Infiltration Effect}

A proponent of the visibility presumption could argue that invisible groups are relatively empowered by their ability to infiltrate organizations, as evidenced by the fact that gays have always served in the military. I noted earlier, however, that this power was likely to be limited by the invisible group's fear of exposure. The proponent's response to this was that exposure need not be feared in two cases-the first, in which individuals can take refuge in safe harbors of privacy, and the second, in which individuals can use exposure as a transformative tool.

The proponent might point to the "don't ask" provision of the military's policy as an example of the first case. But Janet Halley has powerfully demonstrated the multiple inadequacies of that argument. As an initial matter, the implementing regulations indicate that "don't ask" creates no substantive or procedural rights, but only provides guidance to military officials. ${ }^{291}$ It is thus unsurprising that military officials have on occasion flatly ignored this guidance. ${ }^{292}$ In addition, the guidance provided by the policy permits officials to substitute indirect questions for the prohibited direct ones, allowing the same ends to be achieved through more oblique means. ${ }^{293}$ Finally, "don't ask" does not preclude military officials from initiating investigations based on inquiries made by other governmental branches, evidence of conduct reflecting a propensity to engage in homosexual conduct, or evidence of public or private "coming out" statements. ${ }^{294}$

The policy's carve-out of certain gay-related activities that will not constitute "homosexual conduct" would also seem to create a safe harbor.

291. See Enlisted Administrative Separations, Dep't of Defense Directive 1332.14, encl. 4, $\S \mathrm{G}$ (Dec. 21, 1993) [hereinafter Enlisted Administrative Separations], quoted in Halley, supra note 233 , at 180 (providing guidelines for factfinding inquiries into homosexual conduct).

292. See Halley, supra note 233 , at 180.

293. See id. at 180-81.

294. See id. at 181 . 
The Department of Defense directives state that officials may not begin investigations on the basis of conduct such as "going to a gay bar, possessing or reading homosexual publications, associating with known homosexuals, or marching in a gay rights rally in civilian clothes." ${ }^{295} \mathrm{On}$ its face, this carve-out appears to give considerable power to gays, as it putatively shields the classically sacrosanct political activities of association and speech- " [s]uch activity, in and of itself, does not provide evidence of homosexual conduct." 296 But as Diane Mazur points out, the operative language in this limitation is "in and of itself." ${ }^{297}$ Thus, while an investigation may not proceed on the basis of the fact that an individual "associat[es] with known homosexuals," 298 all that is needed to lift the bar is "some concrete, credible fact probative of gay conduct, such as information that a female servicemember is always seen in the company of the same woman." 299 Mazur goes on to argue that the carve-out was motivated by a desire to protect heterosexual servicemembers when they engaged in these activities, rather than to permit homosexual servicemembers a certain realm of protected activity. ${ }^{300}$

The proponent's second argument-that gays might use their own exposure as a powerful transformative tool-requires a more elaborate response. It is clear that the invisibility of gays has permitted them to rebut stereotypes about themselves more quickly than would have been possible if they were a visible group. This is because closeted gays could serve even in a military that categorically banned gays from service. Working alongside their straight colleagues, these closeted gays could build up personal and professional reputations that contradicted the stereotypes of them. When they came out-or were dragged out-of the closet, the resource of that intimacy and knowledge could be applied against the stereotype with telling effects. If gays were visible, this would not have been a viable strategy. The military would have been able to preserve these stereotypes by excluding gays, thereby removing the data sample that would disprove their erroneous hypotheses.

The classic "let them get to know you before you come out" strategy has led to the retirement of the traditional justifications for why gays are unfit to serve. ${ }^{301}$ Faced with model plaintiff after model plaintiff, ${ }^{302}$ the

295. Enlisted Administrative Separations, supra note 291, § E(4).

296. Id.

297. See Diane H. Mazur, The Unknown Soldier: A Critique of "Gays in the Military" Scholarship and Litigation, 29 U.C. DAVIS L. REV. 223, 247 (1996) (quoting Enlisted Administrative Separations, supra note 291, § E(4)).

298. Enlisted Administrative Separations, supra note 291, § E(4).

299. Mazur, supra note 297, at 247-48.

300. See id. at 248.

301. The strategy is not an immediate panacea, given that the military historically has shown a remarkable ability to sustain stereotypes even while acknowledging contradictory data. Thus, in the early 1990s, an admiral urged his officers to conduct a purge of lesbians, noting that local 
military has not been able to sustain the stereotype that gay servicemembers are less able to serve than straight servicemembers. The current policy is remarkable in that it does not rely on any of the traditional stereotypes that gays constitute security risks, are mentally unfit, and are more likely to spread sexually transmitted diseases. ${ }^{303}$ Instead, the justifications for "don't ask, don't tell"- - unit cohesion, privacy, and sexual tension ${ }^{304}$-primarily focus not on the gay servicemember but on the straight servicemember. This can be counted as a pro-gay achievement, as it correctly traces the source of the dysfunction not to the gay servicemember, but to the straight one. And, as the proponent of the invisibility presumption would point out, it is a victory largely predicated on the ability of gays to rebut an institution's stereotypes through their service within that institution.

Yet that victory is only partial. While the military has altered its justifications, it has not altered its methodology. It is still resting its case on negative stereotypes that are unsupported by rigorous empirical data. ${ }^{305}$ This

commanders had been reluctant to do so because lesbian sailors were generally " "hard-working, career-oriented, willing to put in long hours on the job and among the command's top performers."' Karst, supra note 245, at 553 (quoting Jane Gross, Admiral Praises Lesbians but Urges Their Dismissal, N.Y. TMES, Sept. 2, 1990, at 24). But such gaps between stereotype and reality can be expected to close eventually.

302. See, e.g., Cammermeyer v. Perry, 97 F.3d 1235, 1236 (9th Cir. 1995) (noting that Margarethe Cammermeyer, who was discharged under the military policy predating "don't ask, don't tell," was "a highly decorated nurse" who had received "numerous awards and distinctions, including the Bronze Star for distinguished service in Vietnam"); Steffan v. Aspin, 8 F.3d 57, 59 (D.C. Cir. 1993) (noting that Joseph Steffan, who was discharged under the old policy, "was, by all accounts, an exceptional midshipman" whose "exemplary performance ... had earned him numerous honors and the respect and praise of his superior officers"), vacated, 41 F.3d 677 (D.C. Cir. 1994) (en banc); Watkins v. United States Army, 875 F.2d 699, 701 (9th Cir. 1989) (en banc) (noting that Perry Watkins, who was discharged under the old policy, was "in all respects an outstanding soldier").

303. See Able v. United States, 968 F. Supp. 850, 855 (E.D.N.Y. 1997) (noting that the government had abandoned its previous arguments that homosexuals were mentally ill, a greater security risk, or more likely to spread infectious diseases), rev'd on other grounds, 155 F.3d 628 (2d Cir. 1998); see also Cammermeyer v. Aspin, 850 F. Supp. 910, 924 (W.D. Wash. 1994) (noting that the government had retired its argument that homosexuals presented a security risk).

304. See Able, 968 F. Supp. at 858 (noting that the government's only remaining rationales are that the policy secures unit cohesion, promotes the privacy of heterosexual servicemembers, and reduces sexual tension).

305. It is true that the military has from time to time adduced anecdotal evidence to support its position. Thus, General Schwarzkopf has opined that "[t]he introduction of an open homosexual into a small unit immediately polarizes that unit." Policy Concerning Homosexuality in the Armed Forces: Hearings on S. 1298 Before the Senate Comm. on Armed Services, 103d Cong. 595-96 (1995) (statement of H. Norman Schwarzkopf, U.S. General); see also id. at 821 (1995) (statement of John P. Otjen, U.S. General) (" [B]ased on my experience, [a] statement [of homosexual orientation] alone will cause disruption within the unit."). Yet this evidence contradicts the findings of studies conducted by the General Accounting Office and the RAND Corporation. The RAND Corporation study noted that there were no serious problems concerning gays in the military in Canada, Israel, the Netherlands, and Norway, all of which permit gays to serve openly. See RAND, supra note 231, at 14, quoted in Able v. United States, 880 F. Supp. 968, 978 (E.D.N.Y. 1995), vacated, 88 F.3d 1280 (2d Cir. 1996). And both the RAND Report and the GAO Report concluded that domestic organizations analogous to the military have accepted homosexuals into their ranks without significant adverse impact. See RAND, supra note 231, at 
time, however, the military has been careful to rely on stereotypes that gays cannot disprove through infiltration. Because these stereotypes rely on what "open" or visible homosexuals will do to a unit, an invisible homosexual cannot, by definition, disprove the stereotype until she comes out of the closet. At that point, of course, she is generally removed from the military and the stereotype remains largely uncontested.

\section{The Auto-Identification Effect}

Because invisibility creates epistemic uncertainty about status, it heightens the possibility that individuals not identifying as members of a stigmatized group will be revealed to be group members. The conventional wisdom is that this heightened possibility will lead to greater empathy between those individuals and the invisible groups to which they could belong. I earlier noted that this conventional wisdom does not always obtain. In some circumstances, it appeared that this very epistemic uncertainty contributed to the failure of empathy. Homosexuality was briefly offered up as such a circumstance.

"Don't ask, don't tell" increases the likelihood of that empathy failure by flaunting the epistemic uncertainty surrounding sexual orientation. While the military has a stated policy of heterosexual immunity and homosexual vulnerability, it has also defined homosexual acts in such an open-ended way that a straight servicemember will not know a priori how to maintain his straight identity. Such acts are defined to include "any bodily contact which a reasonable person would understand to demonstrate a propensity or intent to engage in" same-sex bodily erotic contact. ${ }^{306}$ As Halley points out, this "reasonable person" standard makes it impossible to know the protocols of straightness. ${ }^{307}$ This may be particularly true given the ambiguously sexual nature of the homosocial bonding that occurs in the military. ${ }^{308}$ Thus, "few servicemembers will be so unambiguously straight

xxiv; GAO, Report to Congressional Requesters, Defense Force Management: DoD's Policy on Homosexuality (June 1992), quoted in Able, 880 F. Supp. at 978. Rather than resolving this factual dispute through rigorous testing (by, for example, permitting homosexuals in certain units to serve openly), the military has chosen simply to assume, rather than to prove, that its position is correct. In so doing, it has implied that in a matter so serious as the national defense, the military's factual assumptions should be given deference. See, e.g., Thomasson v. Perry, 80 F.3d 915, 926 (4th Cir. 1996) (noting that "it is simply impossible to estimate the damage that a particular change [affecting unit cohesion] could inflict upon national security-there is no way to determine and correct the mistake until it has produced the substantial and sometimes irreparable cost of [military] failure." (citations and internal quotation marks omitted)).

306. 10 U.S.C. $\$ 654(f)(3)(B)(1994)$.

307. See Halley, supra note 233, at 215.

308. See William N. Eskridge, Jr., Gaylegal Narratives, 46 STAN. L. REV. 607, 626-30 (1994) (describing seemingly homoerotic male-bonding rituals). But cf. Mazur, supra note 297, at 252 (contrasting the depiction of military life described in Eskridge, supra, with her own experience as a servicemember). 
that they will never wonder whether a reasonable person might construe their actions as homosexual conduct." ${ }^{309}$

\section{The Exit/Voice Effect}

"Don't ask, don't tell" similarly exacerbates the prisoner's dilemma dynamic. As noted above, ${ }^{310}$ the deleterious effects of the prisoner's dilemma on invisible groups may be mitigated in two circumstances. The first is where a group member can come out to a potential ally without coming out generally. "Don't ask, don't tell," as discussed earlier, ${ }^{311}$ minimizes this possibility by threatening all military members with witchhunts and thereby making intragroup confidences less secure. The second is where the prisoner's dilemma is iterated. This latter possibility requires further discussion.

If the prisoner's dilemma is played repeatedly, some individuals will inevitably publicly declare their homosexuality (i.e., come out). After those individuals come out, they provide a political base that can support other invisible individuals in successive plays of the game. To see how this works, let us say that at Time Zero $A$ and $B$ play the game. Both are rational and risk-averse, and therefore both choose not to come out. There may be many more like them that play the game and also remain closeted. If the sample is large enough, however, someone will eventually come out, because not everyone is rational and risk-averse. Let us say that at Time One, $C$ and $D$ play, and $C$ decides to come out. $D$ does not and free rides on $C$ 's visibility. At Time Two, $E$ and $F$ play. In deciding whether to come out, $E$ and $F$ can figure into their calculus not only each other's potential actions, but the actions taken by their predecessors. And because $C$ has come out already, she provides a fixed source of support for $E$ and $F$. Thus, even if $E$ and $F$ are rational and risk-averse, it becomes more likely that either or both of them will come out as well.

When the history of gay liberation in the United States is considered, it clearly comports with the model of the iterated prisoner's dilemma. The powerful social norm of "don't ask, don't tell," which long preceded the military policy, prevented most homosexuals from coming out. Yet over time, there were individuals who revealed themselves, either because they were "irrational" in the sense of being altruistic, or because they were less risk-averse. ${ }^{312}$ Every person who came out thus operated as a resource for

309. Halley, supra note 233, at 215.

310. See supra note 224 and accompanying text.

311. See supra notes 267-272.

312. See LARry Gross, CONTESTEd Closets: The PolitiCs and Ethics OF OUTING 21 (1993) (noting that many early "open" homosexuals were already marginal in society and thus were less concerned with the risks of shouldering the additional stigma of homosexuality). 
others who knew her, making it less likely that an individual in a prisoner's dilemma situation would have no source of support besides other closeted gays. ${ }^{313}$

The "don't ask, don't tell" policy transforms this iterated prisoner's dilemma into a series of one-shot prisoner's dilemmas. The moment of empowerment for gays in the model above occurs when $C$ comes out and provides a stable source of support for $E, F$, and all that follow. By removing $C$ from the military after she comes out, "don't ask, don't tell" deprives her successors of that support. Under the policy, when $E$ and $F$ play the game at Time Two, they are not much better off than $A$ and $B$ were at Time Zero. Of course, the fact that $C$ has come out is important, and $C$ may well oppose the policy from outside of the military. But because $E$ and $F$ have seen $C$ punished, and because $C$ cannot work within the military as a role model or advocate, the beneficial aspects of the iterated prisoner's dilemma are disrupted.

\section{The Manipulation Effect}

"Don't ask, don't tell" did not spring spontaneously from the head of Congress but grew organically out of public culture. In a wide variety of contexts, straights and gays have formed social contracts like "don't ask, don't tell" in which an individual's homosexuality will not be the object of questioning so long as the individual remains silent about his orientation. ${ }^{314}$ The ability of our culture to force gays into this Faustian bargain-in which entitlements are exchanged for identities-is, of course, predicated on the invisibility of gays. It is only because of this invisibility that the disclosure of identity becomes a tradable good that cultural norms can manipulate gays into surrendering.

When this bilateral contract of gay erasure was firmly in place in our culture, there was no need for the state to specify or enforce that contract. In a culture that deemed homosexuality to be the sin that dared not speak its name, ${ }^{315}$ a statist formalization of that contract would have been at best redundant, at worst a form of protesting too much. But as gays sought to counter the social manipulation effect by seizing control of their rights of self-identification, the social harmony assured by the bilateral contract of gay erasure began to erode. The state would now have to use its coercive power to replace the cultural norms that had kept gays in the closet.

"Don't ask, don't tell" must thus be seen as an attempt by the state to sustain the epistemic contract of gay erasure even as that "contract"

313. See William N. Eskridge, Jr., Democracy, Kulturkampf, and the Apartheid of the Closet, 50 VAND. L. REV. 419, 440 (1997).

314. See supra notes $251-255$ and accompanying text.

315. See SEDGWICK, supra note 103, at 202-03. 
becomes ever more damagingly removed from any meaningful notion of consent. Although gays are now less prone than they historically have been to having their identities manipulated in the broader culture, the military seeks to retain the anachronism of gay erasure by force of law. To recognize that the state is doing through coercive means what the culture can no longer sustain through persuasive ones is to recognize that the state is exacerbating the manipulation effect suffered by gays.

\section{The Invisible Irony of "Don't Ask, Don't Tell"}

The current military policy is carefully crafted to ensure that the net effects of gay invisibility are disempowering. Although there is no innate relationship between invisibility and political powerlessness, the military has forged one through force of law. When gays have sought judicial redress for this state harm, however, the courts have assumed that the invisibility on which their harm is predicated actually cuts toward their political power. This is the irony of the visibility presumption when applied to cases in which the state has an animus against an invisible group.

That this irony itself has remained surprisingly invisible may be explained in two ways. First, the "don't ask, don't tell" cases rely on precedent decided prior to the policy for the proposition that gays are not entitled to heightened scrutiny. ${ }^{316}$ The courts are therefore not required to apply the test for heightened scrutiny (including the visibility factor) to these cases. This in turn allows the courts to evade the contradiction between the assumption that invisibility is always empowering and the facts they have before them. Second, and probably more importantly, the courts do not see the contradiction because they have no interest in granting heightened scrutiny to more groups. The courts will not relinquish their gatekeeping factors, even if they are proved illogical, unless they can be reassured that some other limiting principle will obtain. It is to this problem that I now turn.

\section{RECONSTRUCTING THE HEIGHTENED SCRUTINY JURISPRUDENCE}

I hope that I have persuaded the reader that the immutability and visibility factors may not be justified either on substantive (Part III) or processual grounds (Parts IV-V), and that the harms of the visibility presumption can be severe (Part VI). Although these arguments, if

316. See, e.g., Holmes v. California Army Nat'l Guard, 124 F.3d 1126, 1132 (9th Cir. 1996) (relying ultimately on High Tech Gays v. Defense Indus. Sec. Clearance Office, 895 F.2d 563, 574 (9th Cir. 1990)); Richenberg v. Perry, 97 F.3d 256, 260 (8th Cir. 1996) (relying ultimately on Padula v. Webster, 822 F.2d 97, 103-04 (D.C. Cir. 1987)). 
accepted, should convince the reader that the factors should be discarded, it is unlikely that these arguments, without more, will persuade the courts to do so. This is because the courts' historically tenacious hold on the immutability factor, and their current retention of the visibility factor, suggest that these factors are fulfilling a need in the equal protection jurisprudence. Without identifying that need and providing an alternative means of fulfilling it, it may be difficult to convince the courts to jettison the two factors.

I therefore seek in this Part to reconstruct the heightened scrutiny jurisprudence. This reconstruction proceeds by making three points. First, I identify the need that the factors are fulfilling in the jurisprudence by looking back to the moment of their creation. I demonstrate that the factors were generated to justify the protection of race and sex, and that they have been retained because of their gatekeeping function in limiting the number of groups deemed to deserve the courts' solicitude. This suggests that the courts are unlikely to retire these factors unless they are supplied with an alternative means of limiting the number of protected groups.

Second, in seeking to discover this alternative limiting principle, I look to the larger doctrinal context in which the factors are embedded. I show that if the immutability and visibility factors are removed, the remaining prongs of the doctrinal test-the history of discrimination prong and the political powerlessness prong-emphasize classes over classifications, antisubordination over formal equality. While the Supreme Court appears to have rejected this class-based view of heightened scrutiny, I argue that eliminating the discredited factors clears the doctrinal path toward a reconsideration of the antisubordination interpretation of the equal protection guarantee. I thus argue that the limiting principle for determining which groups will be protected should be developed within a framework that focuses attention solely on disempowered classes. I suggest that the proper way of constructing such a limiting principle is to refine our conception of such political powerlessness and to ensure that this analysis is consistently applied.

My final point focuses on the political feasibility of reconstructing heightened scrutiny jurisprudence. Although my proposal to replace the immutability and visibility factors with a refined and consistent political powerlessness analysis will strike some as parochially directed to serve indistinct groups, this is not the case. Even disempowered distinct groups (such as blacks and women), who appear to be privileged under the immutability and visibility factors, should nonetheless favor the retirement of these factors. This is because the immutability and visibility factors support a classification-based analysis that has outlived its usefulness. Although that analysis promoted the positive assimilation of blacks and women in an era when the principal harm was segregation, it now impedes 
them in that assimilation by blocking integrative efforts, such as affirmative action, that reason from an antisubordination paradigm.

\section{A. The Origins of the Immutability and Visibility Factors}

Tracing the immutability and visibility factors to their roots demonstrates that they were formulated in an attempt to isolate the commonalities between the paradigm groups of race and sex in the early 1970s. That insight generates two points. First, it makes the courts' use of these factors all the more suspect, as principles derived from a data sample of two are unlikely to be accurate across all contexts. Second, it suggests that the longevity of the immutability and visibility factors arises from the courts' desire to protect race and sex as the paradigm groups and their related anxiety about having to protect too many groups.

As noted above, ${ }^{317}$ the Supreme Court has not articulated a clear theory for why certain classifications warrant heightened scrutiny and others do not. Rather than operating from a priori principles, the equal protection jurisprudence has been driven by the groups asking for protection. Generally, the inquiry has not been, "What principles define groups that are worthy of judicial protection?" but rather, "Is group $X$ in or out?" Although certain factors have been generated from the latter inquiry, these factors have been selected based upon the protected groups at issue rather than vice versa.

Under this group-driven analysis, new groups are admitted by showing that they are like groups that have already established their claim to protection. Viewing this dynamic as characteristic of civil rights politics, Jane Schacter has dubbed it the "discourse of equivalents," a system of repressive analogy that deploys the status quo as the normative baseline against which new claims must be measured. ${ }^{318}$ Schacter criticizes the fact that the legitimacy of new civil rights legislation, such as that of gay rights statutes, is seen to be dependent on how closely analogous the proposed legislation is to preexisting legislation protecting race, sex, disability, and religion. ${ }^{319}$ She correctly argues that the fact that discrimination takes a form that has no ready historical analogue does not mean it is not worthy of redress.

Schacter's complaint, made in the context of legislation, is also applicable to the heightened scrutiny jurisprudence, where the courts have engaged in such analogical reasoning. Indeed, the courts operate from an even more restrictive framework than that adopted by the legislatures, as

317. See supra note 12 and accompanying text.

318. Schacter, supra note 214, at 283, 285.

319. See id. at 291-311. 
the courts' current standards have been generated with primary reliance on only two groups. To lay out the typical test one last time, the courts currently deploy a number of factors including: (1) whether the group has suffered from a history of discrimination; (2) whether the group is currently politically powerless; and (3) whether the group is marked by an "obvious, distinguishing, or immutable characteristic []." 320 All three prongs of this test derive from Frontiero v. Richardson, ${ }^{321}$ in which a plurality of the Supreme Court accepted that women, the group asking for heightened scrutiny, were sufficiently similar to blacks, the paradigm group that had already received that protection. ${ }^{322}$ In reaching this determination, the plurality reasoned that women, like blacks, had suffered a history of discrimination, ${ }^{323}$ that women, like blacks, were politically powerless, ${ }^{324}$ and that women, like blacks, were defined by an immutable ${ }^{325}$ and highly

320. Bowen v. Gilliard, 483 U.S. 587, 602 (1987) (quoting Lyng v. Castillo, 477 U.S. 635 , $638(1986))$.

321. 411 U.S. 677 (1973) (plurality opinion).

322. It may be argued that the visibility factor has an older pedigree. The famous fourth footnote of United States v. Carolene Products, 304 U.S. 144, 152 n.4 (1938), directs judicial attention to "discrete and insular minorities." Professor Louis Lusky, who witnessed the formulation of the footnote, has advanced an interpretation of "discreteness" that equates it with "visibility." Lusky, supra note 41, at $1105 \mathrm{n} .72$. He thus disagrees with the Court's finding in Graham v. Richardson, 403 U.S. 365, 371-72 (1971), that aliens constitute a "discrete and insular" minority, because, inter alia, "many [aliens], who are anglophones, pass unnoticed." Lusky, supra note 41 , at 1105 n.72. If Lusky's view is correct, the visibility factor dates back to 1938.

I agree with Bruce Ackerman, however, that it is "not obvious whether most constitutional lawyers endow the word 'discrete' with independent significance in their understanding of Carolene doctrine." Ackerman, supra note 75, at 728-29. Indeed, Justice Stone, the constitutional lawyer who authored the footnote, appears not to have given Lusky's construction to the word "discrete." After Carolene Products, the next Supreme Court opinion to refer to "discreteness and insularity" was a dissent in Minersville School District v. Gobitis, 310 U.S. 586, 606 (1940) (Stone, J., dissenting). See also Regents of the Univ. of Cal. v. Bakke, 438 U.S. 265, 290 n.28 (1978) (tracing references to "discreteness and insularity" in Supreme Court opinions). In his Gobitis dissent, Justice Stone posited that Jehovah's Witnesses were a "discrete and insular minorit[y]," thereby manifesting an understanding of the phrase he had coined that is at odds with Lusky's interpretation. Gobitis, 310 U.S. at 606. This evidence shores up the reading of the word "discrete" that the Graham majority implicitly adopted.

Nonetheless, it might be fairly contended that the word "discrete" may have been interpreted to mean "visible" by various courts that ignored, misunderstood, or rejected Justice Stone's subsequent use of the word in a dissenting opinion and relied instead on the text of Carolene Products. This possibility, however, merely supports my ultimate point that the visibility factor was derived in part from race, insofar as this interpretation of "discrete" would only be possible if the paradigm group against which it was interpreted was race-based, as opposed to the other "invisible" political and religious groups mentioned in the Carolene footnote.

323. See Frontiero, 411 U.S. at $684-85$ (plurality opinion) ("There can be no doubt that our Nation has had a long and unfortunate history of sex discrimination.... [!ndeed, throughout much of the 19th century the position of women in our society was, in many respects, comparable to that of blacks under the pre-Civil War slave codes.").

324. See id. at 685 ("Neither slaves nor women could hold office, serve on juries, or bring suit in their own names....").

325. See id. at 686 (" [S] ex, like race ..., is an immutable characteristic determined solely by the accident of birth ...."). 
visible ${ }^{326}$ characteristic. To those inured to these factors, the analysis seems unexceptional, until one realizes that the Frontiero plurality is formulating the test rather than applying it.

It follows from this realization that the origins of the immutability and visibility factors do little to justify them. When the data sample of groups from which such principles are generated is small, a pair of analytical dangers arises. One is that random commonalities between admitted groups will be used to exclude other deserving groups. This is problematic because the mere fact that two oppressed groups share a characteristic does not mean that the characteristic is the constitutive element of their oppression. To take an extreme illustration, two individuals with the same initials may be oppressed, but given that it is unlikely that their initials are the source of their oppression, it would be anomalous to bar those with different initials from obtaining relief. The other related danger is that even if a characteristic causes the oppression of two groups, it may not be the cause of all oppressions. The fact that both blacks and women were historically denied the right to vote both mirrored and contributed to discrimination against them. Yet most would view this commonality as too narrow to constitute a heightened scrutiny factor ${ }^{327}$ Indeed, while the Frontiero Court noted this commonality, ${ }^{328}$ it did not enshrine historical disenfranchisement as part of its heightened scrutiny test but adverted instead to the more general criterion of a history of discrimination.

The existence of these dangers makes it important to view with great caution the transformative moment when analogies transmute into abstract principles. Although the formalization of these criteria into "tests" encourages us to accept them as transcendental, we must be mindful of the often narrow contexts from which they arise, and therefore of their potential for misapplication in other contexts. In the case of equal protection jurisprudence, that caution takes the form of noting that the immutability and visibility factors were generated with only two classifications-race and sex-in mind. Those two data points were used to draw a line that has had dramatic implications for all other groups.

A defender of the common law might admit that it was a mistake to generate principles of exclusion from a data set of two groups without being overly troubled by this concession. His equanimity might arise from the belief that the common law has its own internal mechanism to correct such mistakes. Assuming that some of the criteria so generated are wrong, at some point a group worthy of heightened scrutiny will not satisfy at least

326. See id. at 686 (" $\mathrm{Tnn}$ part because of the high visibility of the sex characteristic, women still face pervasive, although at times more subtle, discrimination ....").

327. But cf. Schacter, supra note 214 , at 292 (describing a conservative lobbying group that argued against pro-gay legislation because blacks, but not gays, were denied the right to vote).

328. See Frontiero, 411 U.S. at 685 (plurality opinion). 
one of them. Forced to choose between the protection of the group and the retention of the factor, courts might well reject or reinterpret the factor. The immutability factor has been challenged in precisely this way. ${ }^{329}$ That principles are mistakenly extrapolated from limited data sets may not be such a problem after all, as the system will purge such mistakes over time as the data set is expanded.

But general faith in the common law's self-correcting nature may be misplaced in the specific context of heightened scrutiny, because the decision to jettison an established factor in order to admit a deserving group may be impeded by the courts' desire to limit the number of groups protected. An examination of the origins of the assimilationist bias reveals not only that the courts view race and sex as the paradigm groupings for purposes of heightened scrutiny, but also that they are loath to extend protection beyond these groups. The Frontiero plurality manifested this restrictive animus by privileging the race-based classification as the touchstone against which the sex-based classification had to be rubbed. Although the plurality acknowledged that national origin and alienage were also suspect classifications, it did not consider whether the sex-based classification might have been analogous to either of these other paradigms of oppression. ${ }^{330}$ Subsequent to Frontiero, the Court articulated this restrictive animus more clearly. The Cleburne Court declined to give the mentally retarded heightened scrutiny in part because it would otherwise "be difficult to find a principled way to distinguish a variety of other groups" such as "the aging, the disabled, the mentally ill, and the infirm." 331 Because of this restrictive animus, courts may be less willing to challenge factors that they think are incorrect. After all, even incorrect factors perform the gatekeeping function of limiting the number of groups protected.

The courts' restrictive animus is obviously open to criticism. It can be read as an argument against "too much justice," ${ }^{332}$ for the fact that many groups are deserving of the courts' protection is not, in itself, a principled reason for excluding any one of them. It can also be criticized as leading to a "first in time is first in right" jurisprudence, which privileges groups that made their claims before the judiciary imposed an arbitrary cutoff. Still I do

329. See cases cited supra notes 15-18.

330. The narrowness of the frame of reference is somewhat surprising, given that alienage had been deemed a suspect classification only two years before in Frontiero. See Graham v. Richardson, 403 U.S. 365, 371 (1971). Had alienage been considered alongside race as an already-protected group, we could not have had the factors that were derived from Frontiero, for alienage is neither an immutable nor a visible characteristic. Thus, even if the Court had examined all the data it had before it at the time, the assimilationist bias would not have been introduced into the jurisprudence.

331. City of Cleburne v. Cleburne Living Ctr., 473 U.S. 432, $445-46$ (1985).

332. I take the phrase from McClesky v. Kemp, 481 U.S. 279, 339 (1987) (Brennan, J., dissenting). 
not pursue these critiques here, because it is hard not to sympathize with the courts' desire to place some limitation on the number of groups to which it owes extra solicitude. Moreover, the courts are unlikely to accept a solution that rejects the validity of their restrictive animus. Yet accepting the need for a limiting principle obviously does not mandate acceptance of the immutability and visibility factors. The challenge, then, is to find a better limiting principle.

\section{B. A Refined Political Powerlessness Analysis as a Limiting Principle}

Before choosing a limiting principle, I first contextualize the immutability and visibility factors in a larger debate occurring in the heightened scrutiny jurisprudence. That debate is one between classes and classifications. ${ }^{333}$ The class-based view of equal protection states that the courts should focus on disempowered classes, like blacks, women, or gays. The classification-based view states that courts should focus not on classes but on the classifications that create the classes-such as race, sex, or sexual orientation. The class-based view can be characterized as asymmetrical, given that it extends protection to one class within a classification while denying protection to another--to blacks, for example, but not to whites. The classification-based view, on the other hand, is symmetrical, since it treats classes within a classification similarly-if blacks get heightened scrutiny, so must whites.

The tension between the class-based view and the classification-based view manifests itself in the standard heightened scrutiny test. Two prongs of the test-history of discrimination and political powerlessness-comport with the class-based view. These prongs direct the court's attention to one class within a classification-blacks, not whites, have suffered a history of discrimination; blacks, not whites, are politically powerless. The other prong of the test, which asks whether a group is marked by an "obvious, distinguishing, or immutable characteristic," advances a classificationbased view. This prong, which contains the immutability and visibility factors, urges the courts to think in terms of classifications-if blacks are marked by immutable and visible characteristics, so are whites.

The Supreme Court has resolved this tension in favor of the classification-based approach. In Adarand Constructors v. Pena, ${ }^{334}$ a majority of the Court identified and endorsed the "consistency" principle, which states that "the standard of review under the Equal Protection Clause is not dependent on the race of those burdened or benefited by a

333. See Neil Gotanda, A Critique of "Our Constitution Is Color-Blind," 44 STAN. L. REv. 1, 40-52 (1991).

334. 515 U.S. 200 (1995). 
particular classification." ${ }^{335}$ Thus, all racial classifications reviewable under the equal protection guarantee must be strictly scrutinized. ${ }^{336}$ As Justice Stevens noted in dissent, the problem with this consistency principle is that it tends to overlook the ways in which legislation might legitimately treat them equally, occluding the difference "between a 'No Trespassing' sign and a welcome mat." ${ }^{337}$ The majority defended against this criticism by noting that the principle only requires the same standard of scrutiny to be applied to all classes within a classification, and that this does not dictate that the same outcome be reached for all classes. ${ }^{338}$ In practice, however, the dissent appears to have the better argument, for even if courts are not formally required to strike down all legislation under heightened scrutiny, this is precisely what they have done in the (admittedly few) years since Adarand. ${ }^{39}$

I will not pursue this critique of classification-based analysis further, as my point here is not to provide a comprehensive critique of classificationbased analysis. Rather, it is to underscore that the proposed retirement of the immutability and the visibility factors clears the ground for a different kind of analysis. For if these factors are retired, the remaining factors indicate a class-based analysis. It is also to speculate that if we are to propose a limiting principle, that limiting principle should arise out of a class-based, rather than a classification-based analysis.

Merely rejecting a classification-based analysis in favor of a classbased analysis, of course, mitigates the problem of limitation by eliminating all groups that are deemed not to be politically powerless and to have suffered a history of discrimination. Groups such as whites, men, and the legitimate would all be denied heightened scrutiny. But it also clearly exacerbates the numerosity problem by permitting disempowered groups that are not marked by immutable or visible characteristics to ask the courts for heightened scrutiny. If we are to propose a limiting principle, then, that principle will have to determine which of these disempowered groups are eligible for judicial protection.

Before suggesting a reconstructive principle, I emphasize that I set it forth only in its broadest outlines. The main thrust of this Article is to demonstrate the need to retire the immutability and visibility factors. Although I have attempted to conceptualize what might replace these factors, I have not done so in any detail, because doing so would require another article. Put another way, I have considered the immutability and

335. Id. at 222 (1995) (quoting City of Richmond v. J.A. Croson Co., 488 U.S. 469, 493-94 (1989) (plurality opinion)).

336. See id.

337. Id. at 245 (Stevens, J., dissenting).

338. See id. at 229.

339. See cases cited supra note 5 . 
visibility factors with some particularity because I seek to contribute to the closure of a debate about their legitimacy; in contrast, I only speculate as to the reconstructive principle because I seek to open another debate.

I propose that the limiting principle should be a refined analysis of political powerlessness. Currently, the Court has proffered three tests for political powerlessness. In United States v. Carolene Products, the Court asked whether groups were "discrete and insular minorities." 340 In Frontiero, a plurality of the Court looked to whether a group was underrepresented in the "[n]ation's decisionmaking councils." ${ }^{341}$ And in Cleburne, the Court examined whether the group was unable "to attract the attention of the lawmakers." 342

There are two major problems with the current political powerlessness analysis. First, the standards are applied inconsistently across contexts. Obviously, whatever standard is used, it should be applied to any group that comes before a court. At the time Cleburne was decided, the Carolene Products test and the Frontiero test were the two available tests for political powerlessness. It is hard to believe that the mentally retarded would not have been deemed politically powerless if either of the extant tests (especially the latter) had been applied. The fact that the Cleburne Court decided to apply a different test under which it was much harder to prove political powerlessness would lead a cynic to speculate that the Court created a new test to avoid granting the mentally retarded heightened scrutiny. For a test to be legitimate, it must be applied consistently.

Second, the standards are coarse in the extreme. Even if any one of the three tests were applied consistently, it would be grossly over- or underinclusive. No social scientist would determine a group's political power by looking at only one criterion. As Cass Sunstein has noted, many other factors can influence a group's political power. These include (and here I add some criteria to his original list) the following indicia of transformative and evasive power: (1) the group's income and wealth; (2) its health and longevity; (3) its freedom from public and private violence; (4) its ability to exercise its political rights; (5) its education level; (6) its social position; and (7) the acceptability of prejudice against the group. ${ }^{343}$

Thus, my reconstructive proposal is that a multifactor determination of political powerlessness should perform the gatekeeping function performed by the immutability and visibility factors. In considering whether any group

340. United States v. Carolene Prods., 304 U.S. 144, 153 n.4 (1938).

341. Frontiero v. Richardson, 411 U.S. 677, 686 n.17 (1973) (plurality opinion).

342. City of Cleburne v. Cleburne Living Ctr., 473 U.S. 432,445 (1985).

343. See Sunstein, supra note 12 , at 2430 (listing "poverty, education, political power, employment, susceptibility to violence and crime, [and] distribution of labor within the family" as potential markers of social welfare). 
should get heightened scrutiny, the courts would be required to consider all of the factors listed above (and doubtless some others).

This refined political powerlessness test is not a panacea. One obvious criticism is that it will not prevent the courts from acting on their prejudices if they wish to do so. Precisely because the test proliferates the axes of power, some will cut for a group and some against it. It has been said that "[t]here is nothing like a good balancing test for avoiding rigorous argument." " 344

This, however, is a criticism not of one test or another but of judicial discretion. We cannot construct a heightened scrutiny test that does not allow for some judicial discretion. That discretion may always be placed in service of a judge's prejudice against a group. The goal here is not to eliminate judicial discretion but rather to find the test that best channels that discretion into avenues of fair decisionmaking. Tests must be compared with each other, not with an unattainable ideal in which judges have no ability whatsoever to express their prejudices.

When properly compared with the current test, the refined test displays at least five major advantages. First, because the test would have to be applied consistently across groups, courts would be able to make much more sophisticated comparative claims. Courts could expect a judicial database of knowledge along certain axes for every group requesting heightened scrutiny.

Second, this approach would draw on a thicker conception of political power. One way to express this point is to note that the refined test presents for explicit debate factors that are probably in play anyway. For example, Justice Scalia's recent dissent in a recent equal protection case noted that gays "possess political power much greater than their numbers" in part because they "have high disposable income." ${ }^{345}$ None of the three existing tests considers a group's income, disposable or otherwise. ${ }^{346}$ Yet Justice Scalia is clearly right that income and political power are linked. ${ }^{347}$ If such factors should be and are considered, it seems uncontroversial that they should be considered explicitly.

Third, the refined test encourages us to see that different kinds of power may be interconnected. To take the example just given, it may be generally true that gays have higher disposable incomes per capita than straights

344. Rubenfeld, supra note 86, at 761 .

345. Romer v. Evans, 517 U.S. 620, 646 (1996) (Scalia, J., dissenting).

346. See supra notes 340-342 and accompanying text.

347. See, e.g., ROBERT DAHL, DEMOCRACY AND ITS CRTICS 114-15 (1989) (noting correlations between political power and access to money); ANTHONY DOWNS, AN ECONOMIC THEORY OF DEMOCRACY 200-01 (1957) (noting that the voters with the highest incomes generally have the most political power). 
do. ${ }^{348}$ Gay empowerment on this axis, however, may have been created by gay disempowerment on another. The higher disposable incomes of open homosexuals may be explained by a lack of dependents. ${ }^{349}$ But this lack of dependents may be traced in part to social discrimination that prevents gays from gaining custody of children ${ }^{350} \mathrm{It}$ is thus reductive for Justice Scalia to rely on disposable income as a proxy for political power without examining the connection between that disposable income and homophobic discrimination. ${ }^{351}$ Although such connections would not necessarily be made under my test, the generation of data in various categories makes it more likely that connections between the categories will be drawn.

Fourth, this approach would allow courts to diagnose the contours of their disagreements more accurately. For example, blacks are probably more powerful than gays in terms of the acceptability of negative social attitudes toward them, while gays are probably more powerful than blacks in terms of wealth, income, and social position. ${ }^{352}$ If two courts agreed with the preceding sentence, they would understand their ultimate disagreement as theoretical rather than empirical-that is, as relating to the emphases they were placing on these different kinds of power rather than on the factual question of which group had more of which kind of power. If, on the other hand, they disagreed on the empirical question, that would also show up under my more refined test.

348. Lee Badgett notes that three recent surveys have found that the incomes of gay men and lesbians are either comparable to, or greater than, the national median incomes of men and women, respectively. See M.V. Lee Badgett, The Wage Effects of Sexual Orientation Discrimination, 48 INDUS. \& LAB. REL. REV. 726, 729 (1995). Badgett goes on to observe, however, that these survey results are questionable for a number of reasons, including a sample skew toward individuals who were "out," white, urban, and well-educated-that is, toward individuals who possessed attributes that were correlates of wealth. Id. Badgett's own study, which she believes "constitutes a significant methodological advance over other quantitative studies," found that gay, lesbian, and bisexual workers earned less than their heterosexual counterparts, although she notes that the results from the comparison of lesbian to straight female workers were not statistically significant. $I d$. at 726 . Even if gays do not have higher incomes than straights, however, they may still have consistently higher disposable incomes. I therefore assume for the sake of argument that Justice Scalia is correct in his assertion that gays have "high disposable income." Romer, 517 U.S. at 646 (Scalia, J., dissenting).

349. See Nancy Klingeman \& Kenneth May, For Better or for Worse, in Sickness and in Health, Until Death Do Us Part: A Look at Same-Sex Marriage in Hawaii, 16 U. HAW. L. REV. 447,487 (1994) ("Gay and lesbian couples also have a higher discretionary income . . . than their heterosexual counterparts, because they are less likely to have children.").

350. See supra note 255.

351. Another set of interrelated factors in the case of gays is health, income, and social discrimination. Gays might be expected to have better health care given their relatively higher disposable income. Given its best reading, however, "health" would also have to include social resources devoted to the cure of diseases. And to the extent that homophobia has resulted in government inaction on AIDS, which in turn disproportionately affects gays in this country, gay "health" cannot be understood without understanding sexual orientation discrimination.

352. See BERSANI, supra note 111 , at 62 (citing Henry Louis Gates, Jr., Backlash?, NEW YORKER, May 17, 1993, at 49). 
Finally, the refined test would be a more powerful heuristic device for judges. I have elsewhere argued that a purpose of the heightened scrutiny jurisprudence is to force judges to examine themselves as well as legislatures for prejudices against groups making equal protection claims. ${ }^{353}$ Under this reading, the heightened scrutiny test has a didactic function, forcing judges to grapple with the nature of a group before passing judgment. The narrower the heightened scrutiny test is, the less likely judges are to be forced to expand the contours of their existing knowledge about a group. ${ }^{354}$

One common response to this proposal is that under my analysis, disenfranchised prisoners, the illiterate, or the mentally disabled could be deemed more deserving of protection than gays or racial minorities. This response is relatively untroubling - precisely the point of having standards create protected groups rather than vice versa is to interrogate an otherwise sclerotic hierarchy of oppression. If such groups can make their claims to heightened scrutiny on a fair and open field of debate, I have no quarrel with their being granted such scrutiny.

A related concern is that courts will find such a proposal so destabilizing of that hierarchy that they will not accept it. But if the courts have become so rigid that they will nor engage in this (or some other) dialogic reassessment of protected groups, that itself is information that should be public. Exposing that restrictive animus by taking away the doctrinal cover of immutability and visibility on the one hand and by demonstrating the courts' rejection of a reasonable dialogic alternative on the other is thus in itself useful work.

\section{Coalition Building}

The final point is one about coalition building. It might be thought that the argument to retire the immutability and the visibility presumptions is an argument that should only be persuasive to groups that are marked by mutable or invisible characteristics. The movement to retire the assimilationist bias in equal protection, however, should have a much broader appeal. While the assimilationist bias might have been the correct historical response to a regime in which segregation of blacks and women was the harm, it does not currently meet the equality needs of those immutable and visible groups.

353. See Yoshino, supra note 221, at 1765-66.

354. This is perhaps the most direct response to the critique that judges will still express their prejudices under the refined test, because it questions the critique's premise that all judges have made up their minds before applying the test. If we see judges as open to persuasion, a thick description of the group is more likely to assist them in their good-faith deliberations. 
Looking at the origins of the immutability and visibility factors may explain why the courts have been so accepting of the assimilationist aspect of these factors. The paradigm case of race is one that historically linked injustice and segregation-blacks were made a race apart through whites' unwillingness to share schools, churches, restaurants, hotels, conveyances, prisons, hospitals, neighborhoods, and cemeteries with them. ${ }^{355}$ In dismantling this status regime, justice and assimilation logically went together ${ }^{356}$ The second paradigm case of sex, which also fundamentally shaped the doctrine, further encouraged the association of justice and assimilation in the judicial mind. ${ }^{357}$ Unlike the race context, the subordinated group in the sex context was physically integrated into the dominant group's lives-women lived with men as their wives, daughters, and sisters. ${ }^{358}$ Yet they, too, were systematically segregated from many spheres of life into which the equal protection guarantee sought to incorporate them. ${ }^{359}$ An equal protection doctrine that stressed assimilation was therefore a predictable response to the problem it was formulated to remedy, a status regime that enforced itself by segregating on the basis of difference. It is therefore understandable that the negative implications of the assimilationist bias inherent in the immutability and visibility factors would not have been immediately apparent.

This account, however, explains rather than justifies the courts' embrace of the assimilationist bias. Because the assimilationist response is

355. See Benno C. Schmidt, Principle and Prejudice: The Supreme Court and Race in the Progressive Era. Part 1: The Heyday of Jim Crow, 82 CoLUM. L. REv. 444, $472-74$ (1982). See generally C. VANN WOODWARD, THE STRANGE CAREER OF JM CROW (1955) (describing conditions of segregation under Jim Crow).

356. See, e.g., Wendy Brown-Scott, Race Consciousness in Higher Education: Does "Sound Educational Policy" Support the Continued Existence of Historically Black Colleges?, 43 EMORY L.J. 1, 44-46 (1994) (describing integrationist and assimilationist assumptions motivating Brown and subsequent desegregation efforts); Alex M. Johnson, Jr., Bid Whist, Tonk, and United States v. Fordice: Why Integrationism Fails African-Americans Again, 81 CAL. L. REV. 1401, 1428 (1993) (describing the integrationist philosophy as based on the assumption "that once AfricanAmericans and whites were able to inhabit the same physical environment (the process), AfricanAmericans and whites would begin to respect each other as individuals and view race as an irrelevant characteristic like eye color (the ideal)"); Gary Peller, Race Consciousness, 1990 DUKE L.J. 758, 795-802 (describing the conflicting ideologies of integrationism/assimilation and black nationalism); Sharon Elizabeth Rush, The Heart of Equal Protection: Education and Race, 23 N.Y.U. REV. L. \& SOC. CHANGE 1, 25 (1997) (arguing that racially integrated schools are "necessary for people of all races to begin to value each other's differences and learn to relate to each other with equal respect").

357. See, e.g., Candace Saari Kovacic-Fleischer, United States v. Virginia's New Gender Equal Protection Analysis with Ramifications for Pregnancy, Parenting, and Title VI, 50 VAND. L. REV. 845, 852-54 (1997) (discussing the "equal treatment" model of gender equality as based on the assumption "that existing governmental and workplace policies can assimilate the excluded gender because there are no relevant differences between the genders").

358. See Balkin, supra note 14, at 2371.

359. See Christine A. Littleton, Reconstructing Sexual Equality, 75 CAL. L. REv. 1279, 1290 (1987) (discussing the ways in which "separate spheres ideology" kept women out of the public arena). 
specifically tailored to certain kinds of discrimination on the basis of race and sex, it works less well when applied to other forms of discrimination that deploy assimilation's negative aspects. These other forms include discrimination against indistinct groups, where discrimination may operate not by setting a group apart but by engulfing and erasing it. In such cases, the status hierarchy between the dominant and the subordinate group is reinforced, rather than weakened, through an emphasis on assimilation. This was the case of "don't ask, don't tell."

Less intuitively, however, the assimilationist response may also fail to redress some forms of discrimination leveled at formally protected groups. The assimilationist response, which arguably met the needs of blacks and women when segregation was the main issue, is now impeding their equality claims by denying the legitimate claims of difference forwarded by these groups. ${ }^{360}$ In other words, the assimilationist response may not be limited only in scope (i.e., it only protects distinct groups), but also in time (i.e., it only remedies certain historical problems faced by distinct groups). To the extent that blacks and women are increasingly understanding their equality claims to be predicated on a respect for their differences from whites and men respectively, they too will favor an analysis that focuses on classes rather than classifications. Thus, even distinct groups may join indistinct ones in militating for the retirement of these factors.

\section{CONCLUSION}

The projects of American antidiscrimination law in general, and of constitutional equal protection in particular, have both reasoned restrictively from the cases of race and, to a lesser extent, sex. Race-based and sex-based classifications are privileged; other classifications are not. The immutability and visibility factors defend this status quo.

The crux of this Article argues that these factors cannot be justified either on substantive or on processual theories of constitutional interpretation. This is because immutability and visibility are bad proxies for either substantive inequality or processual powerlessness. Thus, my negative prescription is that the factors should be retired.

My affirmative prescription is that the courts should turn away from the corporeal body to the body politic, focusing not on how traits are situated within individuals but on how groups are situated in society. In that latter

360. See, e.g., Nadine Taub \& Wendy W. Williams, Will Equality Require More Than Assimilation, Accommodation or Separation from the Existing Social Structure?, 37 RUTGERS L. REV. 825 (1985) (describing the difficulties with a pure equality/assimilation theory of gender inequality and concluding that requiring assimilation with the male norm does not provide adequate protection for rights of women). 
inquiry, they should refine their conception of political powerlessness to describe more richly the situation of groups asking for their solicitude.

Some who agree with the logic of the moves made here may nonetheless criticize them as naive. They might argue that, if the courts are merely seeking to restrict heightened scrutiny protection to race and sex, proffering doctrinal analysis and reasoned alterations is futile. But if this restrictive animus is indeed the prime mover behind the courts' actions, forcing the courts to recant their illogical doctrinal arguments has an even greater urgency. For when this occurs, the brute fact of the restrictive animus will be laid bare. If I have encouraged readers to confront the palatability of permitting that animus to control this area of jurisprudence, I have done my work. 
